\title{
EFEITO DE FONTES E DOSES DE FÓSFORO NA CULTURA DO CAPIM GAMBA (Andropogon gayanus Kunth VARIEDADE BISQUAMULATUS).
}

NELSON JOSÉ NOVAES

EMBRAPA

Orientador: Prof. Dr. LUIZ EDUARDO GUTIERREZ

Tese apresentada à Escola Superior de Agricultura "Luiz de Queiroz", da Universidade de São Paulo, para obtenção do Título de Doutor em Agronomia. Área de Concentração: Solos e Nutrição de Plantas.

PIRACICABA

Estado de São Paulo - Brasil

Março, 1983 
Aos meus pais

Florindo

01 ga

ofereço

A Marilene

Rogērio e Patrícia, dedico 
Ao Dr. Luiz Eduardo Gutierrez

Ao Dr. Godofredo Cesar Vitti

Ao Dr. Henrique Paulo Haag

Ao Dr. David Ariovaldo Banzato

Ao Dr. Dilermando Perecin

Ao Dr. Paulo Figueiredo Vieira

Ao Cläudio Maluf Haddad

Ao Dr. Fernando Hass

Ao Dr. Marcos Tasso de Miranda

Ao aluno Renato Xavier de Moraes

A Escola Superior de Agricultura "Luiz de Queiroz", da Universidade de São Paulo

A Empresa Brasileira de Pesquisa Agropecuäria (EMBRAPA) 
LISTA DE TABELAS

vi

LISTA DE FIGURAS XIV

RESUMO Xvii

SUMMARY Xix

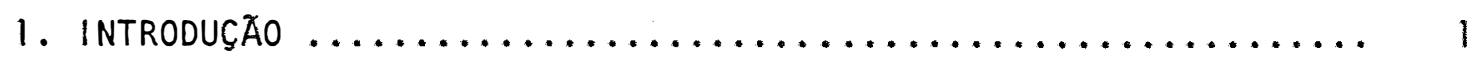

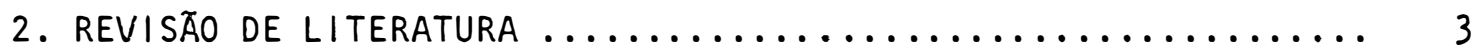

2.1. Andropogon gayanus Kunth $\ldots \ldots \ldots \ldots \ldots \ldots \ldots \ldots \ldots$

2.2. Fertilização fosfatada ....................... 13

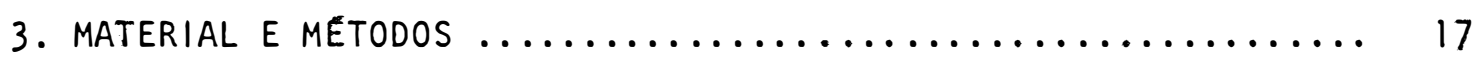

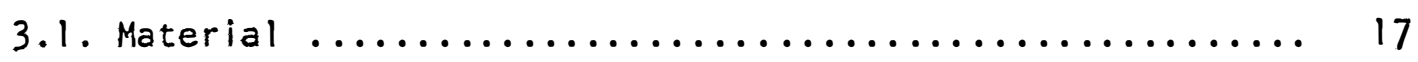

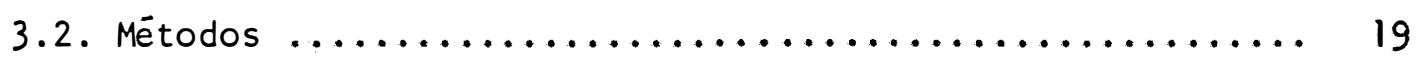

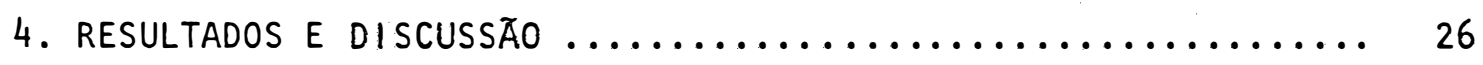

4.1. Efeito da adição de adubos fosfatados na produção de ma-

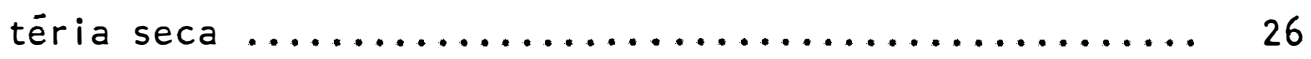

4.2. Efeito dos tratamentos sobre a concentração e quantidade

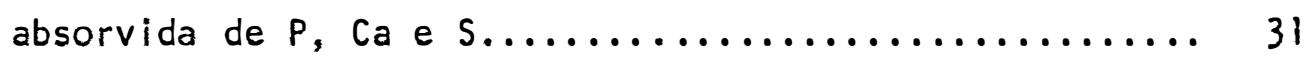

4.3. Efeito dos tratamentos sobre os teores de $P$, Ca e $S$ do

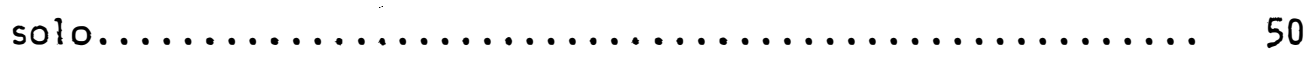

4.4. Efeito dos tratamentos sobre as relações $N / P, P / S$ e N/S

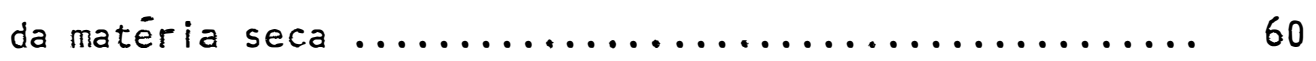

4.5. Efeito dos tratamentos sobre os teores de proteína e da digestibilidade de matēria seca $\ldots \ldots \ldots \ldots \ldots \ldots \ldots$ 
Pảgina

5. CONCLUSסES .............................. 75

LITERATURA CITADA ........................ 77

APENDICE ............................... 86 


\section{LISTA DE TABELAS}

Tabela n?

Pàgina

1 Principais características quilmicas de amostras de ter ra, da ärea experimental.................. 18

2 Fontes de fósforo e suas principais características

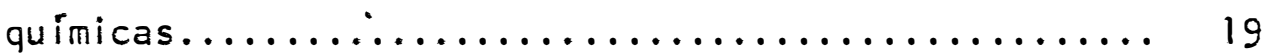

3 Esquema dos tratamentos utilizados no experimento.... 20

4 Doses, fontes e preparo das soluções de micronutrien-

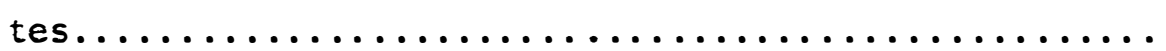

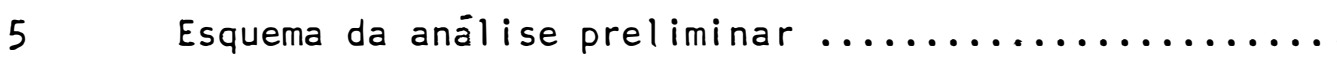

6 Produção de matēria seca, a $105^{\circ} \mathrm{C}$, da parte aérea (g/vạ so) em função das fontes e doses de $\mathrm{P}_{2} \mathrm{O}_{5}$ total..... 87

7 Produção de matéria seca, a $105^{\circ} \mathrm{C}$, das raízes (g/vaso) em função das fontes e doses de $\mathrm{P}_{2} \mathrm{O}_{5}$ total........ 88

8 Produção de matéria seca total, a $105^{\circ} \mathrm{C}$ (g/vaso), em função das fontes e doses de $\mathrm{P}_{2} \mathrm{O}_{5}$ total.......... 89 
9 Concentração de fösforo em \% na matéria seca $\left(105^{\circ} \mathrm{C}\right)$, da parte aérea, em função das fontes e doses de $\mathrm{P}_{2} \mathrm{O}_{5}$

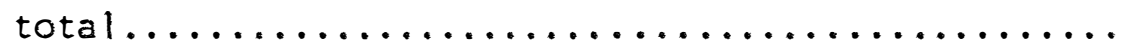

10 Concentração de cālcio em \% na matéria seca $\left(105^{\circ} \mathrm{C}\right)$, da parte aérea, em função das fontes e doses de $\mathrm{P}_{2} \mathrm{O}_{5}$ to-

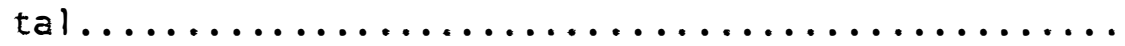

11 Concentração de enxofre em \% na matēria seca $\left(105^{\circ} \mathrm{C}\right)$, da parte aérea,em função das fontes e doses de $\mathrm{P}_{2} \mathrm{O}_{5}$ to tal

12 Fósforo absorvido (mg/vaso), pela parte aérea das plantas,em função das fontes e. doses de $\mathrm{P}_{2} \mathrm{O}_{5}$ total..

13 Cálcio absorvido (mg/vaso) pela parte aérea das plantas, em função das fontes e doses de $\mathrm{P}_{2} \mathrm{O}_{5}$ total.....

14 Enxofre absorvido (mg/vaso) pela parte aérea das plan tas, em função das fontes e doses de $\mathrm{P}_{2} \mathrm{O}_{5}$ total.... 95

15 Teores de fösforo ( $\mu \mathrm{g} / \mathrm{m}$ lTFSA) nos solos, apōs a colhei

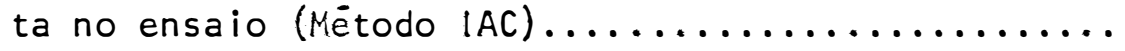


Tabela n?

Pägina

16 Teores de fósforo ( $\mu \mathrm{g} / \mathrm{m}$ ITFSA) nos solos, após a colhei ta do ensaio (Método Bray -1$) \ldots \ldots \ldots \ldots \ldots \ldots \ldots \ldots \ldots \ldots \ldots \ldots \ldots \ldots$

17 Teores de cälcio (emg/100mltFSA) nos solos, após a co-

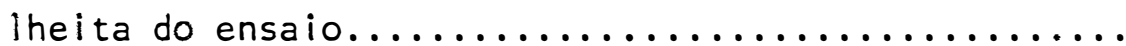

18 Teores de $\mathrm{S}_{-} \mathrm{SO}_{4}$ (ppm) nos solos, após a colheita do en

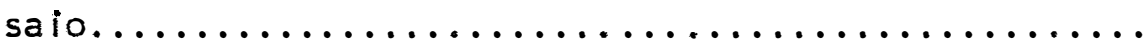

19 Relação N/P da parte aérea das plantas, em função das fontes e doses de $\mathrm{P}_{2} \mathrm{O}_{5}$ total $\ldots \ldots \ldots \ldots \ldots \ldots \ldots$

20 Relação $P / S$ da parte aērea das plantas, em função das fontes e doses de $\mathrm{P}_{2} \mathrm{O}_{5}$ total ................... 101

21 Relação N/S da parte aérea das plantas, em função das

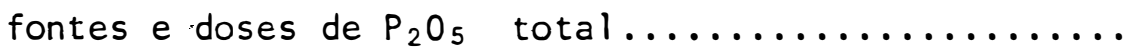

22 Concentração de nitrogênio em \%, na matéria seca $\left(105^{\circ} \mathrm{C}\right)$, da parte aérea em função das fontes e doses de 103 $\mathrm{P}_{2} \mathrm{O}_{5}$ total

Teor de proteína em \% na matéria seca $\left(105^{\circ} \mathrm{C}\right)$, da parte 104 aērea, em função das fontes e doses de $\mathrm{P}_{2} \mathrm{O}_{5}$ total..... 
24 Digestibilidade em \% na matéria seca da parte aérea $\left(105^{\circ} \mathrm{C}\right)$, em função das fontes e doses de $\mathrm{P}_{2} \mathrm{O}_{5}$ total ...

25 Médias gerais das produções de matéria seca,a $105^{\circ} \mathrm{C}$, da parte aérea das plantas ( $g / v a s o)$, em função de fontes e doses de $\mathrm{P}_{2} \mathrm{O}_{5}$ total,e resumo da anālise estatística.

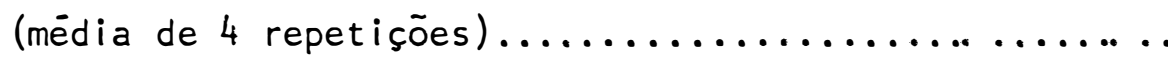

26 Médias gerais das produções de matéria seca, a $105^{\circ} \mathrm{C}$, das raízes (g/vaso) em função das fontes e doses de $\mathrm{P}_{2} \mathrm{O}_{5}$ total, e resumo da anālise estatística (média de 4

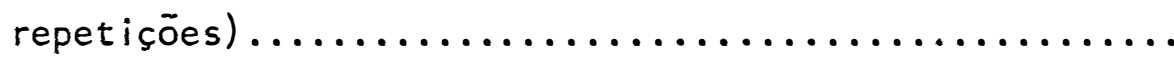

27 Médias gerais das produções de matéria seca total, à $105^{\circ} \mathrm{C}$, (g/vaso) em função de fontes e doses de $\mathrm{P}_{2} \mathrm{O}_{5}$ total, e resumo da anālise estatística (média de 4 repetições)

28 Médias gerais das concentrações de fösforo, em \%, na parte aérea das plantas, em função das fontes e doses de $\mathrm{P}_{2} \mathrm{O}_{5}$ total e resumo da anälise estatística I (média

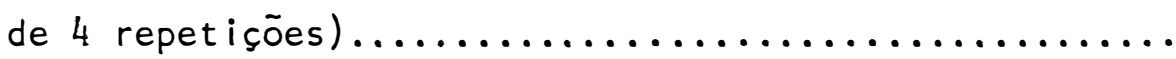


Tabela n?

Pāgina

29 Médias gerais das concentraçōes de cālcio, em \%, na parte aérea das plantas, em função das fontes e doses de $\mathrm{P}_{2} \mathrm{O}_{5}$ total e resumo da anālise estatística (média

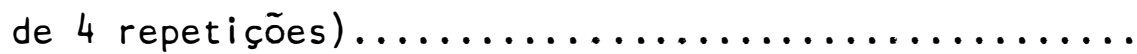

30 Médias gerais das concentraçōes de enxofre, em \%, na parte aérea das plantas, em função de fontes e doses de $\mathrm{P}_{2} \mathrm{O}_{5}$ total, e resumo da anälise estatística (mé-

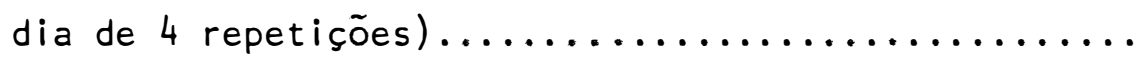

31 Médias gerais das quantidades de fósforo absorvido, (mg P/vaso), na parte aérea das plantas, em função das fontes e doses de $\mathrm{P}_{2} \mathrm{O}_{5}$ total, e resumo da anālise es-

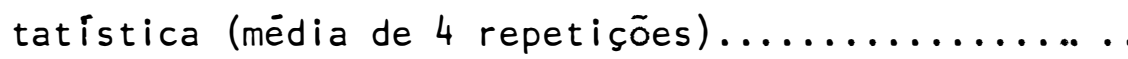

. 32 Médias gerais das quantidades de cālcio absorvido (mg/vaso) na parte aérea das plantas, em função das fontes e doses de $\mathrm{P}_{2} \mathrm{O}_{5}$ total, e resumo da anälise es-

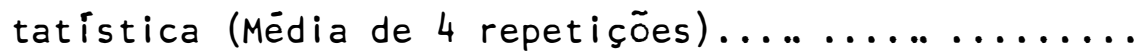

33 Médias gerais das quantidades de enxofre absorvido (mg/vaso), na parte aérea das plantas, em função das fontes e doses de $\mathrm{P}_{2} \mathrm{O}_{5}$ total e resumo da anälise es tatística (mëdia de 4 repetições)............... 
Tabela n?

34 Coeficientes de correlação simples e equações de regressão, calculadas para as características citadas em relação à produção de matéria seca da parte aérea...

35 Teste $t$ para correlação mültipla e correlações parciais obtidas entre produção de matēria seca (Y) com

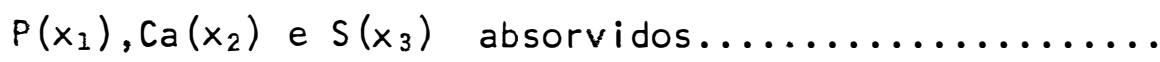

36 Médias gerais dos teores de fösforo ( $\mu \mathrm{g} / \mathrm{mlTFSA}$ ) nos so Ios, após a colheita do ensaio (Método $I A C$ ), e resumo da anālise estatística (Mēdia de 4 repetições)...... 5

37 Médias gerais dos teores de fösforo ( $\mu \mathrm{g} / \mathrm{ml}$ TFSA), nos solos após a colheita do ensaio (Método Bray-1), e resumo da anālise estatística (Média de 4 repetições)...

38 Médias gerais dos teores de cälcio (emg/100ml TFSA) nos solos após a colheita do ensaio, e resumo da anālise

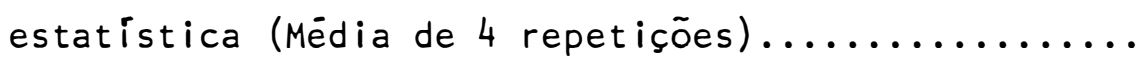

39 Médias gerais dos teores de $\mathrm{S}_{-} \mathrm{SO}_{4}$ (ppm) nos solos, apōs a colheita do ensaio, e resumo de anālise estatística

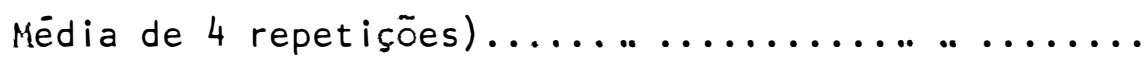


Tabela n?

40 Médias gerais das relações N/P da parte aérea das plantas, em função das fontes e doses de $\mathrm{P}_{2} \mathrm{O}_{5}$ total e resu mo da anälise estatística (Média de 4 repetições).....

41 Médias gerais das relações $\mathrm{P} / S$ da parte aérea das plantas, em função das fontes e doses de $\mathrm{P}_{2} \mathrm{O}_{5}$ total e resu mo da anālise estatística (Mēdia de 4 repetições)..... 62

42 Médias gerais das relações N/S da parte aérea das plantas, em função das fontes e doses de $\mathrm{P}_{2} \mathrm{O}_{5}$ total e resu mo da anālise estatística (Média de 4 repetições).....

43 Médias gerais das concentrações de nitrogênio, em \%, na parte aërea das plantas em função de fontes e doses de $\mathrm{P}_{2} \mathrm{O}_{5}$ total e resumo da anālise estatística (Média de

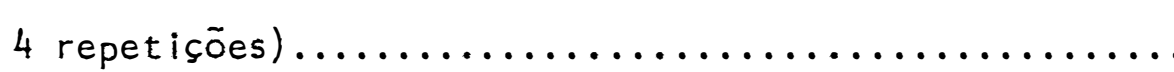

44 Médias gerais dos. teores de proteína, em \%, na parte aé rea das plantas, em função de fontes e doses de $\mathrm{P}_{2} \mathrm{O}_{5}$ to tal e resumo da anälise estatística (Média de 4 repeti-

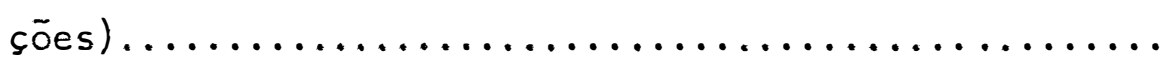


Tabela n?

45 Médias gerais, das digestibilidades da matéria seca (\%) da parte aérea das plantas, em função das fontes e doses de $\mathrm{P}_{2} \mathrm{O}_{5}$ total, e resumo da anälise estatística(Mé dia de 4 repetições)...................... 73 


\section{LISTA DE FIGURAS}

Figura n?

Pàgina

1 Efeito de doses de $\mathrm{P}_{2} \mathrm{O}_{5}$, na produção de matēria seca (g/vaso) da parte aérea....... 32

2 Efeito de doses de $\mathrm{P}_{2} \mathrm{O}_{5}$, na produção de matēria seca (g/vaso) da raiz................ 33

3 Efeito de doses de $\mathrm{P}_{2} \mathrm{O}_{5}$, na produção de ma-

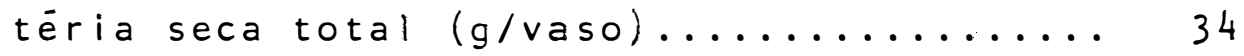

4 Efeito de doses de $\mathrm{P}_{2} \mathrm{O}_{5}$, na concentração de

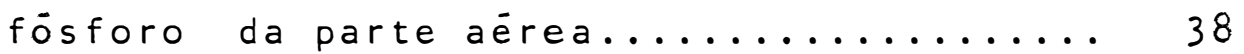

5 Efeito de doses de $\mathrm{P}_{2} \mathrm{O}_{5}$, na concentração de

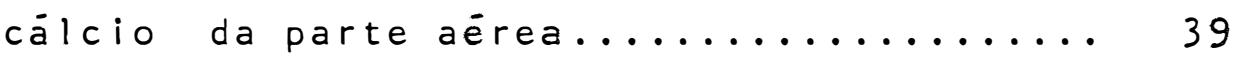

6 Efeito de doses de $\mathrm{P}_{2} \mathrm{O}_{5}$, na concentração de enxofre da parte aērea............... 40

7 Efeito de doses de $\mathrm{P}_{2} \mathrm{O}_{5}$, na quantidade de fösforo extraída pela parte aérea....... 
Figura no

Efeito de doses de $\mathrm{P}_{2} \mathrm{O}_{5}$, na quantidade de cálcio extraída dos solos ...............46

Efeito de doses de $\mathrm{P}_{2} \mathrm{O}_{5}$, na quantidade de

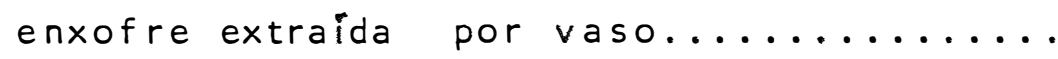

10

Efeito de doses de $\mathrm{P}_{2} \mathrm{O}_{5}$, no teor de fósforo nos solos após a colheita (Método IAC) 54

11 Efeito de doses de $\mathrm{P}_{2} \mathrm{O}_{5}$, no teor de fósforo nos solos após a colheita (Método Bray-1) 55

12 Efeito de doses de $\mathrm{P}_{2} \mathrm{O}_{5}$, no teor de cálcio nos solos após a colheita ........... 56

13 Efeito de doses de $\mathrm{P}_{2} \mathrm{O}_{5}$, no teor de enxofre nos solos após a colheita..........

14 Efeito de doses de $\mathrm{P}_{2} \mathrm{O}_{5}$, na relação $\mathrm{N} / \mathrm{P}$, da parte aērea.........................65

15 Efeito de doses de $\mathrm{P}_{2} \mathrm{O}_{5}$, na relação $\mathrm{P} / \mathrm{S}$, da

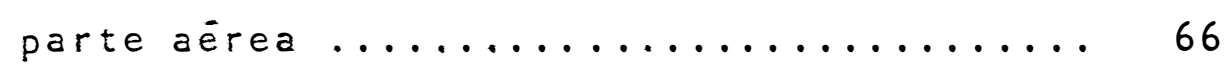


Figura no

Pàgina

16 Efeito de doses de $\mathrm{P}_{2} \mathrm{O}_{5}$, na relação $\mathrm{N} / \mathrm{S}, \mathrm{da}$

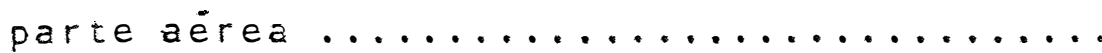

17 Efeito de doses de $\mathrm{P}_{2} \mathrm{O}_{5}$, na concentração de nitrogènio, da parte aērea.............66 68

18 Efeito de doses de $\mathrm{P}_{2} \mathrm{O}_{5}$, no teor de proteina, da parte aérea....................69

19 Efeito de doses de $\mathrm{P}_{2} \mathrm{O}_{5}$, na digestibilidade "in vitro" da matéria seca, da parte aérea. 70 
EFEITO DE FONTES E DOSES DE FÓSFORO NA CULTURA DO CAPIM GAMBA (Andropogon gayanus Kunth VARIEDADE BISQUAMULATUS).

Candidato: Nelson Josē Novaes Orientador: Prof.Dr. Luiz Eduardo Gutierrez

\section{RESUMO}

Foram conduzidos em vasos com terra em casa de vegetação, ensaios com fontes e doses crescentes de fósforo $(0,100,200$ e $300 \mathrm{~kg} / \mathrm{ha}$ de $\mathrm{P}_{2} \mathrm{O}_{5}$ ) em capim Gamba (Anäropogon gayanus Kunth Var. Bisquamulatus), vi sando verificar o comportamento do fosfato de Araxá parcialmente solubilizado (FAPS), quanto à sua capacidade de fornecer fósforo (P) e cálcio (Ca) às plantas, em comparação com o superfosfato simples e fosfato natural de Araxá, em um solo ácido de vegetação de cerrado do Município de São Carlos-SP.

Aos 75 dias apös à semeadura, determinou-se o peso de matéria seca da parte aérea, raiz e total em cada tratamento; os teores na parte aérea e as quantidades absorvidas de $\mathrm{P}, \mathrm{Ca}$ e enxofre (S); as relaçōes entre os macronutrientes aniōnicos (N/P, P/S e N/S) na parte aérea; - teor de proteína bruta e a digestibilidade "in vitro" da matéria seca. Foram retiradas amostras de solo no final do ciclo e procedeu-se à deter minação dos teores de $\mathrm{P}$ (extração em $\mathrm{H}_{2} \mathrm{SO}_{4} \quad 0,05 \mathrm{~N}$ e $\mathrm{NH}_{4} \mathrm{~F} 0,03 \mathrm{~N}+$ $\mathrm{HCl} 0,025 \mathrm{~N})$, de $\mathrm{Ca}(\mathrm{KCl} \mathrm{I}, \mathrm{ON})$ e $\mathrm{S}_{-} \mathrm{SO}_{4}\left(\mathrm{NH}_{4} \mathrm{OAC} 0,5 \mathrm{~N}\right)$.

Os dados obtidos permitiram concluir que: 
- Houve efeito da adubação fosfatada na produção de matéria seca do capim Andropogon.

- A eficiência do FAPS na produção de matéria seca, é ligeiramente inferior quando comparada ao superfosfato simples, mas supe rior ao fosfato de Araxá.

- o superfosfato, seguido pelo FAPS, foram superiores ao fosfato de Araxá como fornecedores de P e Ca.

- A produção de matéria seca correlacionou-se positivamente com as quantidades absorvidas de Ca e S, sendo que entretanto, o efeito do P não foi possível de ser separado do de Ca, pois ambos tiveram alta correlação entre si.

- As quantidades absorvidas de fósforo (mg/vaso) foram: 0,$55 ; 7,34 ; 6,63 ; 10,62$ e 5,99, respectivamente para Testemunha, FAPS (1-2 mm), FAPS (2-4mm), superfosfato simples e fosfato de Araxá.

- Os teores de P no solo $(B r a y-1), \mathrm{Ca}(\mathrm{KCl}, 1, \mathrm{ON})$ S- $\mathrm{SO}_{4}\left(\mathrm{NH}_{4} \mathrm{OAC}, 0,5 \mathrm{~N}\right)$ correlacionaram-se com doses e fontes de $\mathrm{P}_{2} \mathrm{O}_{5}$ utili zadas.

- As relações N/P, P/S e N/S na parte aërea aos 75 dias após o plántio variaram respectivamente de 10 a $16 ; 0,57$ a 1,51 e 9 a 14 . - Os teores de proteína variaram de 4,6 a 5,7\% decrescendo das fontes menos para mais solüveis, bem como o aumento das doses doses de $\mathrm{P}_{2} \mathrm{O}_{5}$.

- Os valores mäximos da digestibilidade "in vitro", da matéria seca estimados em torno de $42 \%$, responderam à aplicação do FAPS e do superfosfato. 
EFFECT OF SOURCES AND LEVELS OF PHOSPHORUS IN THE GAMBA GRASS (Andropogon gayanus Kunth Var. Bisquamulatus) CULTURE.

Author: Nelson José Novaes Adviser: Luiz Eduardo Gutierrez

SUMMARY

Trials with different sources and increasing levels of phosphorus $\left(0-100-200\right.$ and $300 \mathrm{~kg} / \mathrm{ha}$ of $\left.\mathrm{P}_{2} \mathrm{O}_{5}\right)$ were carried out in pots in a green house, with the Gamba Grass (Andropogon gayanus Kunth var. Bisquamulatus), to evaluate the compatibility of the phosphate of Araxá partially soluble (FAPS) to supply phosphorus and calcium to the plants, as compared to the superphosfate $\left(20 \% \mathrm{P}_{2} \mathrm{O}_{5}\right)$ and natural phosphate, in an acid soil of the "cerrado" region of são Carlos, São Paulo, Brazil.

Seventy-five days after seeding, the dry matter weights of the aerial part, the root and total, the content of $\mathrm{P}, \mathrm{Ca}$ and $S$ in the aerial part and the absorbed amount, the relations among the anionic macronutrients (N/P, $P / S$ and $N / S$ ) in the aerial part, the content of crude protein and the "in vitro" digestibility were determined in each treatement. Samples of soil at the end of the cycle were collected, and the content of $\mathrm{P}$ (extracted in $\mathrm{H}_{2} \mathrm{SO}_{4} 0.05 \mathrm{~N}$ and $\mathrm{NH}_{4} \mathrm{~F} 0.03 \mathrm{~N}+$ $+\mathrm{HCl} 0.025 \mathrm{~N})$, of $\mathrm{Ca}(\mathrm{KCl} \quad \mathrm{OON})$ and of $\mathrm{S}-\mathrm{SO}_{4}\left(\mathrm{NH}_{4} \mathrm{OAC} 0.5 \mathrm{~N}\right)$ were 
de termined.

The results suggest the following conclusions:

- There was an effect of the phosphorus fertilization in the production of dry matter.

- The efficiency of the FAPS, producing dry matter, is slightly lower than the superphosphate but is better than the phosphate of Araxá.

- The superphosphate, followed by the FAPS, were superior to the phosphate of Araxá as P an Ca suppliers.

- the production of dry matter was correlated with the amounts of $\mathrm{Ca}$ and $S$ absorbed. It was not possible to evaluate the effects of the $P$, due to its high correlation with Ca.

- The amounts of absorbed $P(\mathrm{mg} / \mathrm{pots})$ were $0.55,7.34,6.63$, 10.62 and 5.99 for the control, FAPS $(1-2 \mathrm{~mm})$, FAPS $(2-4$ $\mathrm{mm}$ ) superphosfate and natural phosfate, respectivily.

- The contents of $\mathrm{P}(\mathrm{Bray}-\mathrm{I}), \mathrm{Ca}(\mathrm{KCl} \mathrm{I} . \mathrm{ON})$ and $\mathrm{S}-\mathrm{SO}_{4}\left(\mathrm{NH}_{4}\right.$ OAc $0.5 \mathrm{~N}$ ) in the soil, were correlated with levels and sources. of $\mathrm{P}_{2} \mathrm{O}_{5}$ utilized.

- The relations $N / P, P / S$ and $N / S$ in the aerial part, seventy-five days after seeding, ranged from 10 to 16 , 0.57 to 1,51 and 9 to 14 respectively. 
- The contents of crude protein ranged from 4.6 to $5.7 \%$ decreasing from the sources less to the more soluble, and with increasing levels of $\mathrm{P}_{2} \mathrm{O}_{5}$.

- The values of the "in vitro" digestibility, estimated to be around $42 \%$, had response to the amount of FAPS and superphosphate utilized, 
1. INTRODUÇÃO

Na América Latina, cerca de $70 \%$ da carne bovina é produzida nas regiões tropicais. A América Tropical possui maior rebanho bovi "per capita" do que a América do Norte, Europa Ocidental e Africa Tropical; sendo que, entretanto, a produção de carne por animal e o consumo "per capita" são relativamente baixos.

Aproximadamente $51 \%$ (850 milhões de ha) da América Tropi cal é coberta por solos altamente intemperizados; oxissolos e ultisso los. Desse total, aproximadamente $300 \mathrm{milhões} \mathrm{de} \mathrm{ha} \mathrm{estão} \mathrm{cobertos} \mathrm{por}$ vegetação de savana e 550 milhões por vegetação florestal (JONES, 1979).

o Brasil Central conta com uma vasta àrea desses solos sob vegetação de cerrado, sendo que a economia dessa extensa região se alicerça na pecuária $(41,7 \%$ do rebanho bovino nacional, VILELA, 1977), baseada em pastagens naturais de baixa capacidade de suporte, periodica mente sujeitos a seca e ao fogo (EMRICH, 1967).

A principal barreira para a produção de carne

nessas 
àreas è o inadequado fornecimento anual de forragem, causado principalmente pela deficiência hidrica e baixo indice de fertilidade dos solos, apresentando acidez elevada com altos teores de alumínio permutável, bai xos teores de bases trocáveis e elevada fixação de fósforo.

Assim, a identificação e o uso de espécies forrageiras adaptadas ao solo e condições climäticas dessas äreas, como provavelmen te o capim Gamba, è um meio de aumentar a produção de carne bovina. Por outro lado, a possibilidade do emprego de fontes alternativas de fósfo ro na adubação da pastagem, como os fosfatos naturais parcialmente solu bilizados, surgem como um potencial não só para o fornecimento de fósforo, como também de enxofre e cälcio, principalmente em pastagens.

Os objetivos do presente trabalho são os de verificar as reações a fontes e niveis de fösforo do capim Gamba (Anảropogon gayanue Kunth var. Bisquamulatus), em condições controladas (vasos com terra em casa de vegetação), utilizando-se de um solo äcido de cerrado. 


\section{REVISÃO DE LITERATURA}

\subsection{Andropogon gayanus Kunth}

o capim Gamba (Anâropogon gayanus Kunth var. Bisquamulatus) è originärio da Rodésia do Sul e Nigéria. Em 1974 foi introdu- . zido nos planaltos orientais da Colómbia, onde foi intensamente estudado pelo Centro de Informaçōes sobre Pastos Tropicais da CIAT*. Em dezem bro de 1977 começou sua evolução no CPAC $\%$, muito embora tenha sido in troduzido pela primeira vez no Brasil em 1942 (CIAT, 1980).

Trata-se de uma gramínea perene, cespitosa, alcançando dois metros ou mais de altura, folhas abundantes, macias, de coloração azulada e possuindo um estreitamento na base que lhe fornece aspecto de falso pecíolo, pilosidade aveludada e inflorescência em panícula de rácemos com aspecto macio e sedoso (ALCÂNTARA e BUFARAH, 1979).

o sistema radicular é muito desenvolvido, fixando forte

\footnotetext{
* Centro Internacional de Agricultura Tropical, Cali, Colómbia. *: Centro de Pesquisa Agropecuária do Cerrado, Planaltina, Brasil.
} 
mente as touceiras ao solo e penetra a regular profundidade, constituin do um dos fatores que contribuem para sua boa resistência a seca. (EMRI $\mathrm{CH}, 1967)$.

Segundo ANDRADE et aliz (1980), as espécies do gēnero Brachiaria, principalmente a Brachiaria decumbens, são as gramíneas mais utilizadas atualmente para a formação de pastagens na região dos cerrados. Apesar de sua boa adaptação às condições de solo e clima de cerrados, apresentam alguns problemas:

a) Sofrem danos severos quando atacadas pela cigarrinha das pastagens,

b) Devido à sua pouca compatibilidade com leguminosas, a utilização em pastos consorciados é muito difícil,

c) Animais jovens, principalmente, pastejando essas gra míneas, tem apresentado problemas de fotossensibilização.

Diante desses problemas, evidenciou-se a necessidade de se encontrar novas espécies de gramíneas alternativas para a formação de pastagens. Nesse sentido o CPAC está indicando o Andropogon, que em três anos de pesquisas mostrou, dentre outras, as seguintes qualidades:

a) É bem compatível com leguminosas e não apresenta prọ blemas para a formação de pastagens consorciadas,

b) E menos atacado pela cigarrinha das pastagens, que as braquiārias,

c) Até o momento não causou problemas de fotossensi bilidade,

d) É bem tolerante à seca e ao fogo, 
e) Tem potencial para produzir bons rendimentos de sementes. (ANDRADE et alii, 1980).

Além dessas qualidades, o Andropogon segundo outros pes quisadores, se comporta muito bem em oxissolos e ultissolos, tolerand• solos com alta acidez e elevados teores de $\mathrm{Al}^{+3}$ trocável. Em comparação com outras gramíneas forrageiras, requer niveis mais baixos de $N$, utili za mais eficientemente $O P$ do solo, apresenta sistema radicular profundo e um crescimento rápido e vigoroso na estação chuvosa (CIAT, 1979). EMRICH (1967) estudando a competição entre cinco grä míneas forrageiras para a formação de pastagens em solo fortemente ácido de cerrado (LVA de Minas Gerais), verificou que o Anárope gon gayanus Kunt var. squamulatus, Stapf, além de demonstrar maior re sistência à seca e menor exigência quanto a acidez e baixa fertilidade do solo, alcançou em todos os cortes a melhor média para o tratamento testemunha, bem como elevada média de produção.

Num solo argiloso-arenoso da região da India, o capim Gamba juntamente com a Brachiaria brizantha, superaram as gramineas Cer. chrus ciliaris, Chloris gayana, Dichanthium annulatum, Heteropogon contortus, Pennisetum pedicillatum, Pennisetum polystachyum, Urochloa mozambicensis, Bothriochloa intermedia, Dichanthium caricosum e Paspalum notatum. Neste experimento SINGH e CHATTERJEE (1965), alcançaram com o Andropogon, produções de matéria seca de $708 \mathrm{~kg} / \mathrm{ha} / \mathrm{semana}$ na estação chuvosa e $613 \mathrm{~kg} / \mathrm{ha} / \mathrm{semana}$ na primavera e inverno.

Analisando as produções de matéria seca de doze gramíneas perenes utilizadas para pastoreio, num período de 3 anos, SINGH e CHATTERJEE (1968), observaram que o Andropogon gayanus, juntamente com 
a Brachiaria bryzantha foram superiores as demais, quer nos quatro cor tes efetuados ao ano (intervalo de 6 a 8 semanas) na estação chuvosa, quer quando cortados somente 3 vezes ao ano por ocasião do período seco. SINGH et alii (1972) estudando o comportamento de värias gramíneas em solos àcidos da India $(\mathrm{pH}=5,5)$, obtiveram com o Andropogon, maior produção de matēria verde $(576 \mathrm{~kg} / \mathrm{ha})$ com $21-44 \%$ de matēria seca, seguida da Brachiaria brizantha com $507 \mathrm{~kg} / \mathrm{ha}$ de matēria verde com $22-44 \%$ de matëria seca.

Verificando-se a produção estacional de oito capins num Latossol Vermelho Escuro de Goiās, obteve-se na época chuvosa maior pro dução do Andropogon em relação as demais $(12.612 \mathrm{~kg} / \mathrm{ha}$ de matéria seca), enquanto que na época seca as diferenças de produção entre os capins cairam bastante, sendo que, entretanto, os capins Andropogon e gordura (Melinis minutiflora) foram os que mais se destacaram nessa ëpoca crítica. Por outro lado, o Andropogon apresentou as maiores taxas de crescimento da cultura (TCC), cerca de $93,97 \mathrm{~kg}$ de matéria seca a $35^{\circ} \mathrm{C} / \mathrm{ha} / \mathrm{dia}$ na época da chuva (EMGOPA*, 1979).

Durante a época seca, quando hä uma queda nas taxas de crescimento, o Andripogon gayanus e a Brachiaria brizantha, mostraram as menores reduções de produção de matēria seca em comparação a outras grạ mineas testadas por SINGH et alii (1972).

Avaliando por um período de dois anos, as associações de Cenchrus ciliaris com Andropogon gayanus, Panicum maximum, Stylosanthes

* Empresa Goiana de Pesquisa Agropecuária. 
guyanensis, Centrosema pubescens e Pueraria javanica adubados com $67 \mathrm{~kg}$ de $\mathrm{N} / \mathrm{ha}, 89 \mathrm{~kg}$ de $\mathrm{P}_{2} \mathrm{O}_{5} / \mathrm{ha}$ e $45 \mathrm{~kg}$ de $\mathrm{K}_{2} \mathrm{O} / \mathrm{ha}$, ASARE (1974) observou que a associação com o Andropogon foi superior, sendo que no primeiro ano a produção foi de $28.000 \mathrm{~kg} / \mathrm{ha}$ e no segundo caiu para $20.000 \mathrm{~kg}$ de matéria seca/ha.

Em outro ensaio de competição conduzido por PEDREIRA et alii (1975) num solo Podzöl ico Vermelho Amarelo var. Laras, adubado, o Andropogon gayanus, com uma produção média de $18.070 \mathrm{~kg}$ de matéria seca/ha/ano, foi superior a Brachiaria mutica, Brachiaria dictyoneura, Bra chiaria spp, Brachiaria sp (NO-63), não diferindo da produção apresentada pelo Panicum maximum.

CIAT (1980) cita que o capim Andropogon, segundo resulta dos do CPAC, produziu $30 \%$ de matéria seca a mais do que Brachiaria decumbens associada com leguminosas. Assim a capacidade de carga do capim Andropogon em associação com Stylosanthes capitata e CaZopogonium muconoides, foi de 3,0 e 1,0 animal/ha, respectivamente na estação chuvosa e seca.

Estudando o potencial do Andropogon gayanus ultissolo, àcido bem drenado e de baixa fertilidade, na Colômbia, aplicando 40kg/ ha de $\mathrm{P}_{2} \mathrm{O}_{5}$ em consorciação com Centrosema pubescens e Styrosanthes quanensis, GROF (1981), obteve produções de $18.710 \mathrm{~kg} / \mathrm{ha} / \mathrm{ano}$ e $15.300 \mathrm{~kg} /$ /ha/ano, com os cortes efetuados a $15 \mathrm{~cm}$ do solo em intervalos de 45 dias durante dois anos.

0 Andropogon é bem adaptado à condições de baixa fertilidade do solo, embora seja capaz de responder a aplicações de fertilizantes. (THOMAS et aiti, 1981). 
A resposta do Andropogon ao nitrogênio foi semelhante à do Panicum maximum e da Brachiaria decumbens em condições de baixo pH e alta saturação de alumínio conforme CIAT (1979). No nível zero de nitrogènio o Andropogon produziu $21,3 \mathrm{t} / \mathrm{ha}$ de matéria seca, enquanto os outros dois capins produziram $13 \mathrm{t} / \mathrm{ha}$. 0 Andropogon respondeu atè o nivel de $50 \mathrm{~kg}$ de nitrogênio/ha, mas o P.maximum e a B. decumbens o fizeram até os níveis de 200 e $400 \mathrm{~kg} / \mathrm{ha}$ respectivamente.

De acordo com JONES (1979), um mínino de $600 \mathrm{~mm}$, anuais de chuva são necessārios para resposta a fertilização do nitrogênio.Após este valor, cada $100 \mathrm{~mm}$ adicionais de precipitação (atē o limite de $1.250 \mathrm{~mm}$ ) provocou un; aumento de $8 \mathrm{~kg}$ de matēria seca for ha/ano e por kg de nitrogênio aplicado, atē $100 \mathrm{~kg}$ de $\mathrm{V} / \mathrm{h} a / \mathrm{ano}$.

A p-incipal limitante ao crescimento das forrageiras nos oxissolos e ultissolos da América Latina é a pequena disponibilidade de fösforo destes solos.

Apesar de experimentos em vaso com Andropogon evidenciarem um baixo requerimento em fösforo (CIAT, 1978), boas respostas tem sido observadas a campo.

Ensaios realizados num solo pobre de Caramigua, na Colóm bia, comprovaram a resposta dos capins Andropogon, P. maximum (colonião), Brachiaria decumbense Hyparrhenia rufa (jaraguā), à adu bação fosfatada. Todos responderam atē a dose de $400 \mathrm{~kg} / \mathrm{ha}$ de $\mathrm{P}_{2} \mathrm{O}_{5}$. Sem a adição de fertilizante: fosfatado, as produções de Andropogon,Brachia riá, jaraguà e colonião, foram respectivamente $35 \%, 20 \%, 10 \%$ e $0 \%$ do má ximo (CIAT, 1978). THOMAS et alii (1981) afimaram que experimentos

THOMAS et alii (1981) afirmaram que experimentos 
realizados no CPAC, em Latossolo Vermelho Escuro, com niveis de 0, 26, 62 e $104 \mathrm{~kg} / \mathrm{ha}$ de fösforo, na forma de superfosfato triplo, mostraram que a produção de matéria seca do Anáropogon gayanus cv. Planalti na foi diretamente relacionada com niveis de fósforo. Observaram também resposta daquela gramínea ao enxofre, magnésio e cálcio.

Trabalhos de pesquisa tem demonstrado que o Rndropogon, apresenta menor concentração de fósforo na parte àérea em relação à ou tras gramíneas forrageiras, dando uma idéia da grande eficiência de uti lização deste elemento. (ORELLANA, 1981)

Em um ensaio conduzido numa aérea não adubada, HAGGAR (1970), conseguiu com o Anáropogon, uma produção de $4.000 \mathrm{~kg} / \mathrm{ha} /$ corte. Observações feitas durante três anos, mostraram que a concentração de fósforo em amostras tomadas a intervalos de 14 dias, na estação chuvovosa, variou de $0,045 \%$ até $0,08 \%$ nas folhas e $0,025 \%$ a $0,063 \%$ nos cau les.

ASARE (1974) comparando associação de Cenchrus ciliaris, com Andropogon gayanus, Panicum maximum, Stylosanthes guyanensis, Centrosema pubescens e Puerária javanica encontrou os seguintes teores de fósforo na matéria seca: C. ciliaris 0,23\%, P. Maximum, 0,24\%; S.guyanen sis, $0,28 \%$, C.pubencens, 0,23\%, P.javanica, 0,21\% e A. gayanus, $0,18 \%$.

Em outro experimento comparativo, realizado em casa de vegetação utilizando solo arenoso com uma adubação de $0,15,30,60,120$ e $180 \mathrm{mg}$ de fósforo por vaso, FALADE (1975) observou que a produção máxima de Andropogon correspondeu a adubação de $60 \mathrm{mg}$ de $\mathrm{Ca}\left(\mathrm{H}_{2} \mathrm{PO}_{4}\right)_{2} \mathrm{H}_{2} \mathrm{O}$, por vaso. O capim apresentou uma concentração de 0,19\% de fósforo. ob servou que as exigências das forrageiras obedecem a seguinte ordem de- 
crescente:Pennisetum purpureum, Anäropogon gayanus, Panicum maximum, Cy nodon plectostachyum.

A avaliação dos efeitos de níveis e fontes de fósforo na concentração de fösforo e cálcio em um Latossolo Vermelho Amarelo (LVA) do cerrado do Brasil Central mostrou que o superfosfato triplo, o termofosfato e o fosfato de rocha (Araxā) aplicados nas dosagens de 60, 120 e $240 \mathrm{~kg} / \mathrm{ha}$, não fizeram variar a concentração de fósforo $(0,07 \%)$ do Andropogon, atestando segundo o autor, a baixa exigência em fósforo daquela gramínea (CIAT, 1979). Esta mesma fonte relata que o Andropogon a presenta acentuada resposta a adubação fosfatada, especialmente quando aplicado juntamente com o calcärio.

Em pastagens da Nigēria, as concentrações médias de cālcio, fósforo e potássio encontrados por HAGGAR (1970) foram de 0,29\%, $0,067 \%$ e $1,32 \%$ nas folhas e 0,20\%, 0,049\% e 2,04\% respectivamente nos caules.

No estägio de florescimento NOORUDDIN e ROY (1974) encon traram $0,94 \%$ para o cálcio e $0,31 \%$ para o fósforo.

ENGUNJOBI (1974) estudou na Nigēria a produção de matēria seca, concentração de cinzas, nitrogēnio e minerais em uma pastagem dominada por Andropogon gayanus. Verificou que o nitrogênio, o cälcio e o magnésio não mostraram valores diferentes entre abril e setembro. A matëria seca apresentou concentrações de $0,45 \%$ de N, $0,14 \%$ de P, $1,01 \%$ de $\mathrm{K}, 0,32 \%$ de $\mathrm{Ca}$ e $0,12 \%$ de $\mathrm{Mg}$.

Estudando a marcha de absorção dos nutrientes em Andropo gon gayamus, ORELLANA (1981) encontrou as seguintes concentrações: nas folhas aos 80 dias; $1,36 \%$ de $N, 0,12 \%$ de P, $0,27 \%$ de Ca e $0,07 \%$ de S; no 
caule os teores foram $0,50 \%$ de $\mathrm{N}, 0,11 \%$ de $\mathrm{P}, 0,27 \%$ de $\mathrm{Ca}$ e $0,06 \%$ de $\mathrm{S}$. Aos 120 dias as concentrações foram respectivamente: $1,2 \%$ de $\mathrm{N}, 0,07 \%$ de $\mathrm{P}, 0,35 \%$ de $\mathrm{Ca}$ e $0,09 \%$ de S para as folhas, e $0,50 \%$ de $\mathrm{N}, 0,07 \%$ de $\mathrm{P}$, Q19\% de Ca e $0,05 \%$ de $S$ nos caules.

0 valor nutritivo de um capim pode ser avaliado pelo conhecimento da fração do mesmo, que não é recuperada através das fezes, ou seja, através da porção digestível do alimento.

A digestibilidade de um al imento pode ser medida diretamente "in vivo" através de ensaios com animais ou "in vitro" pelas téc nicas de laboratōrio.

Trabalhos de pesquisa tem evidenciado que o valor nutritivo do Andropogon, dado em função do teor de nutrientes, digestibilida de e consumo voluntário (palatabilidade) é considerado de médio para baixo em relação às forrageiras tropicais.

Assim è que MILLER e RAINS (1963), na Nigéria em ensaios de digestibilidade "in vivo", com värios capins crescendo em solo areno-argiloso variando do vermelho ao cinza, de acordo com as condições de drenagem, verificaram que o Andropogon gayanus apresentou valores de di gestibilidade da matéria seca de $61,6 \%$ e $52,4 \%$ em ovinos e $54,8 \%, 54,0 \%$ e 53,6\% em bovinos, dependendo do solo, época e altura de corte.

Estudos realizados também na Nigéria, na segunda metade da estação chuvosa, sem fertilização nitrogenada, mostraram a queda no teor de proteína bruta e digestibilidade, a medida que as folhas amadureciam. (HAGGAR e AHMED, 1970). Os autores afirmam ainda, que a digesti bilidade de $65 \%$ e $7 \%$ de proteina bruta 5 ão os niveis ideais que a forra 
gem deve apresentar para uma dieta adequada dos ruminantes. Estes auto res encontraram para o Andropogon, valores de digestibilidade que variavam de $28,3 \%$ na quarta folha, a 66\% na primeira. 0s segmentos do cau le tiveram valores que iam de $32,5 \%$ a $65,9 \%$ para o quarto e primeiro segmentos.

Verificaram ainda, que com o avanço da maturidade, a digestibilidade mostrou um declínio de $0,5 \%$ e $0,4 \%$ por dia, para folhas e caules.

A digestibilidade "in vitro" da matéria seca de 42 capins por um período de 16 semanas, na época das chuvas, foi estudade em Uganda, por REID e POST (1973). Verificaram que a digestibilidade do An dropogon, decresceu de $68 \%$ no inicio das águas, para $43,5 \%$ e que sua digestibilidade foi menor que várias espécies de Brachiarias e Digitárias, sendo semelhante ao colonião.

Outro ensaio de digestibilidade "in vitro" foi realizado por ASARE (1974), em Ghana, estudando pastagens puras e associadas de Cenchrus ciliaris, Andropogon gayanus, Panicum maximu, Stylosanthes gu yanensis, Centrosema pubescens e Pueraria javanica. Nas pastagens puras e associadas, durante dois anos encontrou $33,4 \%$ a $58,2 \%$ e $41,6 \%$ a $47,2 \%$ para C.ciziaris, $40,2 \%$ a $59 \%$ e $37,4 \%$ a $51,6 \%$ para $P$. maximum, $36,6 \%$ a $48,8 \%$ e $28,3 \%$ a $47,8 \%$ para A.gayanus no primeiro e segundo ano respectivamente.

ORELLANA (1981) estudou a digestibilidade "in vivo"l do Andropogon no período de 20 a 140 dias,para folha e de 80 a 140 dias pa ra caules. Neste período houve decréscimo de $82,98 \%$ a $68,30 \%$ para as fo thas. Para os caules a digestibilidade variou de $66,47 \%$ (80 dias) à 
$54,00 \%$ (140 dias).

Diante desses resultados, parece bastante animadora a utilização dessa gramínea em nossas áreas de pastoreio, sendo que, entre tanto, hă necessidade de maiores informações no tocante principalmente à adubação, e em particular a fosfatada para essa cultura.

\subsection{Fertilização Fosfatada}

Os solos brasileiros apresentam em sua grande maioria bai xa fertilidade, principalmente no tocante ao fósforo. De uma maneira ge ral esses solos não são apenas pobres em $P$ disponivel mas também em $P$ total e ainda, em função de suas características mineralögicas, físicas e químicas apresentam grande tendência a insolubilizar (fixar) o fosfato solüvel a eles adicionados (LOT, 1981).

Como supridores de fósforo para as plantas, o superfosfato triplo, superfosfato simples, termofosfato magnesiano (Yoorim) e o fosfato natural de Gafsa (hiperfosfato) se equivalem, quando aplicados a lanço e incorporados ao solo (GOEDERT e LOBATO, 1980).

Por outro lado, com a tendência do mercado de fertilizantes de oferecer förmulas mais concentradas onde as fontes de $N, P$ e $K$ não contém enxofre, tem-se por um lado, a vantagem da economia de trans porte, mas, por outro, verifica-se após alguns anos de cultivo, deficiência desse nutriente. Assim sendo, a utilização hoje de fontes de fós foro com alta solubilidade (superfosfato triplo, MAP, DAP)além de levar a uma considerável perda do investinento realizado em fertilizantes, prin 
cipalmente pela insolubilização dos fosfatos atravēs de reações com outros componentes do solo, leva também as culturas a uma deficiência de s.

Quanto aos fosfatos naturais brasileiros (Patos de Minas, Araxá, Abaeté, Catalão), segundo GOEDERT e LOBATO (1980) mostram uma so lubilidade baixa, tendendo a melhorar com o tempo, sendo ụue o Catalão tem-se comportado de maneira inferior aos demais (LIMA, 1981).

Assim, dada a baixa solubilidade de nossos fosfatos naturais, uma possível solução para mellhorar seu desempentio agronómica poderia ser um tratamento térmico (termofosfato Yoorin, termofosfato IPT) ou um ataque ácido parcial (fosfí: parcialmente acidulado). Outra possibilidade pode ser a associação de aplicação do fosfato natural a lan ço e incorporado ao solo com adubação de manutenção no sulco, utilizando uma fonte solúvel de fósforo (LOBATO, 1982).

Com relação à utilização de fontes de fósforo parcialmente acidulados, a literatura disponível sobre o valor agrícola dos mes mos não é muito abundante.

FRANCO (1977), trabalhando com o fosfato de Araxá acidula do a 5,15 e $25 \%$, com $\mathrm{HCl} \mathrm{e}_{2} \mathrm{SO}_{4}$, observou que, em geral, aumentando a percentagem de acidulação da rocha fosfatada resultou no aumento da quantidade de fósforo solúvel em água e ácido cítrico.

KHASAWNEH e DOLL (1978) fizeram uma revisão de trabalhos a respeito do valor agrícola dos fosfatos naturais parcialmente acidula dos (FNPA), sendo que em 46 de um total de 53 ensaios conduzidos em Ohio, USA, as colheitas obtidas com o produto $20 \%$ acidulado foram maio- 
res ou iguais às conseguidas com o superfosfato.

LEON e FENSTER (1980), utilizando o fosfato da Flörida em forma de pó e microgranulado acidulado a $20 \%$, com $\mathrm{H}_{2} \mathrm{SO}_{4}$, observaram que a dose de $100 \mathrm{Kg} / \mathrm{ha}$ de $\mathrm{P}_{2} \mathrm{O}_{5}$ promoveu aumento no rendimento de grãos de arroz, quando comparado com o fosfato não acidulado,e a microgranulação favoreceu ainda mais este efeito, enquanto que, na dose de $200 \mathrm{~kg} / \mathrm{ha}$ de $\mathrm{P}_{2} \mathrm{O}_{5}$, o fosfato acidulado superou o superfosfato triplo, independente do tamanho do grânulo. Os mesmos autores, trabalhando com diferentes granu lometrias do fosfato da flörida acidulado, verificaram que na máxima do se de $200 \mathrm{Kg} / \mathrm{ha}$ de $\mathrm{P}_{2} \mathrm{O}_{5}$, o gránulo regular evidenciou-se superior aos demais e téve o mesmo comportamento do superfosfato triplo na produção de capim colonião (Panicum maximum).

DASH et alii (1981) mostraram que o FNPA (50-75\%) foi tão bem quanto o superfosfato nas culturas do arroz irrigado por inundação e na do trigo em condições aeröbicas, nos dois casos em solos ácidos.

MALAVOLTA et alii (1981) utilizando de solos com acidez moderada, pobres em $P$ disponível, dois dos quais anteriormente com vege tação de cerrado, conduziram ensaios destinados a comparar a eficiência do fosfato natural parcialmente acidulado da Arafértil (FAPS) com a do super simples (SS) e a do fosfato de Araxá (FA) original, em culturas de arroz de sequeiro, milho e soja. Os resultados obtidos indicaram que; - FAPS proporcionou produções que não diferiram estatisticamente das ob tidas com o SS sendo maiores que as conseguidas com o FA, e os resultados das análises de solos e da diagnose foliar indicaram que o FAPS fun cionou como fonte de $\mathrm{P}$, Ca e S.

NAKAYAMA (1982) em estudos em casa de vegetação com três 
cultivos sucessivos (sorgo sacarino e feijão) em dois solos (LVA e LE) na presença e ausência de calagem verificou o comportamento do fosfato de Araxá parcialmente solubilizado (FAPS) em três granulometrias em com paração com o superfosfato simples, fosfato de Araxā e fosfato de Gafsa. Não se considerando o tipo de solo, calagem e a cultura empregada e nem a granulometria dos FAPS, obtiveram-se es seguintes eficiências relativas médias: $S S=100 ; \quad F A P S=84,79 ; F G=112,91$ e $F A=44,86 \% . \quad$ De maneira geral, pois, a eficiência dos FAPS é pouco menor quando compara da aos superfosfatos e fosfato de Gafsa, mas bem superior à do fosfato de Araxá.

Assim sendo, a possibilidade de utilização de uma fonte de fósforo parcialmente solubilizado, em uma pastagem, parece ser por dema s interessante por apresentar uma pequena fração prontamente solüvel ( $8 \%$ no caso do FAPS), que seria suficiente para garantir o suprimento de $P$ ao vegetal nos estádios iniciais de desenvolvimento, bem como por pos suir uma boa quantidade de $\mathrm{P}_{2} \mathrm{O}_{5}(18 \%)$ numa forma de lenta disponibilidade, garantir o fornecimento do nutriente por um periodo de tempo mais amplo. Congrega-se, assim num ünico produto as boas características de um fosfato natural e de um fosfato solūvel, salientando-se ainda a disponibilidade de caàlcio e enxofre às pastagens (ARAFÉRTIL, 1980).

Mais especificamente com relação ao Andropogon gayanus ,a justificativa do estudo torna-se ma:s que necessäria, pois ensaios de adubação com essa gramínea são ainda incipientes em nosso país. 
3. MATERIAL E METODOS

\subsection{Material}

O experimento foi conduzido em casa de vegetação do Departamento de Agricultura, na Escola Superior de Agricultura "Luiz de Queiroz", em Piracicaba(SP) no período de setembro de 1981 a março de 1982.

\subsubsection{Solo e Espécie Vegetal}

Utilizou-se de um solo ácido de cerrado, coletado na Unidade de Pesquisa de Âmbito Estadual de São Carlos, da EMBRAPA, em São Carlos (SP). As análises químicas do mesmo; realizadas no Laboratório de Fertilidade do Solo da Faculdade de Ciências Agrárias e Veterinárias de Jaboticabal, são apresentadas na Tabela 1. 
Tabela 1. Principais características químicas de amostras de terra da àrea experimental:

\begin{tabular}{|c|c|c|c|c|c|c|c|c|}
\hline \multirow[t]{2}{*}{$\% C$} & \multirow{2}{*}{$\begin{array}{c}\mathrm{pH} \\
\left(\mathrm{H}_{2} \mathrm{O}\right)\end{array}$} & \multicolumn{2}{|c|}{$\mu \mathrm{g} / \mathrm{ml}$ TFSA } & \multicolumn{2}{|c|}{$\mathrm{emg} / 100 \mathrm{ml}$} & TFSA & & $\mathrm{ppm}$ \\
\hline & & $P$ & K & $\mathrm{Ca}^{++}$ & $\mathrm{Mg}^{++}$ & $\mathrm{Al}^{+++}($ & $\left(\mathrm{H}+\mathrm{Al}^{+++}\right)$ & $\mathrm{S}-\mathrm{SO}_{\mathrm{k}}$ \\
\hline 0,81 & 5,0 & 1 & 18 & 0,5 & 0,3 & 0,7 & 4,4 & 14 \\
\hline
\end{tabular}

* obtidas de acordo com a metodologia descrita em RAIJ e ZULLO (1977), exceção feita ao $\mathrm{S}^{-\mathrm{SO}_{4}}$, no qual utilizou-se da metodologia descrita em BARDSLEY e LANCASTER (1965).

0 vegetal escolhido como planta teste foi o capim Gamba (Andropogon gayanus, Kunth, var. Bisquamulatus).

\subsubsection{Fontes de Fösforo}

Na Tabela 2 são apresentadas as fontes de fósforo e as principais características quimicas desses produtos, fornecidas pelo Departamento de Tecnologia da Araxá S.A. Fertilizantes e Produtos Quí micos. 
Tabela 2. Fontes de fósforo e suas principais características químicas.

\begin{tabular}{|c|c|c|c|c|}
\hline \multirow{2}{*}{ CARACTERISTICAS } & \multicolumn{3}{|c|}{ Fontes } & \multirow[b]{2}{*}{$\begin{array}{c}\text { Fosfato } \\
\text { Araxá }\end{array}$} \\
\hline & $\begin{array}{l}\text { FAPS } \div \\
(1-2 \mathrm{~mm})\end{array}$ & $\begin{array}{l}\text { FAPS } * \div \\
(2-4 \mathrm{~mm})\end{array}$ & $\begin{array}{c}\text { Super } \\
\text { Simples }\end{array}$ & \\
\hline $\mathrm{P}_{2} \mathrm{O}_{5}$ total & 26,70 & 27,00 & $19-21$ & 35 \\
\hline $\mathrm{P}_{2} \mathrm{O}_{5}$ Ácido cítrico $2 \%(1: 100)$ & 10,80 & 10,82 & - & - \\
\hline $\mathrm{P}_{2} \mathrm{O}_{5}$ Citrato Amônio $(\mathrm{pH}=7,0 \mathrm{f}$ & 10,50 & 10,40 & 18 & $5-6$ \\
\hline $\mathrm{P}_{2} \mathrm{O}_{5}$ ägua & 9,02 & 8,85 & 16 & - \\
\hline $\mathrm{P}_{2} \mathrm{O}_{5}$ livre & 2,95 & 2,93 & - & - \\
\hline $\mathrm{S}$ & 6,00 & 6,00 & 12,00 & - \\
\hline $\mathrm{CaO}$ & 35,00 & 35,00 & $25-28$ & $42-45$ \\
\hline Água Livre & 2,45 & 2,53 & - & - \\
\hline
\end{tabular}

* FAPS (1-2mm): Fosfato Arafértil parcialmente solubilizado com granulo metria de 1 a 2 milimetros.

$*$ FAPS $(2-4 \mathrm{~mm})$ : Fosfato Arafërtil parcialmente solubilizado com granulometria de 2 a 4 milimetros.

\subsection{Métodos}

\subsubsection{Tratamentos}

Os tratamentos principais (Fontes de P; FAPS $(1-2 \mathrm{~mm})$, FAPS $(2-4 \mathrm{~mm})$, Superfosfato Simples e Fosfato de Araxä), mais os trata mentos secundärios ( $N$ íveis de $P ; 1,2$ e 3 ), com 4 repetições foram mon tados num delineamento inteiramente casualizado com esquema fatorial $(4 \times 3)$ mais uma testemunha adicional (sem $\mathrm{P}$ ), conforme dados da Tabela 3. 
Tabela 3. Esquema dos tratamentos utilizados no experimento.*

\begin{tabular}{|c|c|c|c|c|c|}
\hline Niveis & \multirow{2}{*}{$\begin{array}{c}\text { Vasos } \\
\text { nọ }\end{array}$} & \multirow{2}{*}{$\begin{array}{c}\text { Fonte de } \\
\text { P }\end{array}$} & \multirow{2}{*}{$\begin{array}{l}\mathrm{kg} / \mathrm{ha} \\
\mathrm{P}_{2} \mathrm{O}_{5}(\text { total })\end{array}$} & \multicolumn{2}{|c|}{$\mathrm{mg} /$ vaso } \\
\hline de $P$ & & & & (6kg TFSA) & Adubo \\
\hline 0 & $1-4$ & & 0 & - & \\
\hline 1 & $5-8$ & FAPS $(1-2 m m)$ & 100 & 924 & \\
\hline 1 & $9-12$ & FAPS $(2-4 \mathrm{~mm})$ & 100 & 924 & \\
\hline 1 & $13-16$ & Super Simples & 100 & 1200 & \\
\hline 1 & $17-20$ & Fosfato Araxā & 100 & 684 & \\
\hline 2 & $21-24$ & FAPS $(1-2 m m)$ & 200 & 1848 & \\
\hline 2 & $25-28$ & FAPS $(2-4 \mathrm{~mm})$ & 200 & 1848 & \\
\hline 2 & $29-32$ & Super Simples & 200 & 2400 & \\
\hline 2 & $33-36$ & Fosfato Araxā & 200 & 1368 & \\
\hline 3 & $37-40$ & FAPS $(1-2 m m)$ & 300 & 2772 & \\
\hline 3 & $41-44$ & FAPS $(2-4 \mathrm{~mm})$ & 300 & 2772 & \\
\hline 3 & $45-48^{\prime}$ & Super Simples & 300 & 3600 & \\
\hline 3 & $49-52$ & Fosfato Araxā & 300 & 2052 & \\
\hline
\end{tabular}

* Total de vasos: 4 fontes de $P \times 3$ niveis de $P \times 4$ repetiçöes $\times 1$ solo= $=48$ vasos mais 4 (testemunha) $=52$ vasos 


\subsubsection{Condução}

\section{a) Vasos e Terra}

Foram usados vasos de cerâmica com capacidade para $6 \mathrm{~kg}$ de TFSA, pintados internamente com neutrol 45 e dotados de coletores também impermeabilizados com neutrol.

O solo empregado no ensaio foi coletado da superfície da gleba na profundidade de 0 a $25 \mathrm{~cm}$, destorroado, posto a secar ao ar, peneirado passando por malha de $2 \mathrm{~mm}$ (peneira no 10) e uniformizado por misturas sucessivas de porções.

Após essa mistura foi retirada uma amostra $(0,5 \mathrm{~kg})$ para análise química de rotina desses solos.

Do solo foi retirado no campo uma amostra de cerca de 0,5 tonelada (quantidade necessäria para o experimento, $312 \mathrm{~kg}$ de TFSA).

b) Adubação

$b_{1} \cdot$ Nitrogênio $(N)$

o nitrogênio foi fornecido como uma solução de urēia (12,00 g.uréia/litro), sendo aplicado no plantio, $18 \mathrm{ml}$ dessa solução/ vaso (40 kg/ha de $\mathrm{N}$ ), enquanto que aos 20 dias após a germinação do cá pim, foram aplicados $18 \mathrm{ml}$ de solução (40 kg/ha de $\mathrm{N}$ ).

$$
b_{2} \text {. Potássio }(K)
$$

o potássio foi aplicado como uma solução de cloreto de potāssio $(6,0 \mathrm{~g} \mathrm{KCl} / \mathrm{litro})$, sendo aplicados no plantio $18 \mathrm{ml}$ dessa solu ção por vaso $\left(27 \mathrm{~kg} / \mathrm{ha}\right.$ de $\left.\mathrm{K}_{2} 0\right)$ e $42 \mathrm{ml}$ da solução $\left(53 \mathrm{~kg} / \mathrm{ha}\right.$ de $\left.\mathrm{K}_{2} 0\right)$, qua 
tro semanas apös.

$$
b_{3} \text {. Fösforo }(P)
$$

o fósforo foi fornecido nas doses e fontes já enumeradas na Tabela 2, distribuido de modo uniforme e muito bem homogeneizado com a terra dos vasos, antes da aplicação dos adubos na forma de soluções.

$$
b_{4} \text {. Micronutrientes }
$$

$\mathrm{Na}$ Tabela 4 estão enumeradas as doses, fontes e preparo das soluções de micronutrientes.

TABELA 4. Doses, fontes e preparo das soluções de micronutrientes, ba-.

\begin{tabular}{|c|c|c|c|}
\hline Nutriente & ppm & Quantidade & Forma de Aplicação \\
\hline B & 0,5 & $286 \mathrm{mg} \mathrm{H}_{3} \mathrm{BO}_{3} / \mathrm{litro}$ & Aplicado no plan- \\
\hline $\mathrm{Cu}$ & 1,5 & $402 \mathrm{mg} \mathrm{CuCl}{ }_{2} / 1$ itro & tio numa solução \\
\hline Mn & 3,0 & $1,08 \mathrm{~g} \mathrm{MnCl}_{2}-4 \mathrm{H}_{2} \mathrm{O} / 1$ itro & ūnica (50 ml/vaso) \\
\hline Mo & 0,1 & $25 \mathrm{mg} \mathrm{Na} \mathrm{MoO}_{4} \cdot 2 \mathrm{H}_{2} \mathrm{O} / \mathrm{litro}$ & plantio como suspen \\
\hline $2 n$ & 5,0 & $645 \mathrm{mg}$ Zno/litro\} & são (50ml/vaso) \\
\hline $\mathrm{Fe}$ & 5,0 & $\mathrm{Fe}-$ EDTA $\}$ & $5 \mathrm{ml} /$ vaso no plantio \\
\hline
\end{tabular}
seados em HOAGLAND e ARNON (1950).

c) Semeadura e Desbaste

- Na semeadura, realizada a 30/10/81, foram utilizadas 30 sementes por vaso, colocadas a profundidade de 0,5 a $1,0 \mathrm{~cm}$, distribuin 
das regularmente. Posteriornente irrigou-se com água destilada de modo a levar a umidade do solo de cada vaso a cerca de $2 / 3$ do poder de embebição (l/2 atmosfera).

Quinze dias após a germinação $(18 / 11 / 81)$ foi feitoo desbaste em todos os vasos, deixando-se quatro plantas uniformes, no que diz respeito a altura e número de folhas.

\section{d) Regas}

Duas ou três vezes por semana, foram pesados alguns vasos ao acaso, e restituído o peso da água evaporada, tirando uma média que se aplicou a todos os vasos (usou-se sempre água destilada).

A medida que as plantas foram crescendo, a quantidade de água adicionada aumentou. Estimou-se a quantidade requerida pela observação do grau de umidade do solo e a aparência das plantas. 0 excesso de água que percolou para o coletor foi devolvido à superfície.

\section{e) Cuidados Fitossanitärios}

Durante o transcorrer do experimento, as plantas sofre ram ataque de lagartas, e para combatê-las foi feita uma pulverização com Endrex. (clorado), 24 dias após o plantio.

\subsubsection{Colheita}

No dia 14/01/82, colheu-se a parte aérea das plantas. 0 material colhido foi seco em estufa, à temperatura de $70^{\circ} \mathrm{C}$.

Em 21/01/82, removeu-se as raízes do solo, com auxilio 
de uma peneira e utilizando-se jatos de ägua. As raízes foram lavadas diversas vezes com água destilada, postas a secar a $70^{\circ} \mathrm{C}$ e pesadas. Dos solos dos vasos, foram retiradas amostras de $0,5 \mathrm{~kg}$ para anālises químicas.

Do material (folhas e raízes) colhido e seco a $70^{\circ} \mathrm{C}$, foram tomadas amostras, para determinação da matéria seca a $105^{\circ} \mathrm{C}$.

\subsubsection{Anālise Minerais}

\section{a) Plantas}

Para a determinação de elementos minerais utilizou-se ćos seguintes métodos analíticos; $N$ - Semimicro Kjeldahl; P-Colorimetria do molibdato de amōnio;Ca - absorção atômica, métodos estes citados em SAR RUGE e HAAG (1974), enquanto que o $\mathrm{S}$ foi determinado por turbidimetria em fluxo contínuo (KRUGG et alii 1977).

A proteina foi calculada, multiplicando-se os teores de nitrogènio por 6,25 .

\section{b) Solos}

Nas amostras de solos foram determinados o fósforo em $\mathrm{H}_{2} \mathrm{SO}_{4} 0,05 \mathrm{~N}$ (IAC) e em $\mathrm{NH}_{4} \mathrm{~F} 0,03 \mathrm{~N}+\mathrm{HCl} 0,025 \mathrm{~N}$ (Extrator de Bray-1), O cálcio em $\mathrm{KCl}$ I, ON e O $\mathrm{S}_{-} \mathrm{SO}_{4}$ em acetato de amônio $0,5 \mathrm{~N}$ em àcido acético 0,25N (BARDSLEY e LANCASTER, 1965).

\subsubsection{Digestibilidade}

A digestibilidade "in vitro" da matéria seca da parte aé 
rea foi determinada de acordo com a técnica TILLEY e TERRY (1963).

\subsubsection{Anālise Estatística}

A análise estatística preliminar para cada tipo de parā metro analisado seguiu o esquema conforme a Tabela 5 , de acordo com GOMES, (1973).

Tabela 5. Esquema de análise de varianncia na fase preliminar.

\begin{tabular}{lc}
\hline Causas de variação & GL \\
\hline Testemunha $\times$ Fatorial & 1 \\
Fontes de $P(F)$ & 3 \\
Doses de $P(D)$ & 2 \\
Interação $(F \times D)$ & 6 \\
Resíduo & 39 \\
Total & 51 \\
\hline
\end{tabular}

No caso de interações ( $F \times D$ ) significativas, desdobraram-se os efeitos de doses dentro de cada fonte.

Em todos os casos, foram obtidas as equações de regressão de cada característica analisada em função de doses, separadamente para cada fonte, obtendo as equações que são apresentadas graficamente em resultados e discução. 
4.1. Efeito da Adição de Adubos Fosfatados na Produção de Matéria Seca. Nas Tabelas 6,7 e 8 são apresentados respectivamente as produções de matéria seca da parte aérea, da raiz e total (aérea t raiz) do capim Andropogon, a $105^{\circ} \mathrm{C}$, obtidas pela aplicação de doses e fontes de fósforo, enquanto que nas Tabelas 25, 26 e 27 as médias e o resumo da anālise de variância correspondente.

Analisando-se os dados destas tabelas, verifica-se in cialmente um efeito altamente significativo da adição de qualquer fonte de $P$, na produção de matéria seca, em relação à testemunha, constituin do respostas típicas de solos extremamente pobres em $\mathrm{P}$ nativo disponível, como mencionado por GOEDERT e LOBATO (1980). Respostas positivas de capim Andropogon à adubação fosfatada foram também observadas por CIAT (1978) e THOMAS et alii (1931).

Como a interação fontes versus doses de fösforo não foi 


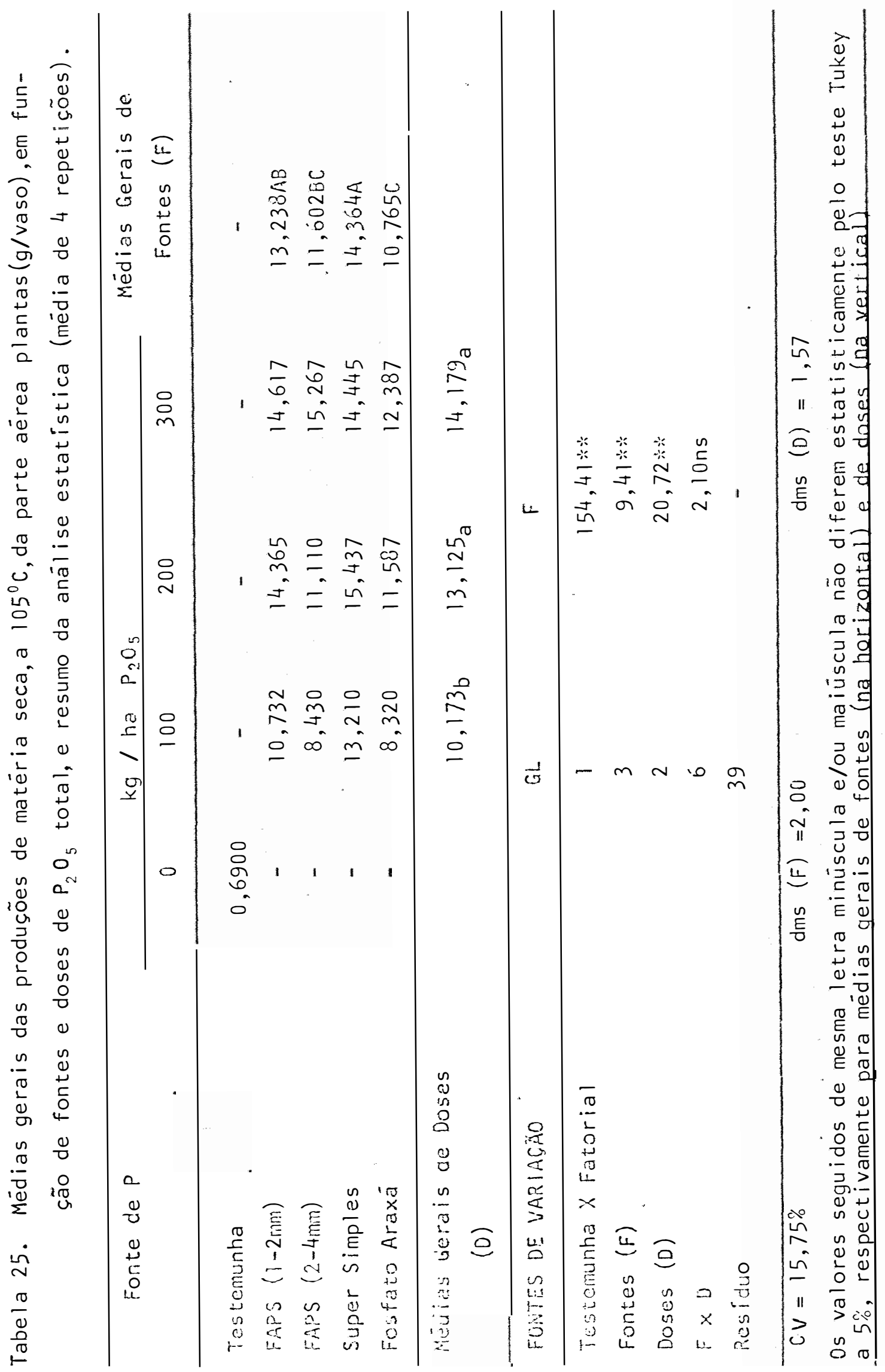




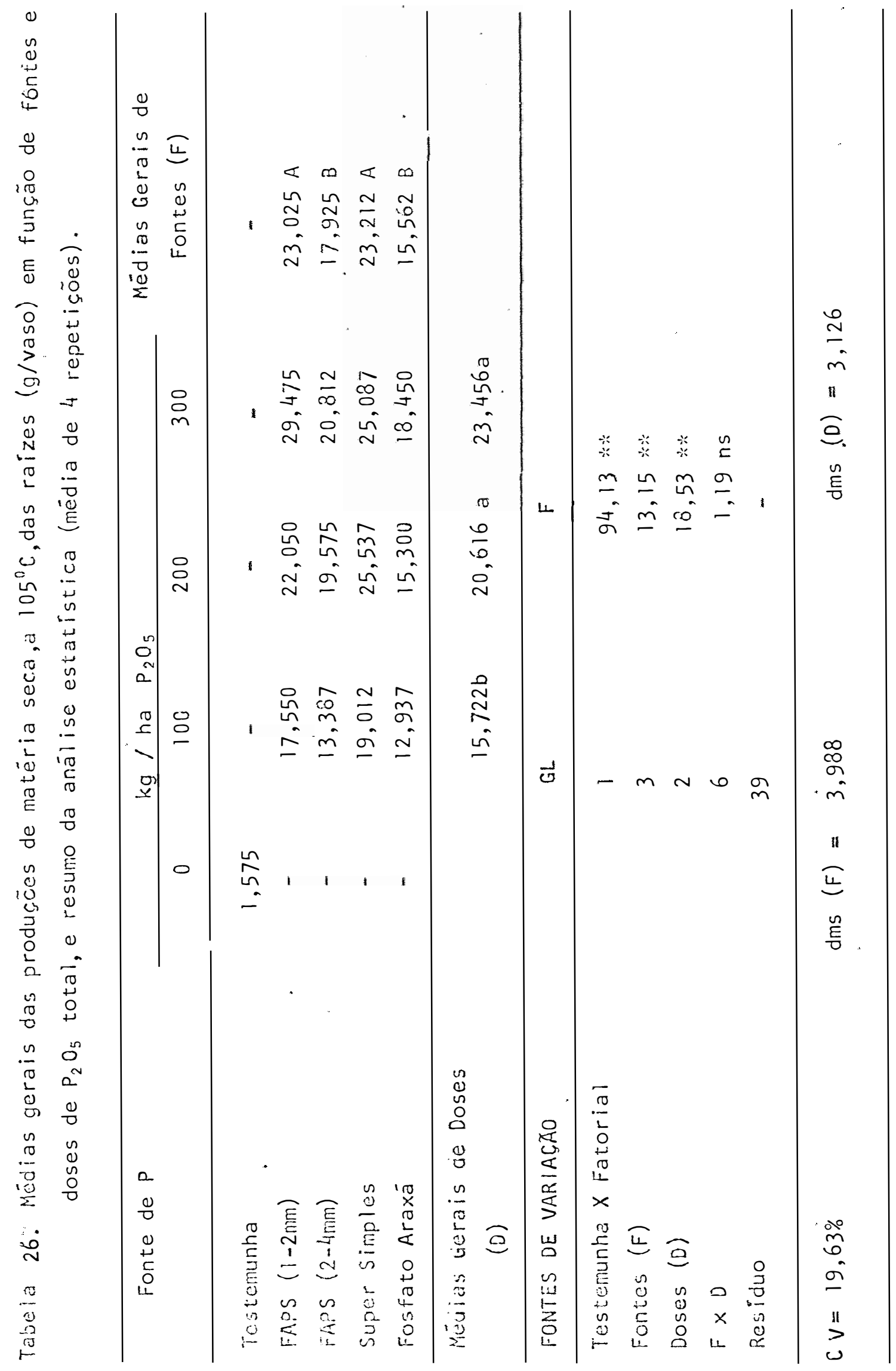




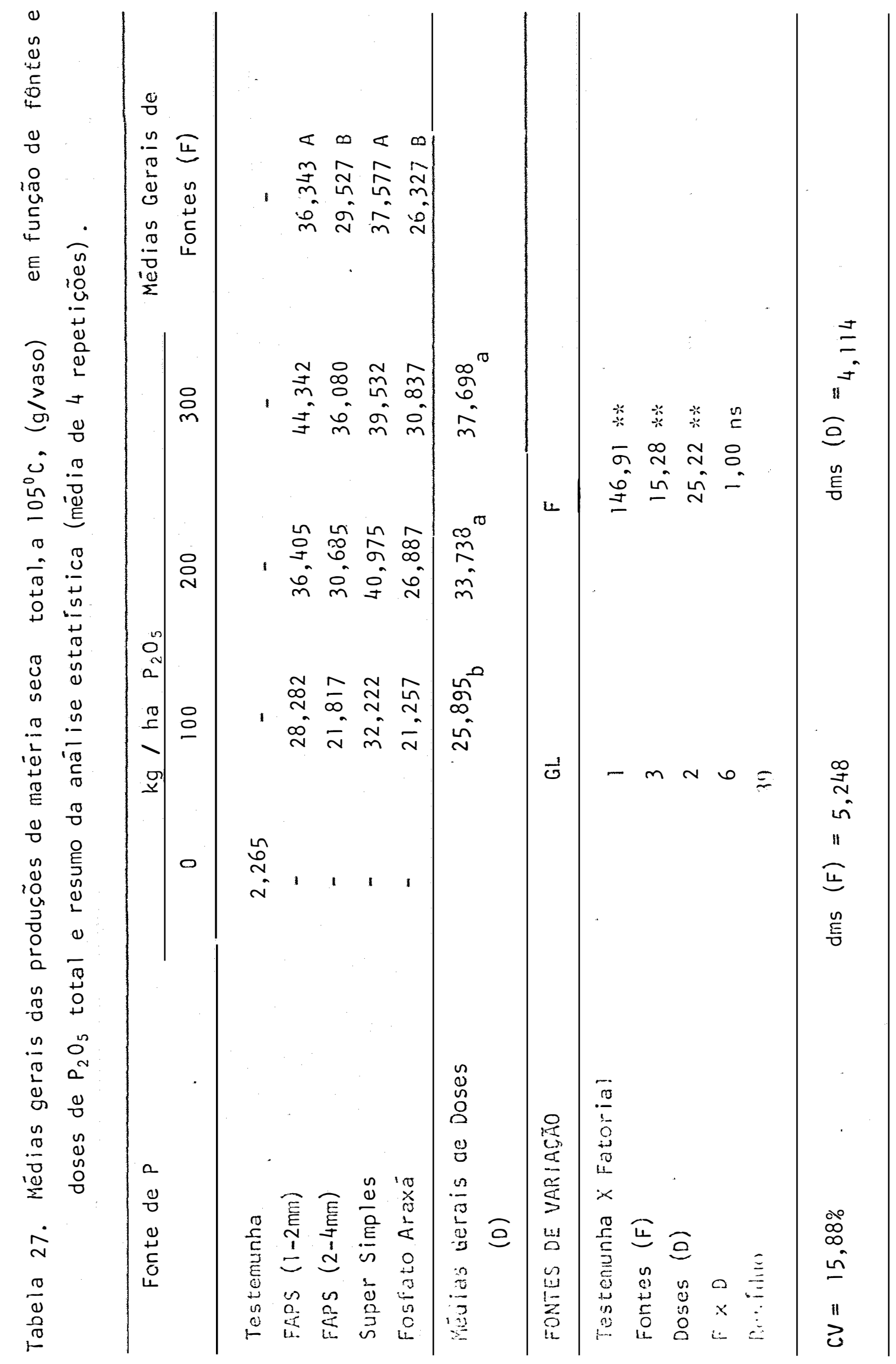


significativa, comparou-se as médias de produção de matéria seca para fontes e doses de P, pelo teste Tukey ao nivel de $5 \%$. Verifica-se pelos dados das Tabelas 25, 26 e 27 que o superfosfato simples (SS) apre sentou comportamento semelhante ao FAPS (1-2mm), apresentando produção de matéria seca superior ao FAPS $(2-4 \mathrm{~mm})$ e ao fosfato de Araxá (FA). Re sultados semelhantes foram também obtidos por NAKAYAMA (1982) que obser vou que a eficiência dos FAPS é pouco menor quando comparada aos superfosfatos, mas bem superior à do fosfato de Araxá. Eficiência superior com FAPS de menor granulometria foram também obtidas por ASHBY et alii (1966); LEON e FENSTER (1980) e NAKAYAMA (1982). Com relação à eficiência do FAPS, conforme citado em MCKEAN e WHEELER (1964)) isso se deve a altos poderes de fixação de $P$ do solo e a altos níveis de $\mathrm{Al}^{3}+$ trocável. Assim, devido à menor proporção de $P$ solúvel em água comparada à dos su perfosfatos, forma-se menor proporção de ácido fosförico. A rocha fosfa tada contida no FAPS poderia então competir com o Fe e o Al do solo; co mo consequência, em vez de se ter a reversão do $\mathrm{H}_{2} \mathrm{PO}_{4}^{-}$a formas não dis poníveis (fosfatos de ferro ou de alumínio) aumentaria o conteúdo de $P$ aproveitável. Logo, o P solúvel em água ou citrato presente inicial mente no FAPS estimularia o desenvolvimento da planta cujas raízes se aproveitariam depois de parte da fração insolúvel quando o primeiro tivesse sido consumido e esta última sofresse transformação em formas aproveitāveis (MALAVOLTA et alii, 1931 ).

Por outro lado, verifica-se que com exceção do superfos fato simples, em que não houve diferenças entre as doses de $\mathrm{P}_{2} \mathrm{O}_{5}$ utilizada, que em todas as demais fontes a produção de matéria seca au- 
mentou . linearmente com o aumento do P aplicado (Figuras 1, 2 e 3), su gerindo que doses mais elevadas do que as empregadas poderiam aumentar ainda mais a produção de matēria seca. No Estado de Minas Gerais, BRAGA et alii (1972) conduzindo experimentos em quatro locais do Triângulo Mi neiro num Latossolo Vermelho Escuro - textura média (cerrado) encontraram também um efeito linear para a produção de grãos de soja até a maior dose utilizada, isto é, $300 \mathrm{Kg} / \mathrm{ha}$ de $\mathrm{P}_{2} \mathrm{O}_{5}$.

4.2. Efeito dos Tratamentos sobre a Concentração e Quantidade Absorvida de P, Ca e S.

Nas Tabelas 9 a 11 são apresentadas respectivamente as concentrações de $\mathrm{P}$, Ca e $\mathrm{S}$ em porcentagem de matéria seca a $105^{\circ} \mathrm{C}$, enquanto que nas de 12 a 14 , as quantidades respectivas desses nutrientes absorvidos em mg/vaso. As médias gerais desses parāmetros, bem como o resumo da anālise de variância são apresentadas respectivamente nas Tabelas de 28 a 33 .

Com relação às concentrações de $\mathrm{P}$ na matéria seca obser va-se apenas com relação ao superfosfato simples, um aumento nas mesmas, com o aumento das doses de $\mathrm{P}_{2} \mathrm{O}_{5}$, enquanto que para o $\mathrm{Ca}$ verifica-se um aumento linear das concentrações, exceto para o FAPS (1-2 mm), o que po de ser observado pela anālise das Figuras 4 e 5 .

Já, com relação às concentrações de S na matéria seca, houve tendência de um efeito quadrático das doses de $\mathrm{P}_{2} \mathrm{O}_{5}$ nas mesmas (Figura 6), enquanto que as variações dessas concentrações, dentro das diversas fontes empregadas, não apresentaram resultados coerentes, prin cipalmente em função dos teores de $\mathbf{S}$ garanticos nas mesmas. 
M.S.aérea

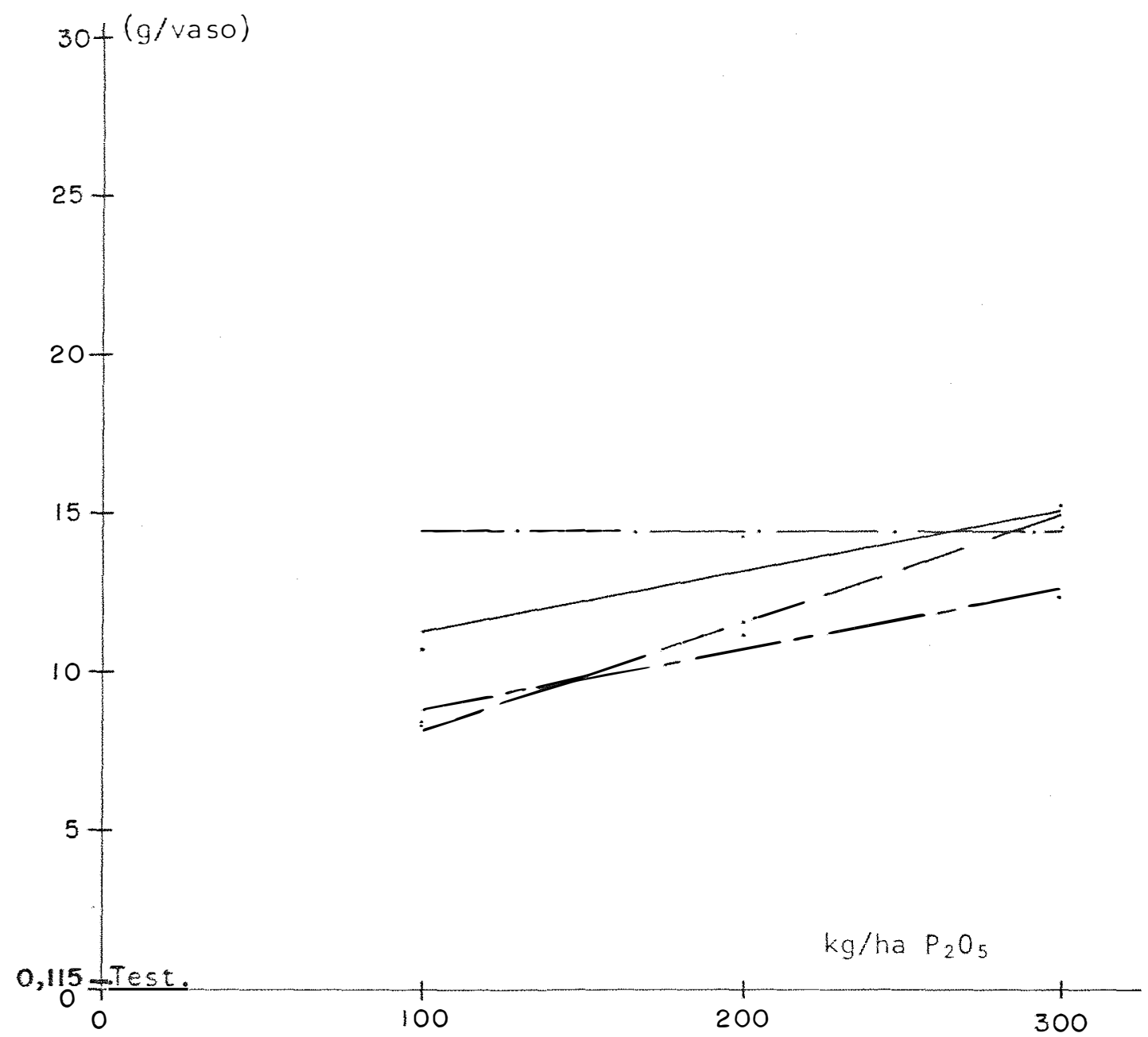

\begin{tabular}{lll}
- FAPS $(1-2 \mathrm{~mm})$ & $Y=9,535+0,0194 x$ & $r^{2}=0,79 * *$ \\
\hline FAPS $(2-4 \mathrm{~mm})$ & $Y=4,765+0,0342 X$ & $r^{2}=0,98 * *$ \\
- Super Simples & $Y=14,39$ & \\
\hline- Fosfato Araxä & $Y=6,697+0,020 \mathrm{X}$ & $r^{2}=0,89 * *$
\end{tabular}

Figura 1. Efeito de doses de $\mathrm{P}_{2} \mathrm{O}_{5}$, na produção de matéria seca (g/vaso) da parte aérea. 


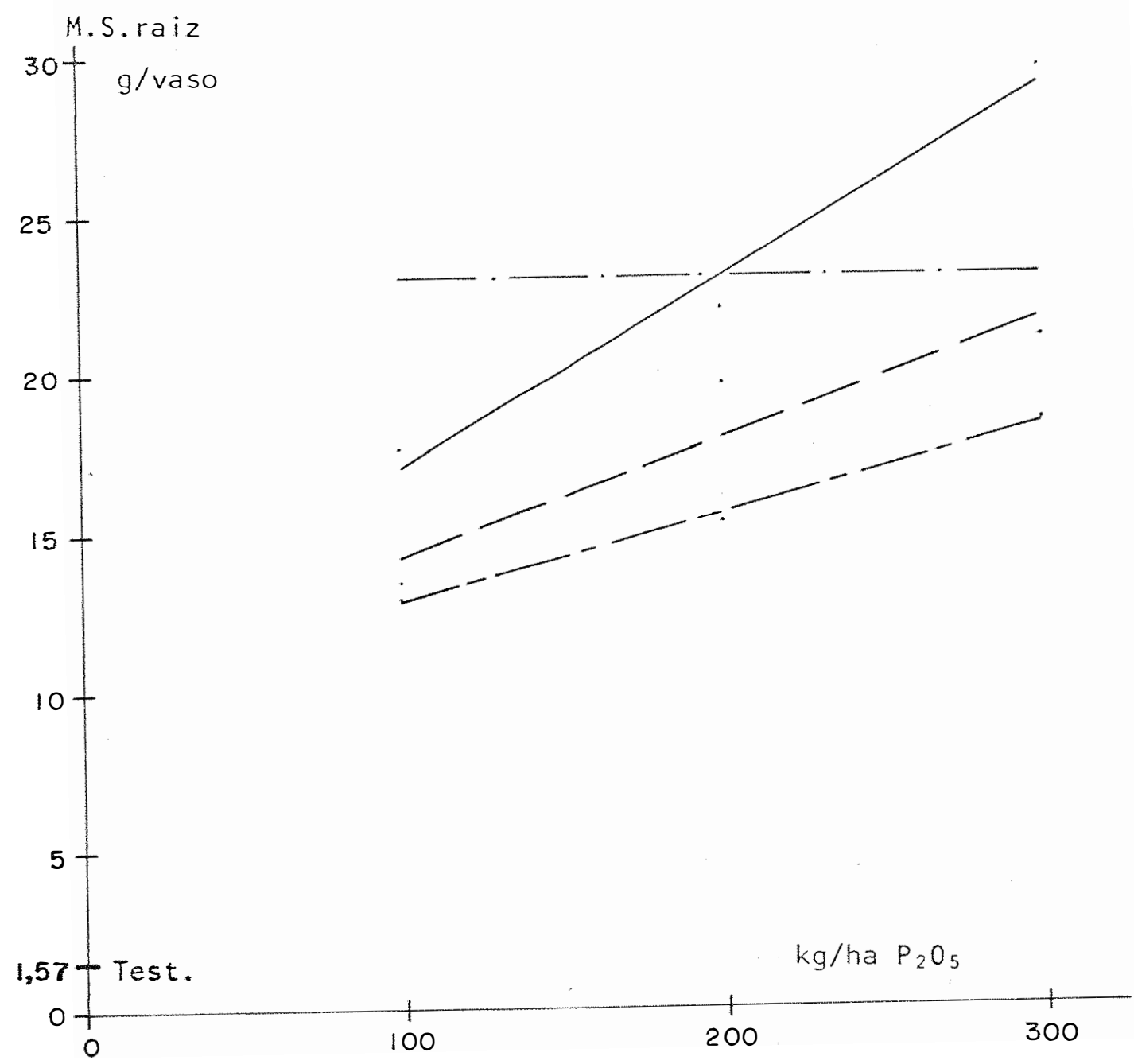

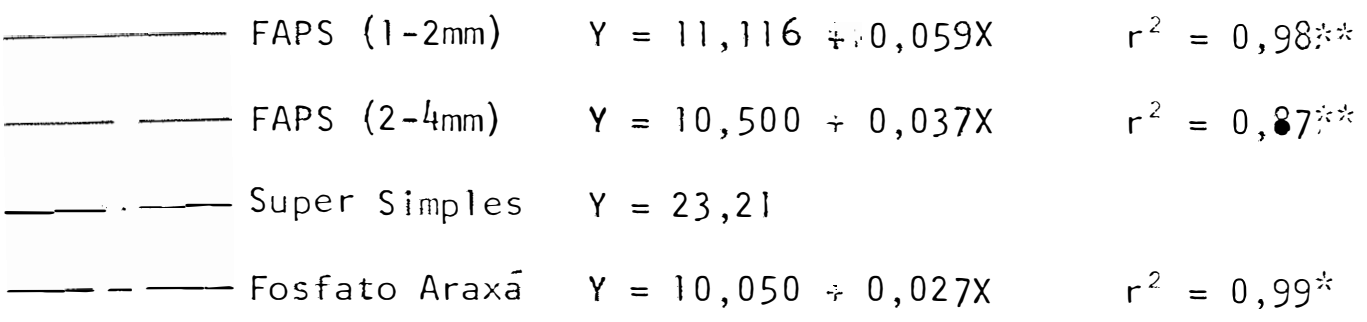

Figura 2. Efeito de doses de $P_{2} \mathrm{O}_{5}$, na produção de matéria seca (g/vaso) da raiz. 
M.S.Total

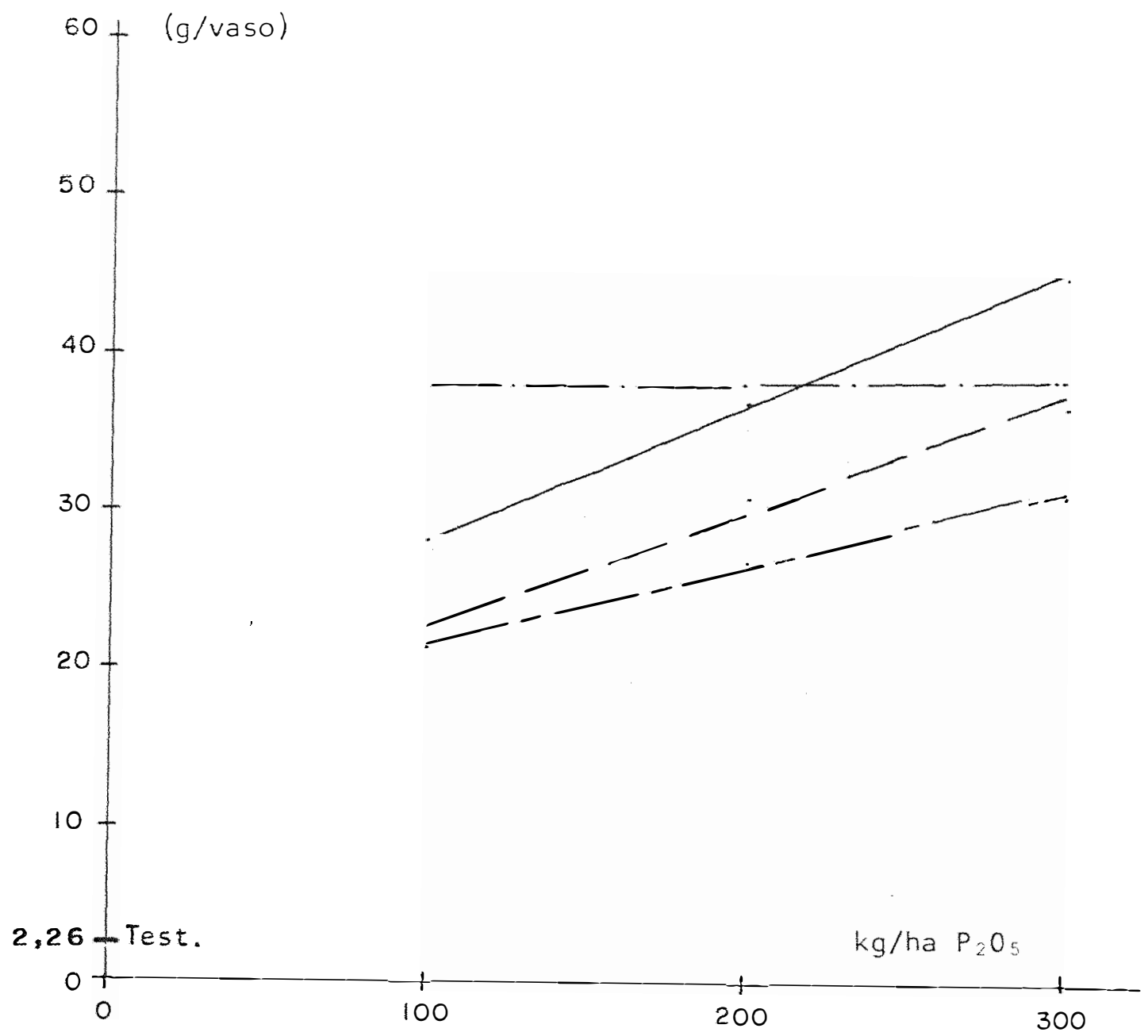

$\begin{array}{lll}- \text { FAPS }(1-2 \mathrm{~mm}) & Y=20,283+0,080 \times & r^{2}=0,99 \therefore \therefore \\ - \text { FAPS }(2-4 \mathrm{~mm}) & Y=15,265+0,071 \mathrm{X} & r^{2}=0,98 \therefore * \\ - \text { Super Simples } & Y=37,57 & \\ - \text { - Fosfato Araxá } & Y=16,543+0,04 \times & r^{2}=0,99 \therefore *\end{array}$

Figura 3. Efeito de doses de $\mathrm{P}_{2} \mathrm{O}_{5}$, na produção de matéria seca total (g/vaso) 


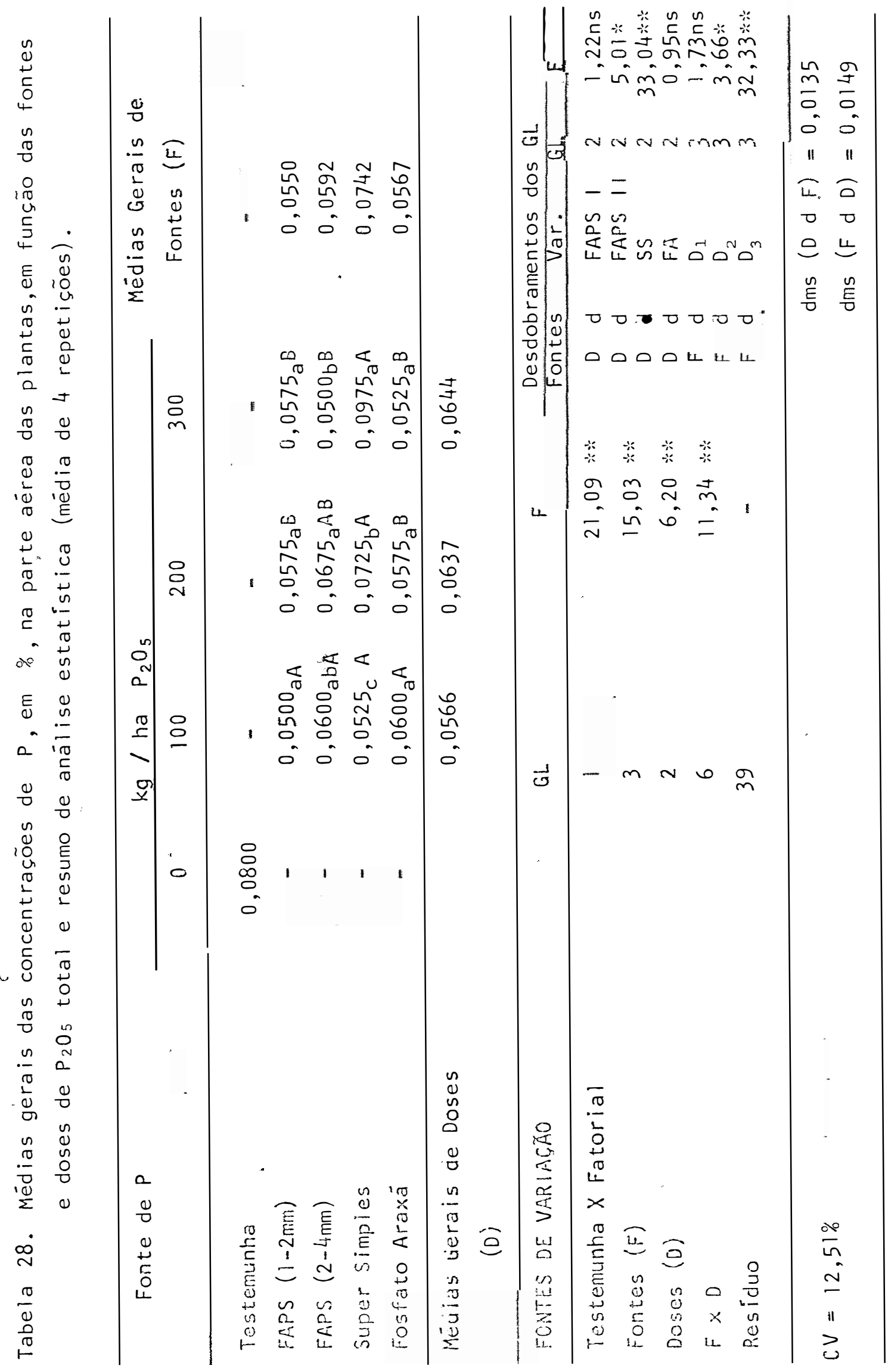




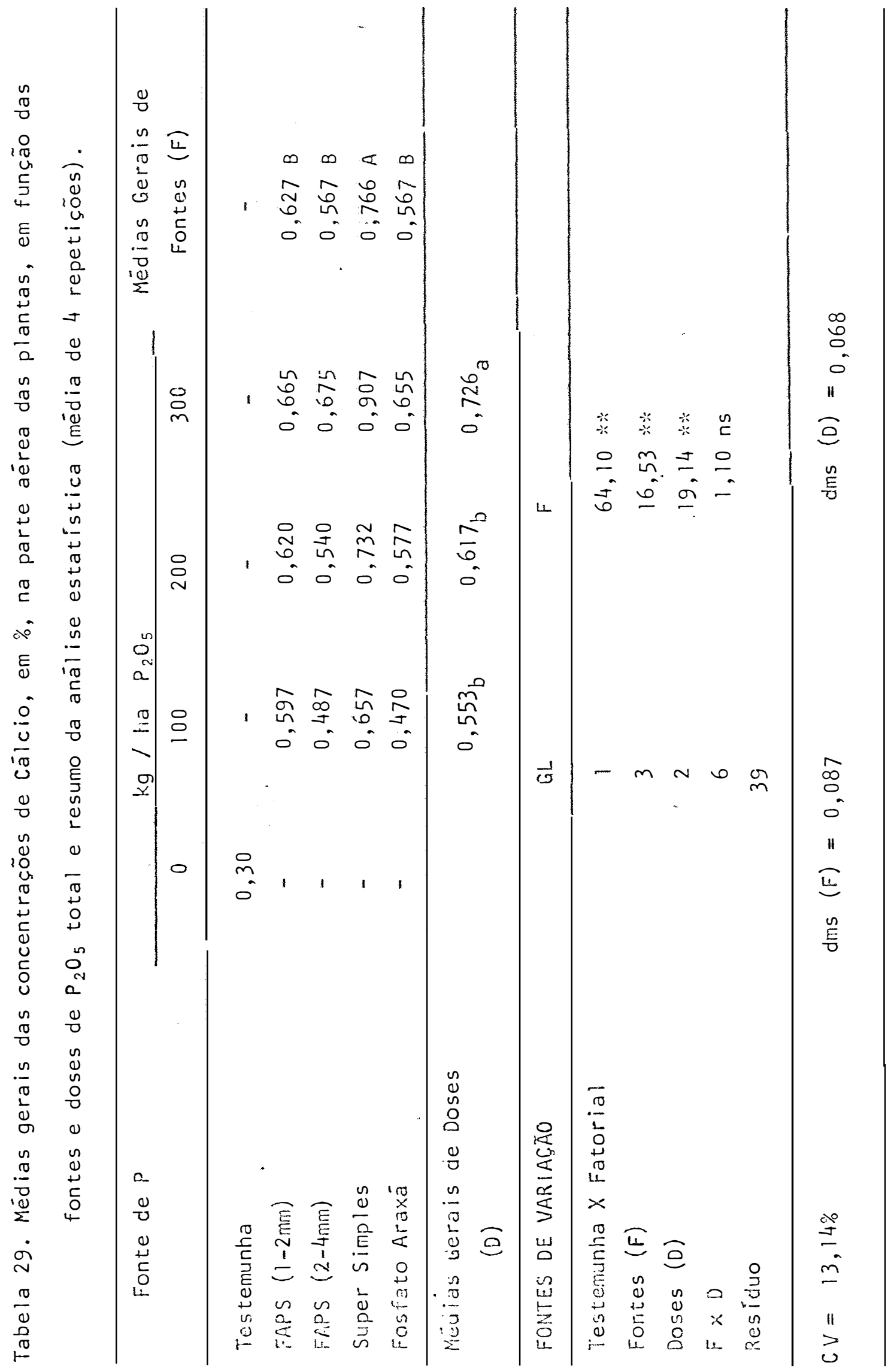




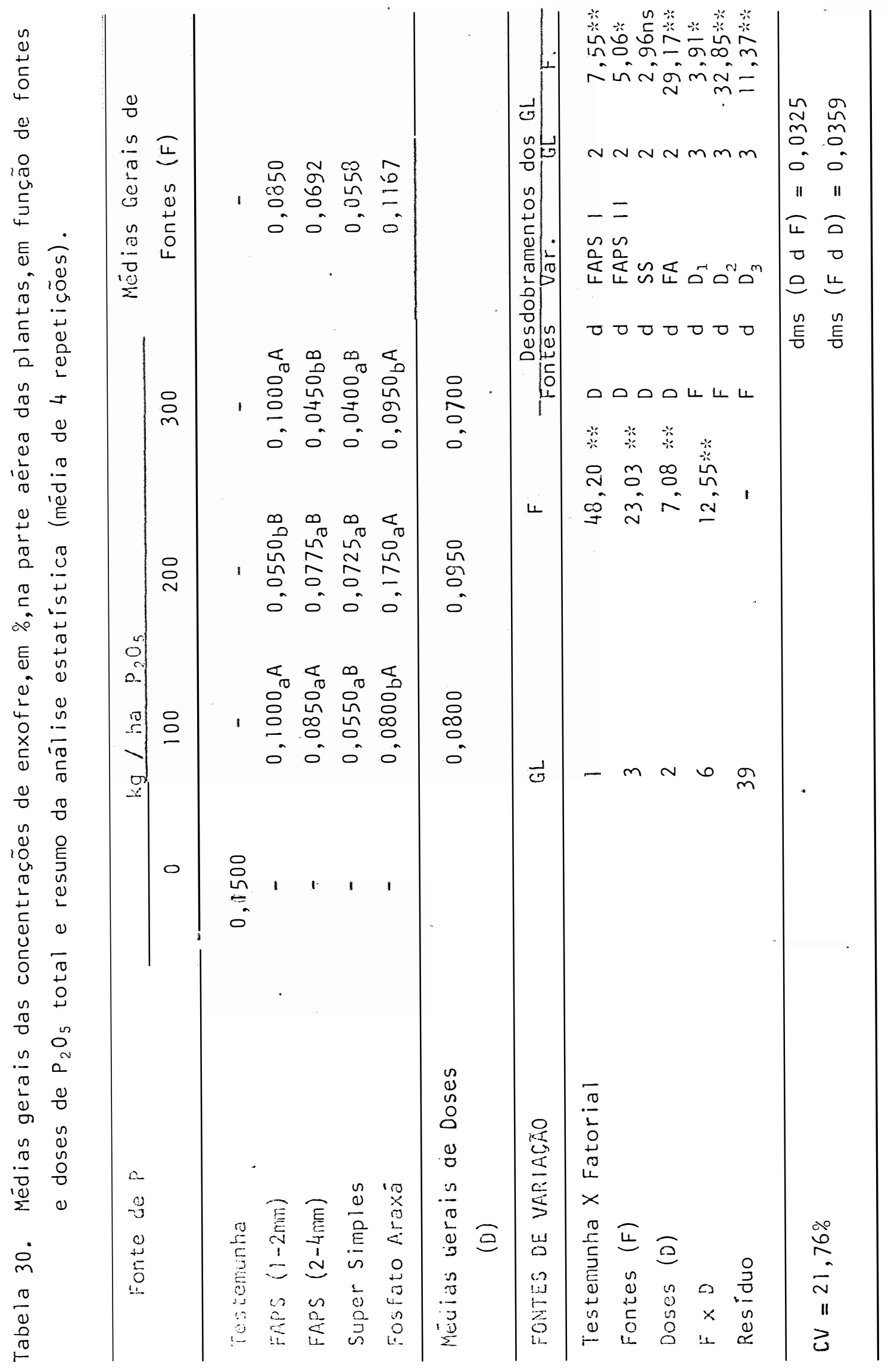




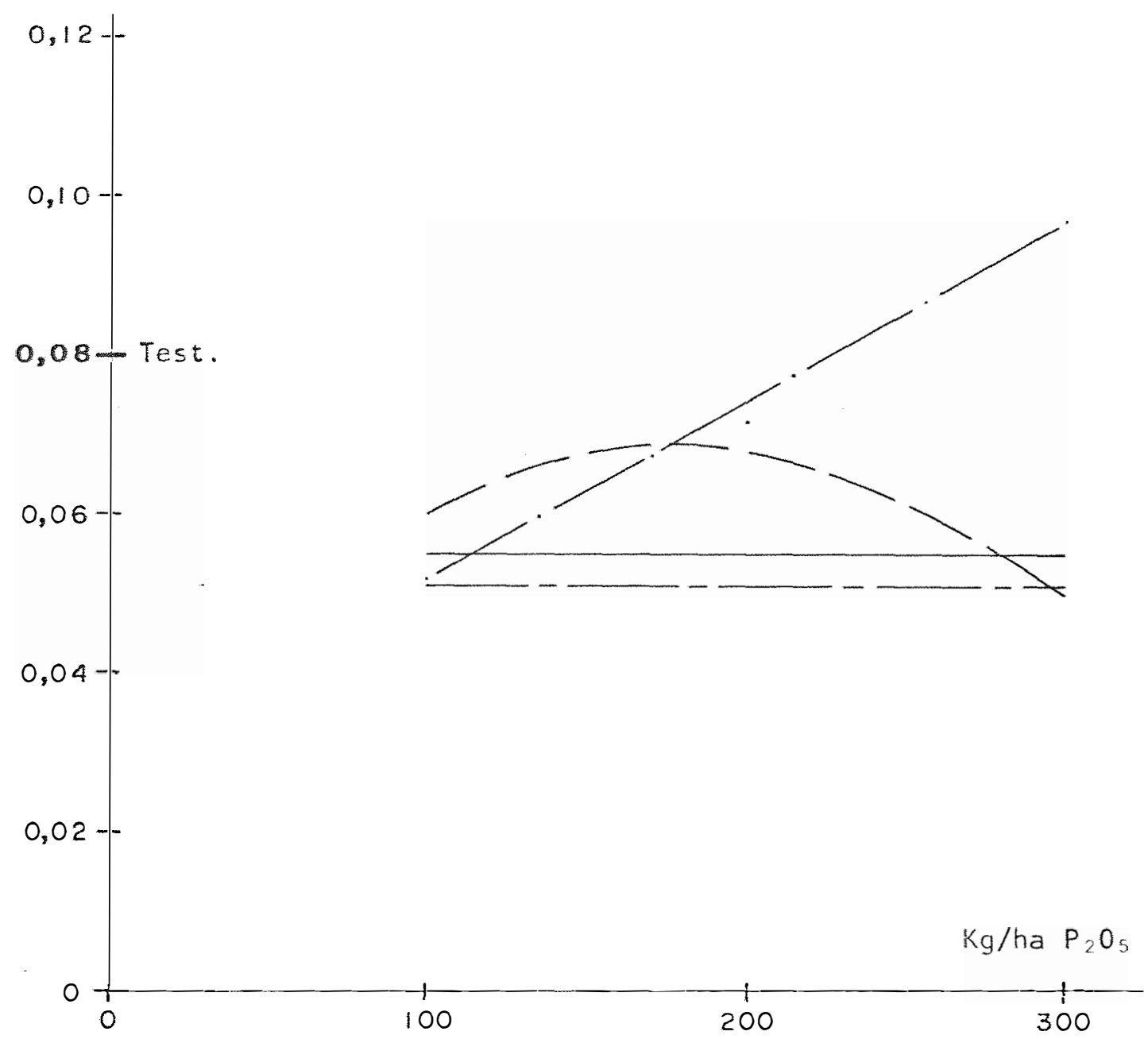

$\begin{array}{lll}- \text { FAPS }(1-2 \mathrm{~mm}) & Y=0,055 & \\ - \text { FAPS }(2-4 \mathrm{~mm}) & Y=0,0275 \div 0,00045 X-0,0000012 X^{2} & R^{2}=1,00 * * \\ - \text { Super Simples } & Y=0,029 \div 0,0002 X & r^{2}=0,97 * * \\ - \text { Fosfato Araxá } & Y=0,051 & \end{array}$

Figura 4. Efeito de doses de $\mathrm{P}_{2} \mathrm{O}_{5}$, na concentração de Fósforo da parte aérea. 


$$
\mathrm{Ca}(\%)
$$

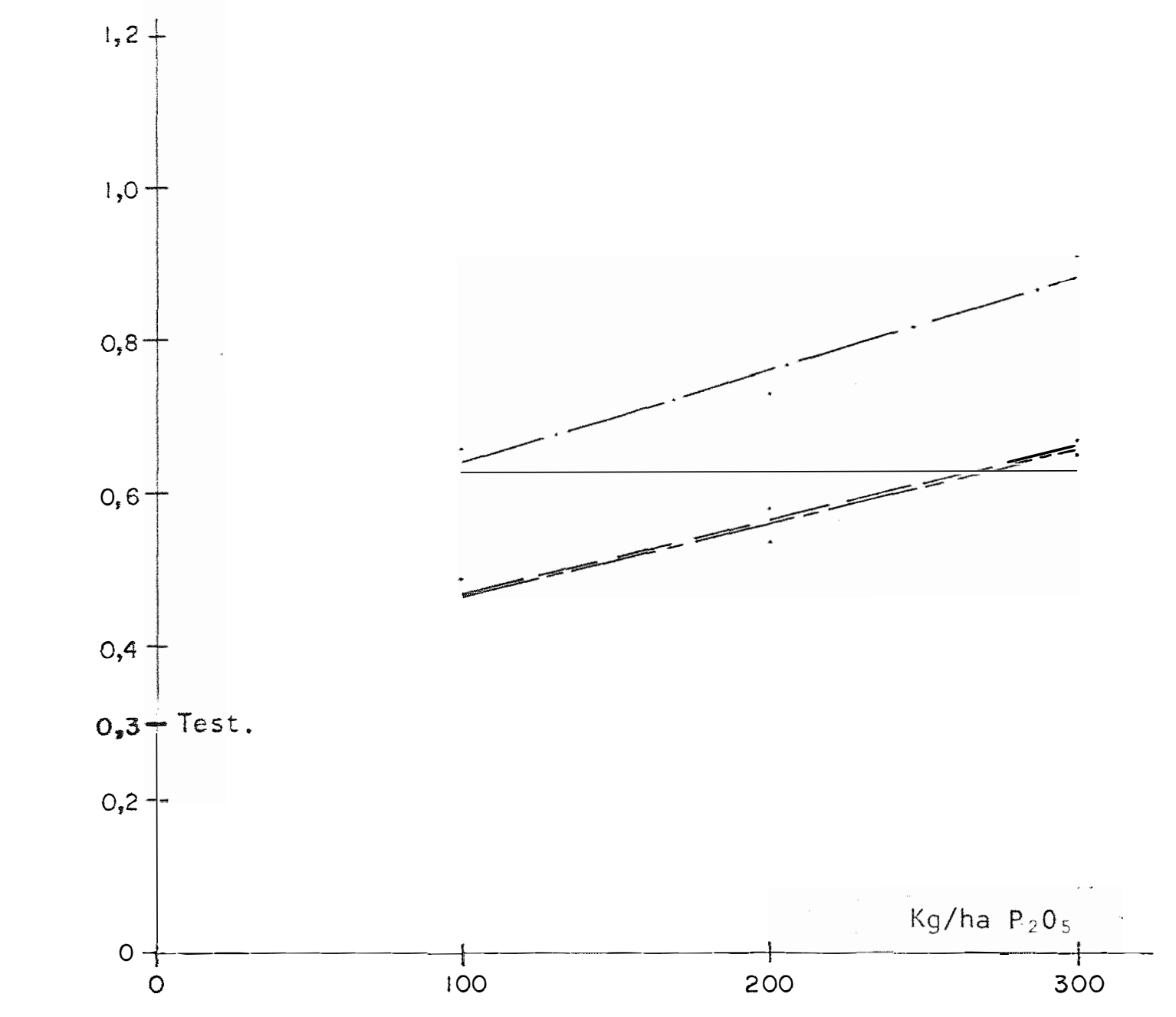

\begin{tabular}{lll}
- FAPS $(1-2 \mathrm{~mm})$ & $Y=0,627$ & \\
\hline- FAPS $(2-4 \mathrm{~mm})$ & $Y=0,380 \div 0,0009 x$ & $r^{2}=0,94 * *$ \\
- Super Simples & $Y=0,516 \div 0,0012 x$ & $r^{2}=0,95 * *$ \\
- - Fosfato Araxá & $Y=0,382+0,0009 x$ & $r^{2}=0,99 * *$
\end{tabular}

Figura 5. Efeito de doses de $\mathrm{P}_{2} \mathrm{O}_{5}$, na concentração de cálcio da parte aérea. 

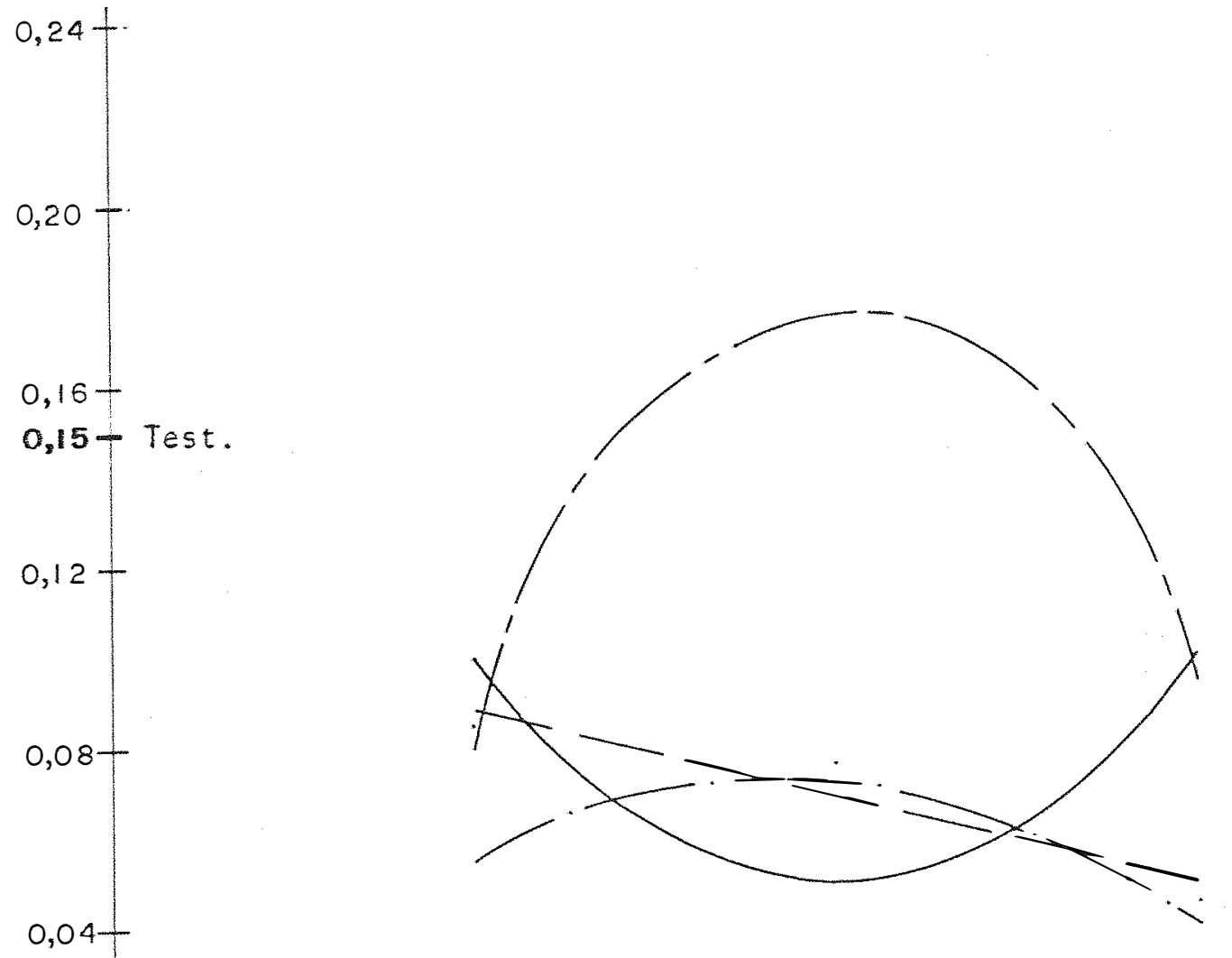

$\begin{array}{lll}- \text { FAPS }(1-2 \mathrm{~mm}) & Y=0,235-0,0018 X+0,0000045 X^{2} & R^{2}=1,05 * \% \\ - \text { FAPS }(2-4 \mathrm{~mm}) & Y=0,109-0,0002 X & r^{2}=0,88 * * \\ - \text { Super Simples } & Y=-0,0125+0,00092 X-0,0000025 X^{2} \quad R^{2}=1,00 \% * \\ - \text { Fosfato Araxá } & Y=-0,190 \div 0,0035 X-0,0000087 X^{2} \quad R^{2}=1,00 \% *\end{array}$

Figura 6. Efeito de doses de $\dot{P}_{2} \mathrm{O}_{5}$, na concentração de Enxofre da parte aérea. 
Por outro lado a baixa concentração de $P$ encontrada na parte aérea $(0,05$ a $0,097 \%)$ está de acordo com outros trabalhos que de monstram que o capim Gamba apresenta menores concentrações de P na par te aérea em relação à outras gramíneas forrageiras (HAGGAR, 1970;ORELLA $N A, 1981)$. Já as concentrações de Ca $(0,470$ a $0,907 \%)$ e S(0,040 a $0,1750 \%$ ) estão um pouco elevadas para Ca e normais para $S$, quando compa radas com os dados obtidos por ORELLANA (1981).

Evidentemente que muito mais importante para verificação da eficiência das fontes e doses de fósforo utilizadas são as quantidades dos nutrientes absorvidas pelas plantas. Assim, quando são utilizados esses parâmetros (Tabelas 31, 32 e 33 e Figuras 7,8 e 9) nota-se um comportamento dos tratamentos semelhante ao observado com rela ção a produção de matéria seca, ou seja, nos tratamentos onde a produção foi maior, ocorreu maior absorção de $\mathrm{P}$ e Ca, fato esse também obser vado por LIMA (1981), exceção feita ao caso do superfosfato simples, em que o aumento na absorção, não foi acompanhado por um aumento na pro dução de matéria seca. (Figuras 1 e 7).

Para melhor visualização desses efeitos foram obtidos os coeficientes de correlação simples e as equações de regressão calculadas para quantidades absorvidas de $\mathrm{P}$, Ca e $\mathrm{S}$ em relação à produção de matéria seca (Tabela 34 ). 


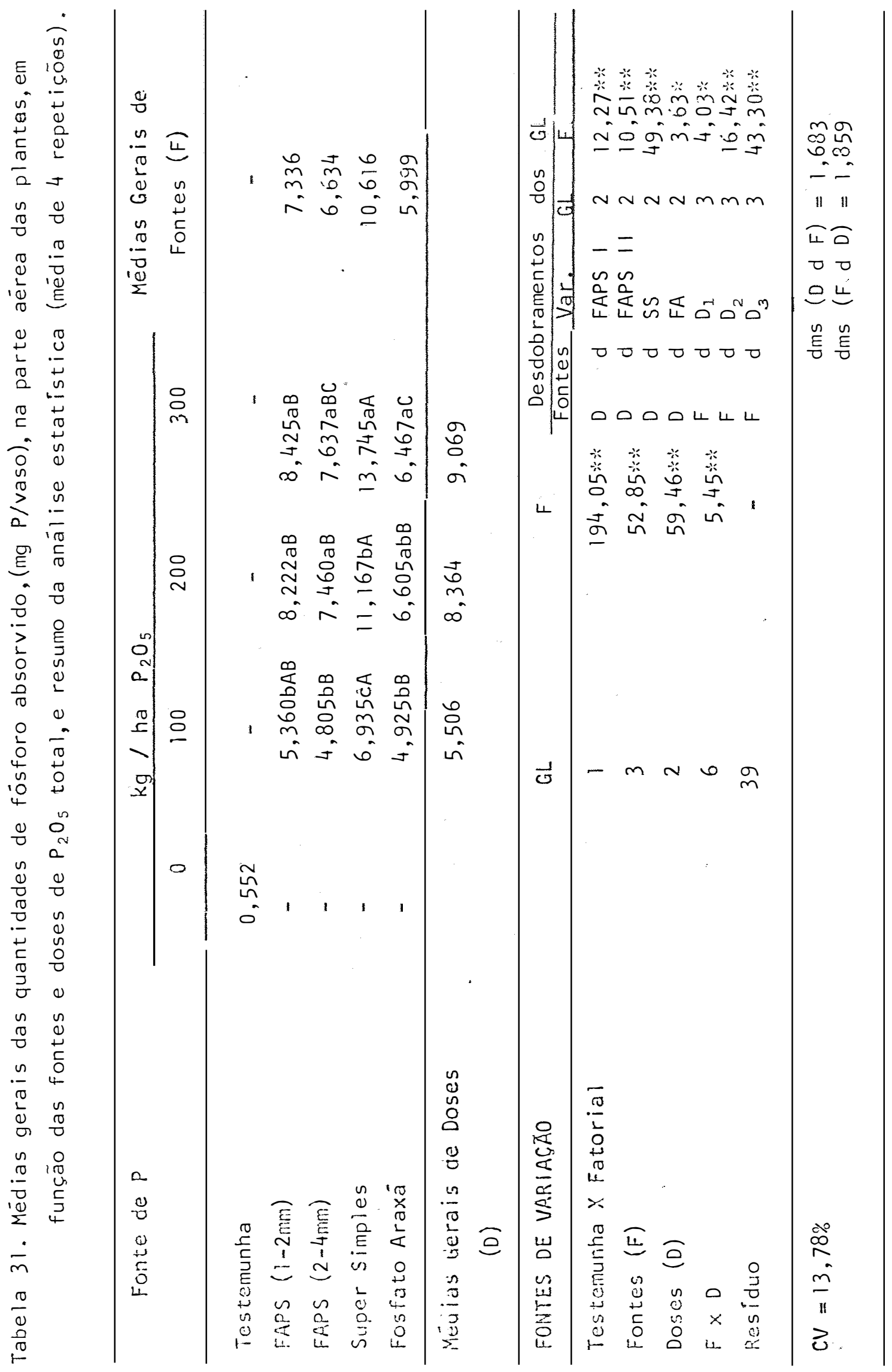




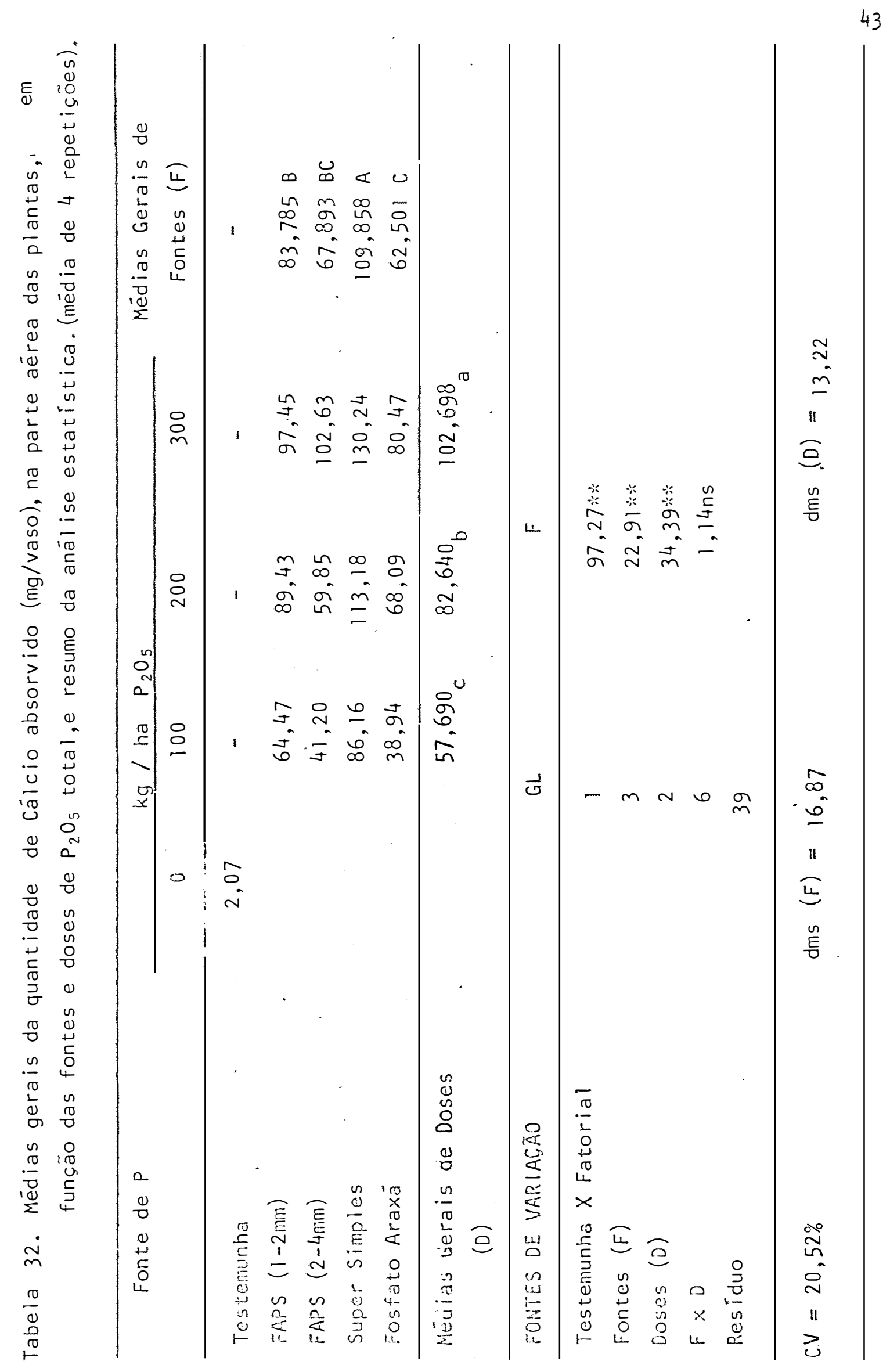




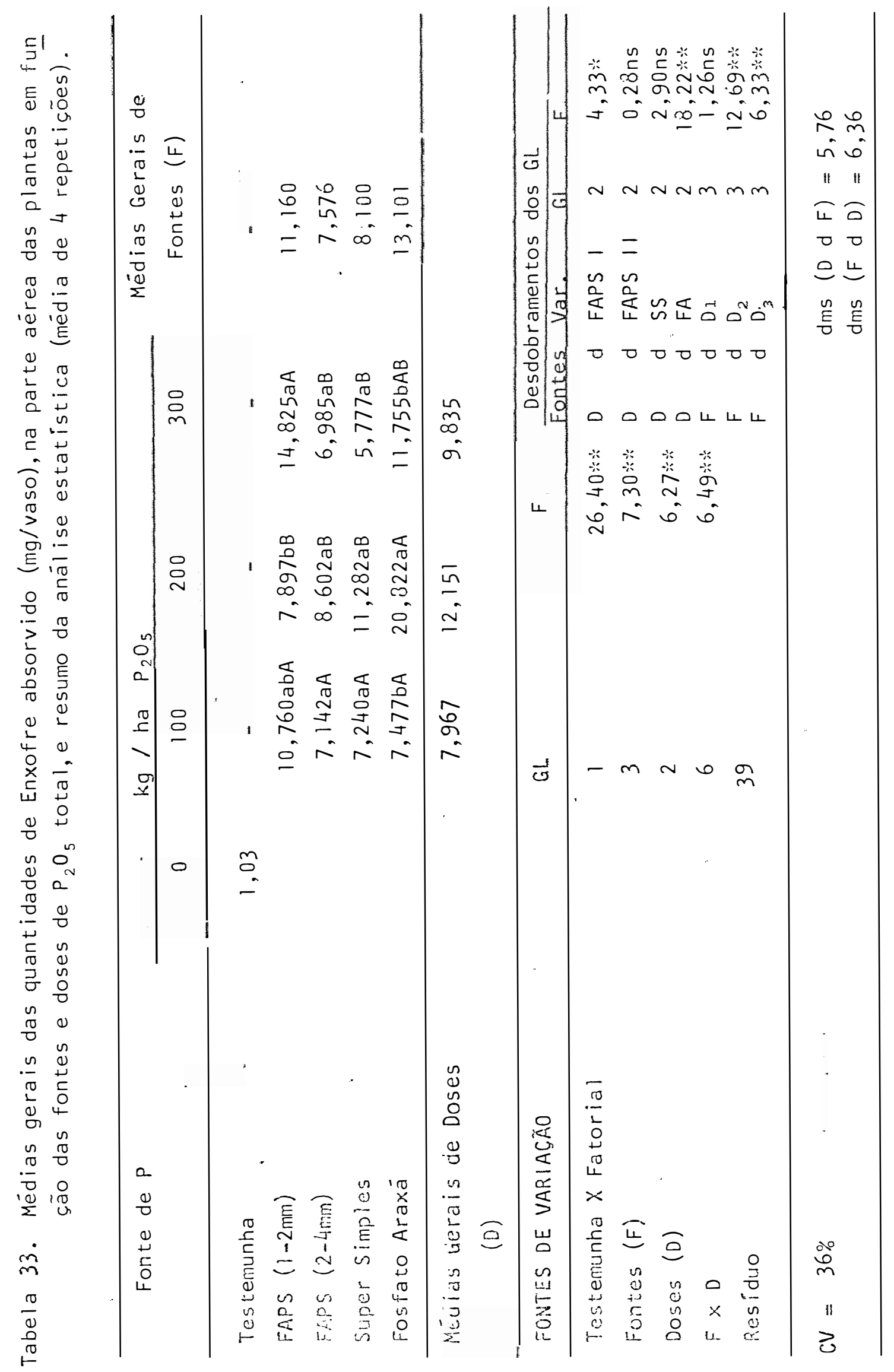




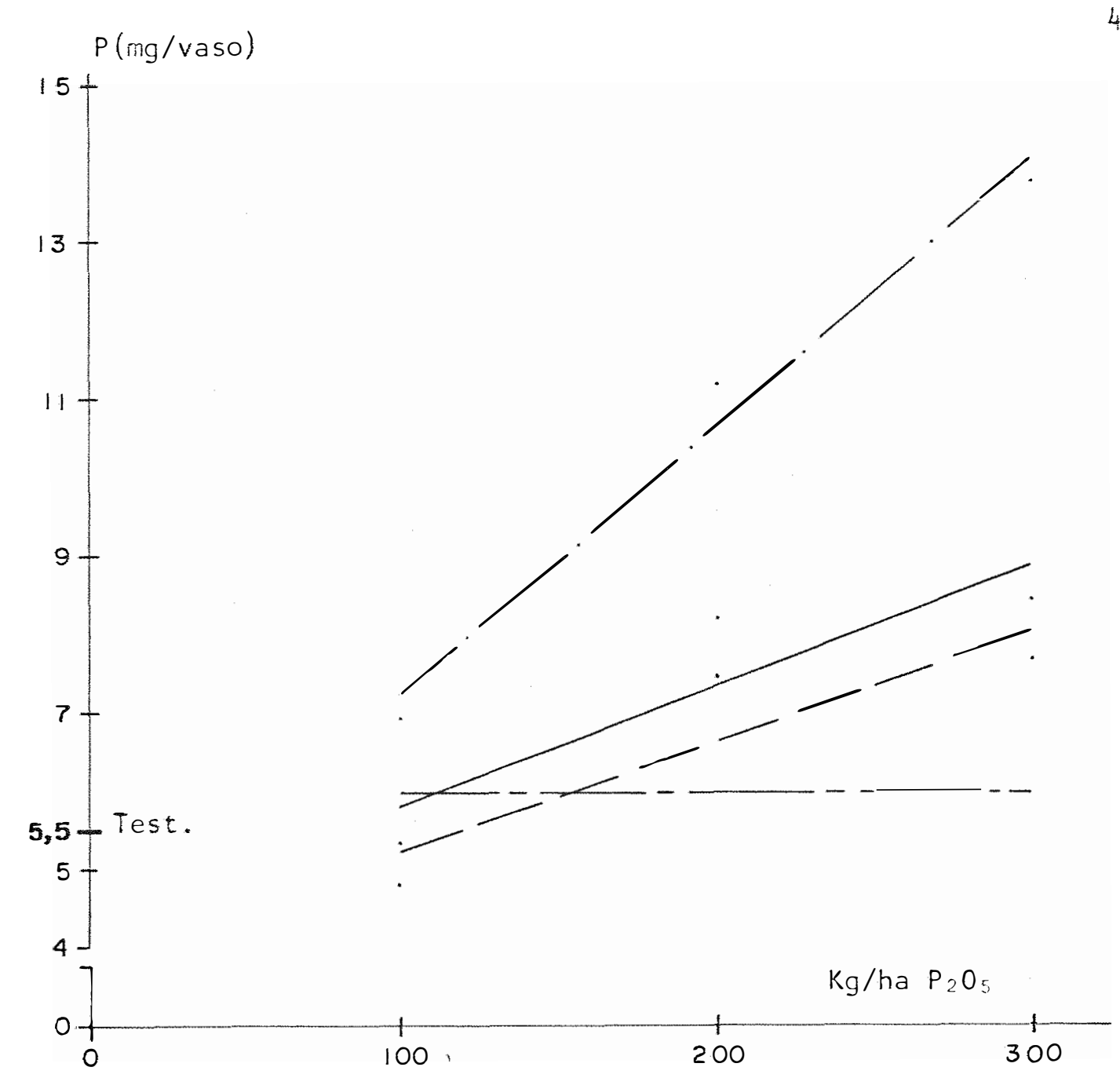

\begin{tabular}{lll} 
FAPS $(1-2 \mathrm{~mm})$ & $Y=4,270+0,0153 x$ & $r^{2}=0,80 * *$ \\
\hline FAPS $(2-4 \mathrm{~mm})$ & $Y=3,801+0,0141 x$ & $r^{2}=0,80 * *$ \\
- Super Simples & $Y=3,805+0,034 x$ & $r^{2}=0,98 * *$ \\
\hline - Fosfato Araxá & $Y=5,99$ &
\end{tabular}

Figura 7. Efeito de doses de $\mathrm{P}_{2} \mathrm{O}_{5}$, na quantidade de Fösforo extraída pela parte aërea. 


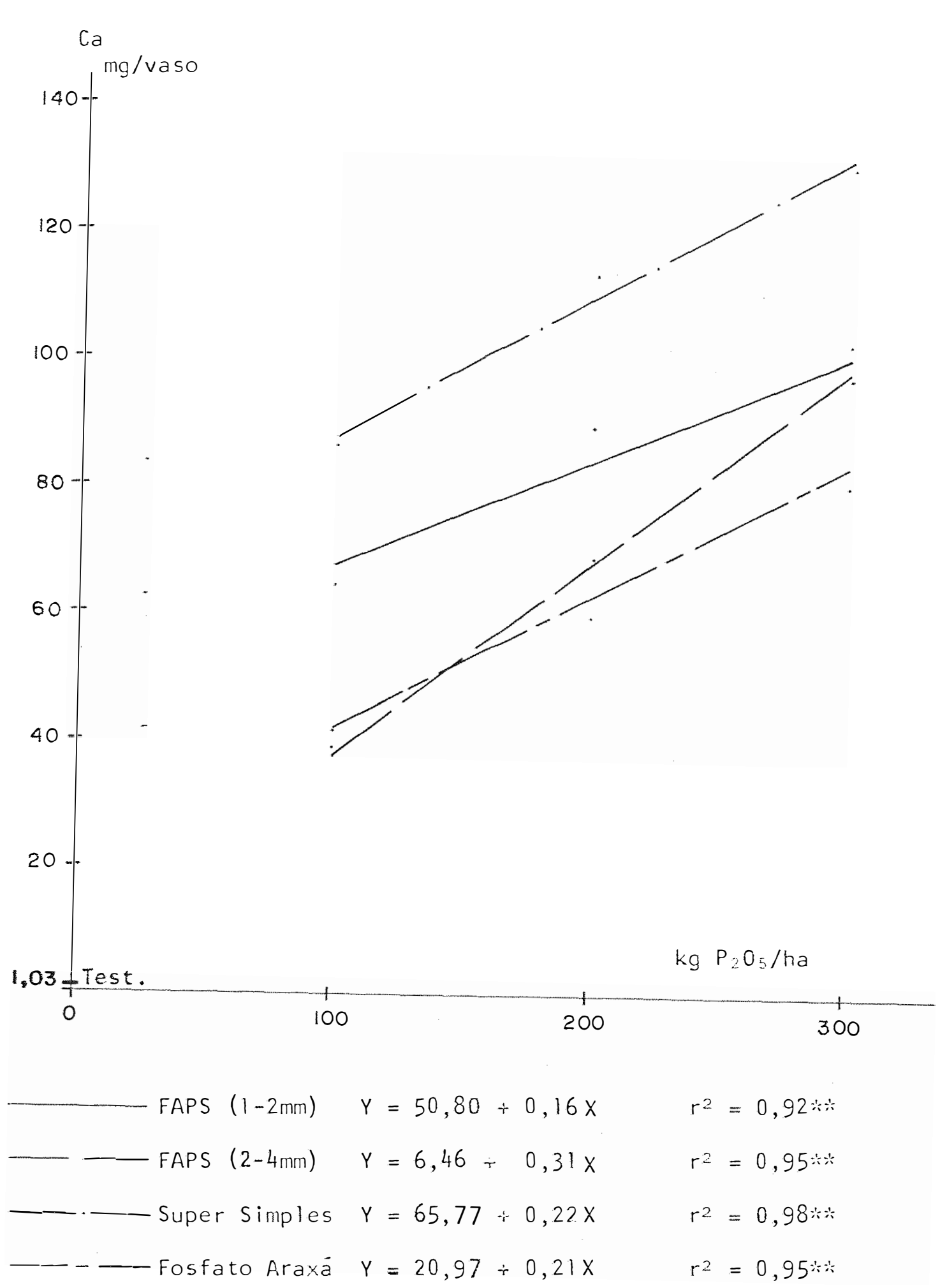

Figura 8. Efeito de doses de $\mathrm{P}_{2} \mathrm{O}_{5}$, na quantidade de cálcio extraída dos solos. 


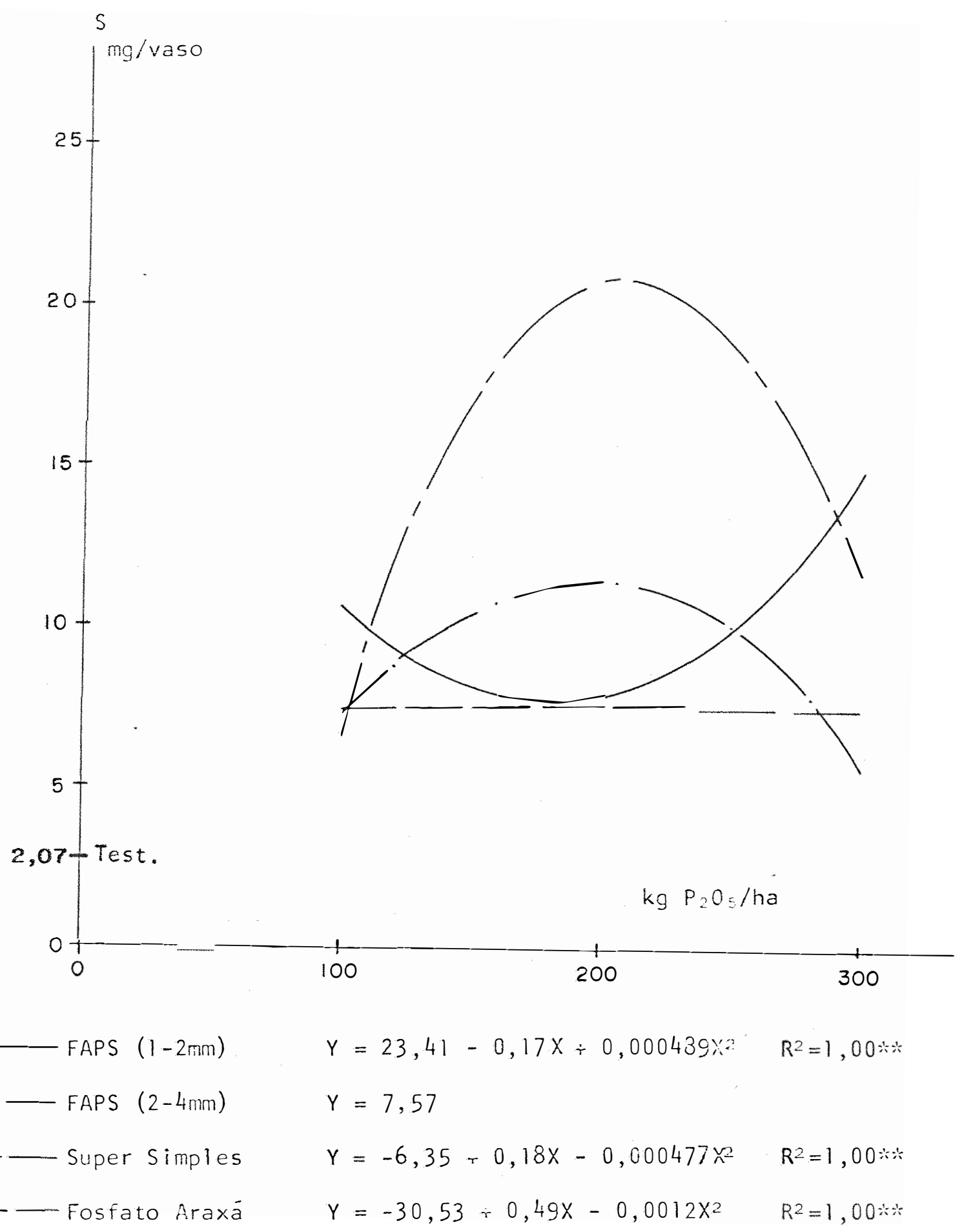

Figura 9. Efeito de doses de $\mathrm{P}_{2} \mathrm{O}_{5}$, na quantidade de Enxofre extraída por vaso. 
Tabela 34. Coeficientes de correlação simples e equações de regressão, calculadas para as quantidades absorvidas de $\mathrm{P}$, Ca e $\mathrm{S}$ em relação à produção de matéria seca da parte aérea, envolven do todas as fontes de $P$ indistintamente.

\begin{tabular}{cll}
\hline Nutriente & $\begin{array}{l}\text { Coeficiente de } \\
\text { correlação }(r)\end{array}$ & $\begin{array}{l}\text { Equação de } \\
\text { regressão }\end{array}$ \\
\hline$P$ & $0,8211 * *$ & $Y=3,8384 \div 1,0909 X$ \\
Ca & $0,9092 * *$ & $Y=3,5721 \div 0,1069 X$ \\
$S$ & $0,4835 * *$ & $Y=8,1304+0,3716 x$ \\
\hline
\end{tabular}

$* *$ significativo a $1 \%$.

Anal isando os dados da Tabela 34 observa-se que ocorreu uma correlação positiva e significativa na seguinte ordem decrescente de influência, $\mathrm{Ca}>\mathrm{P}>\mathrm{S}$.

Evidentemente que os valores dos coeficientes de correlação simples entre as variáveis em questão estão sujeitos a efeitos de outras, assim sendo, procurando analisar de maneira mais especifica os efeitos do P, Ca e S absorvidos na produção, el iminando-se ou fixando-se os efeitos de outras variáveis, obteve-se inicialmente a equação de regressão múltipla com o respectivo teste $t$ para posterior obtenção das correlações parciais, conforme STEEL e TORRIE (1960), estando os re sultados calculados apresentados na Tabela 35. 
Tabela 35. Teste t para coeficientes da regressão e correlações parciais obtidas entre produção de matéria seca $(y) \operatorname{com} P\left(x_{1}\right)$, $C a\left(x_{2}\right)$ e $S\left(x_{3}\right)$ absorvidos.

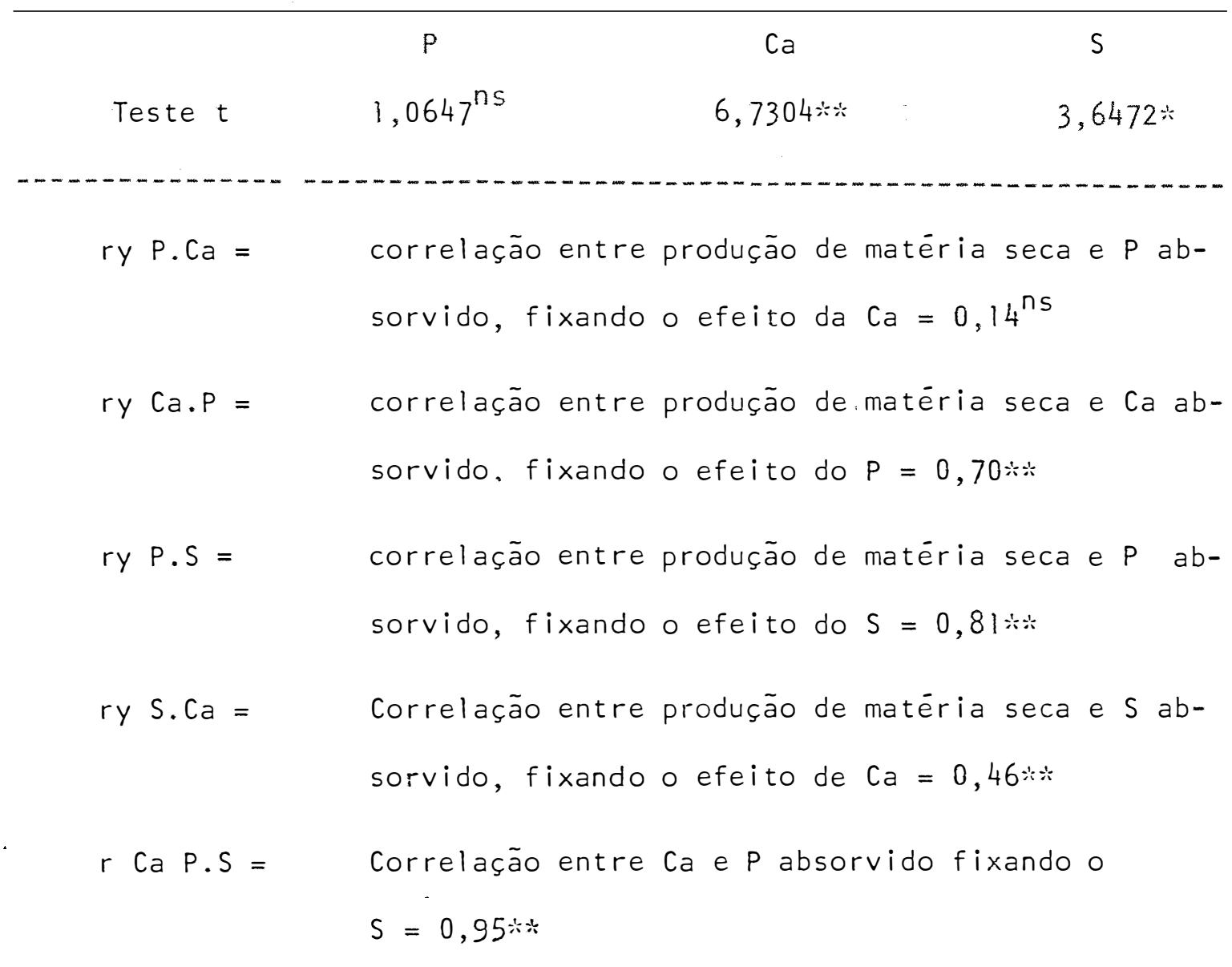

$n s=$ não significativo

* e ** significativos respectivamente ao nivel de 5 e $1 \%$ de probabilidade.

Anal isando-se os dados da Tabela 35 verifica-se inicialmente pelo teste $t$ um efeito significativo apenas do Ca e $S$ absor vidos sobre a produção de matéria seca, enquanto que $O P$ absorvido não se correlacionou com a produção de matéria seca, confirmando os dados de efeito de doses de $\mathrm{P}_{2} \mathrm{O}_{5}$, na produção de matéria seca (Figura 1) com os da quantidade de $P$ extraida. (Figura 7). 
Essa não significância para P,acentua-se ainda mais ąuan do obtemos a correlação parcial ( $r y$ P.Ca $=0,14^{\text {ns }}$ ), sendo que entretanto o efeito do $P$ foi significativo quando é fixado o efeito do S(ryP.S= $=0,81 \% *)$. Por outro lado observa-se uma correlação altamente significa tiva entre o Ca e P absorvidos, fixando o $S(r$ CaP.S $=0,95 * *)$ indicando ser impossivel separar os efeitos de $P$ e Ca das fontes utilizadas, is to é, as fontes utilizadas podem estar sendo igualmente satisfatōrias no fornecimento de $P$, mas não, no de Ca.

Com relação ao efeito do S na produção da matéria seca fixando o efeito de Ca., observa-se que esse nutriente está influencia do na produção com um coeficiente de 0,46 .

4.3. Efeito dos Tratamentos sobre os Teores de P, Ca e S do Solo.

A planta absorve os nutrientes da solução do solo, logo pode-se deduzir que o fosfato aplicado como fertilizante terá que dis solver no solo, ou seja, o P-fertilizante por exemplo, deverá se transformar em P-solução do solo. Desse modo, conforme citado em FERNANDES (1981), a eficiencia de um fosfato pode ser medida pela solubilidade e pela sua capacidade de aumentar o P solúvel na solução do solo, sendo o mesmo avaliado em laboratório, através da análise do solo.

Para avaliação do $P$ solúvel utilizaram-se dos extratores $\mathrm{H}_{2} \mathrm{SO}_{4}$ 0,05N ( $\left./ \mathrm{AC}\right)$, de uso atual em todo Estado de São Paulo e o $\mathrm{NH}_{4} \mathrm{~F} \mathrm{O,O3N}+\mathrm{HCl} 0,025 \mathrm{~N}($ Bray-1) que segundo RAIJ (1978), SFREDO et alii (1979), GOEDERT e LOBATO (1980) parecem refletir melhor a situação de disponibilidade de fósforo.

Os dados de teores de P no solo, após a colheita do ca pim, são apresentados nas Tabelas 15 e 16, enquanto que nas Tabelas 36 


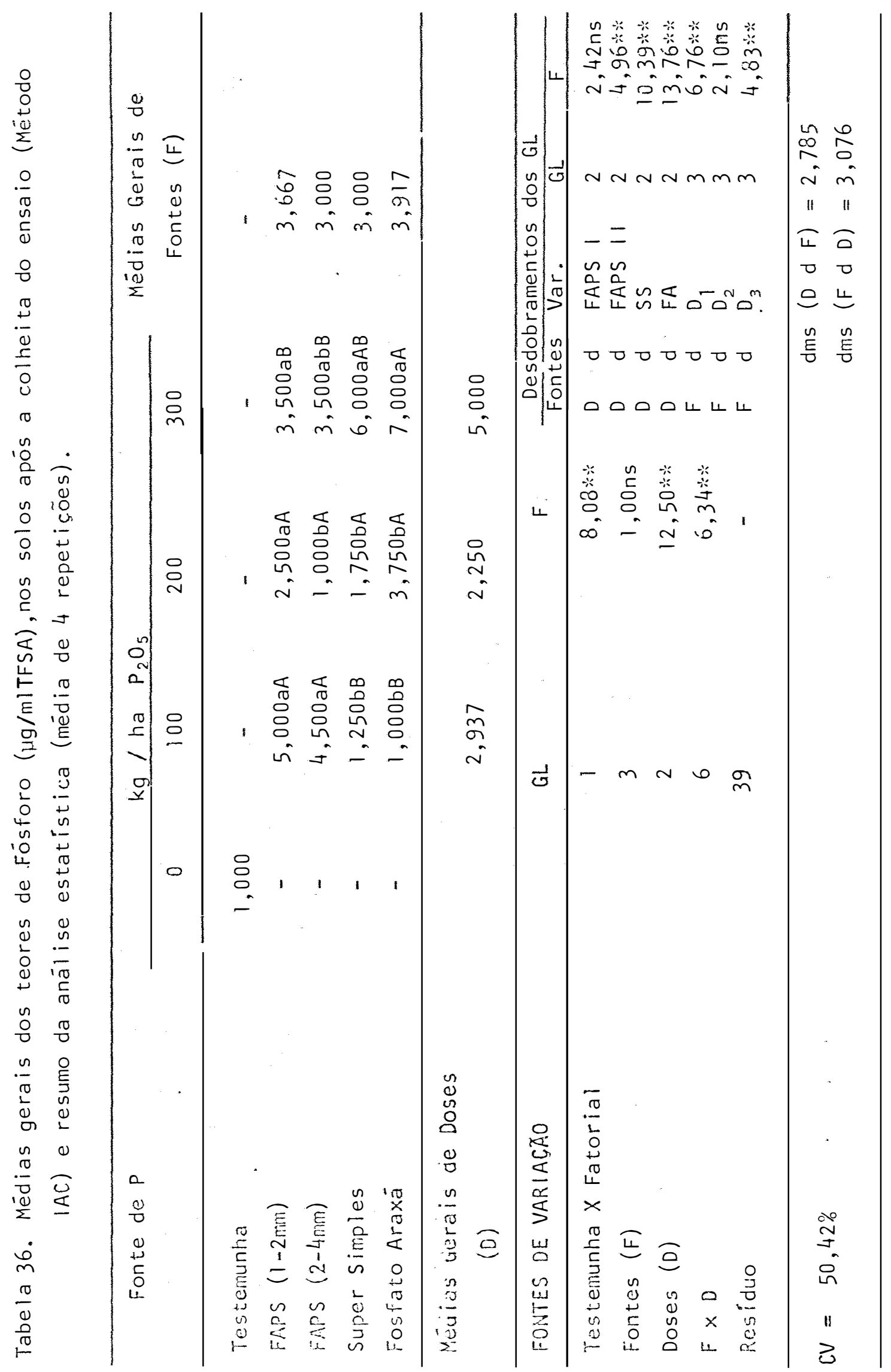




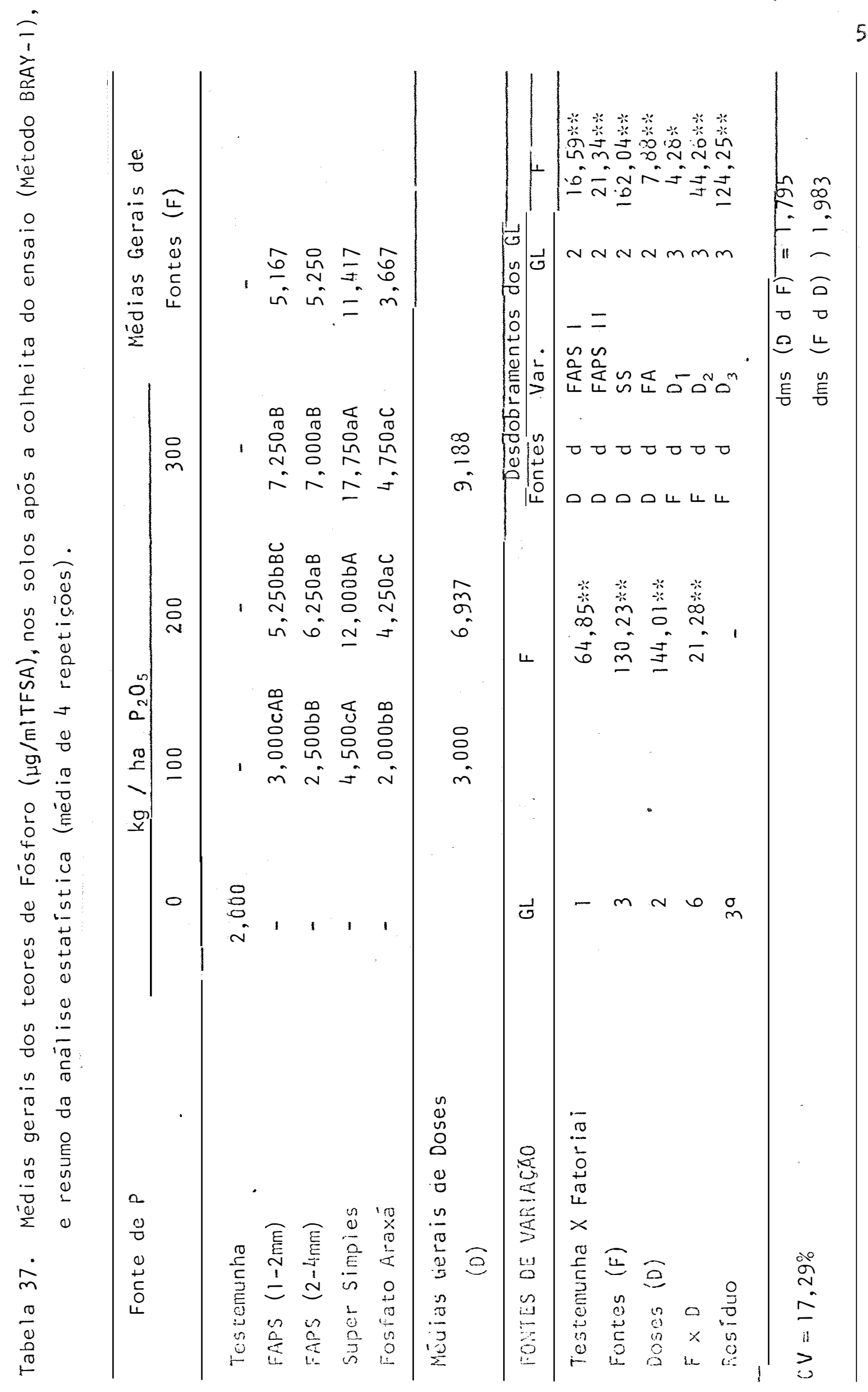


e 37, aparecem as médias desses valores com a respectiva anälise de variância.

$$
\text { Analisando-se os teores de P do solo, solüvel em }
$$
$\mathrm{H}_{2} \mathrm{SO}_{4} 0,05 \mathrm{~N}$, verifica-se não existir coerência nos dados obtidos (Figura 10), enquanto que os teores de $\mathrm{P}$ solüvel pelo método de Bray-l obser va-se um aumento linear do $\mathrm{P}$ do solo com o aumento de doses em todas as fontes utilizadas, bem como um efeito significativo de fontes obedecendo a seguinte ordem decrescente: Super simples > FAPS $(2-4 \mathrm{~mm})=$

= FAPS (1-2mm:) > Fosfato Araxá. (Figura 11). Esse comportamento diferen te dos extratores utilizados estā de acordo com RAlJ (1978) que conclui que possivelmente o uso de extratores ácidos nas condições brasileiras se torne restrito no futuro, tendo o autor apresentado para essa suposi ção dois argumentos: 19) o crescente uso de fosfato natural impossibili taria o emprego de extratores que dissolvem a apatita, tendo aqui acrescentado que provavelmente o extrator Bray-l poderia ser exceção à regra; 29) em solos adubados pode-se esperar que a reserva de $\mathrm{P}$ lábil se encontre em grande parte na forma de fosfato de alumínio, principalmente nos solos äcidos e, neste caso, seriam preferiveis extratores que tenham maior ação em dissolver essa fração, como é o caso dos métodos Bray-1, da resina e mesmo o método de 0lsen. Verifica-se também que os aumentos nos teores de $P$ do solo pelo método Bray-l (Figura 11) correspondem aos aumentos de produção de matéria seca (Figuras de 1 a 3 ); com excessão ao superfosfato simples.

$$
\text { Com relação aos teores de } \mathrm{Ca}(\mathrm{KCl} \quad \mathrm{I}, \mathrm{ON}) \text { e } \mathrm{S}_{-} \mathrm{SO}_{4}
$$

( $\mathrm{NH}_{4}$ OACO, 5N) revelados pela anälise de solo (Tabelas 17 e 18), com aná Iise de variância nas Tabelas 38 e 39 , observa-se um comportamento seme Ihante ao encontrodo para o caso do fósforo. (Figuras 12 e 13), revelan 


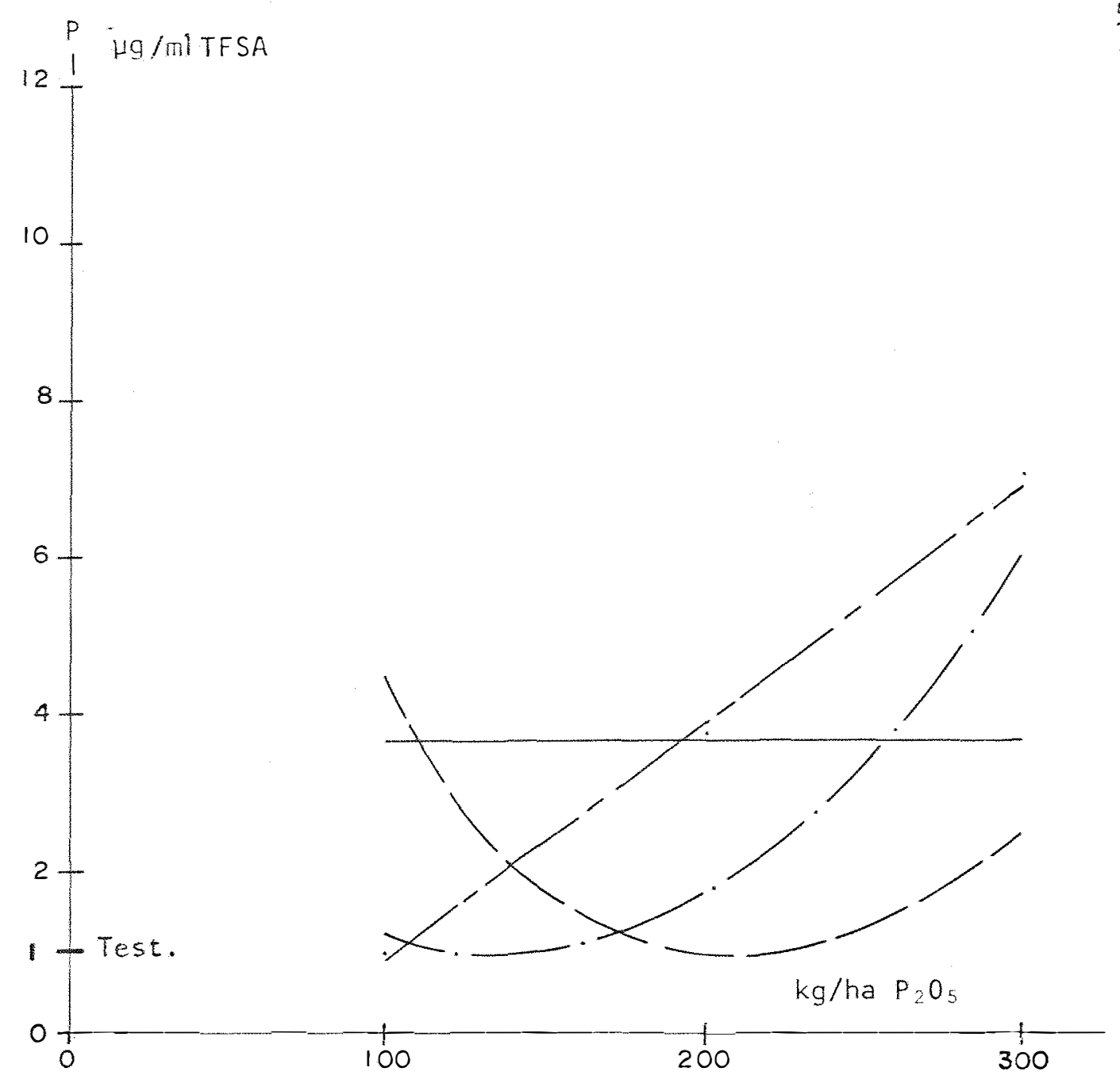

$\begin{array}{lll}- \text { FAPS }(1-2 \mathrm{~mm}) & Y=3,666 & \\ \text { FAPS }(2-4 \mathrm{~mm}) & Y=14,000-0,125 X+0,0003 X^{2} & R^{2}=1,00 * * \\ - \text { Super Simples } & Y=4,500-0,0518 X+0,00018 \times 2 & R^{2}=1,00 * * \\ - \text { Fosfato Araxá } & Y=-2,083+0,030 X & r^{2}=0,99 * *\end{array}$

Figura 10. Efeito de doses de $\mathrm{P}, \mathrm{O}$, no teor de Fósforo nos solos após a colheita (Método IAC). 


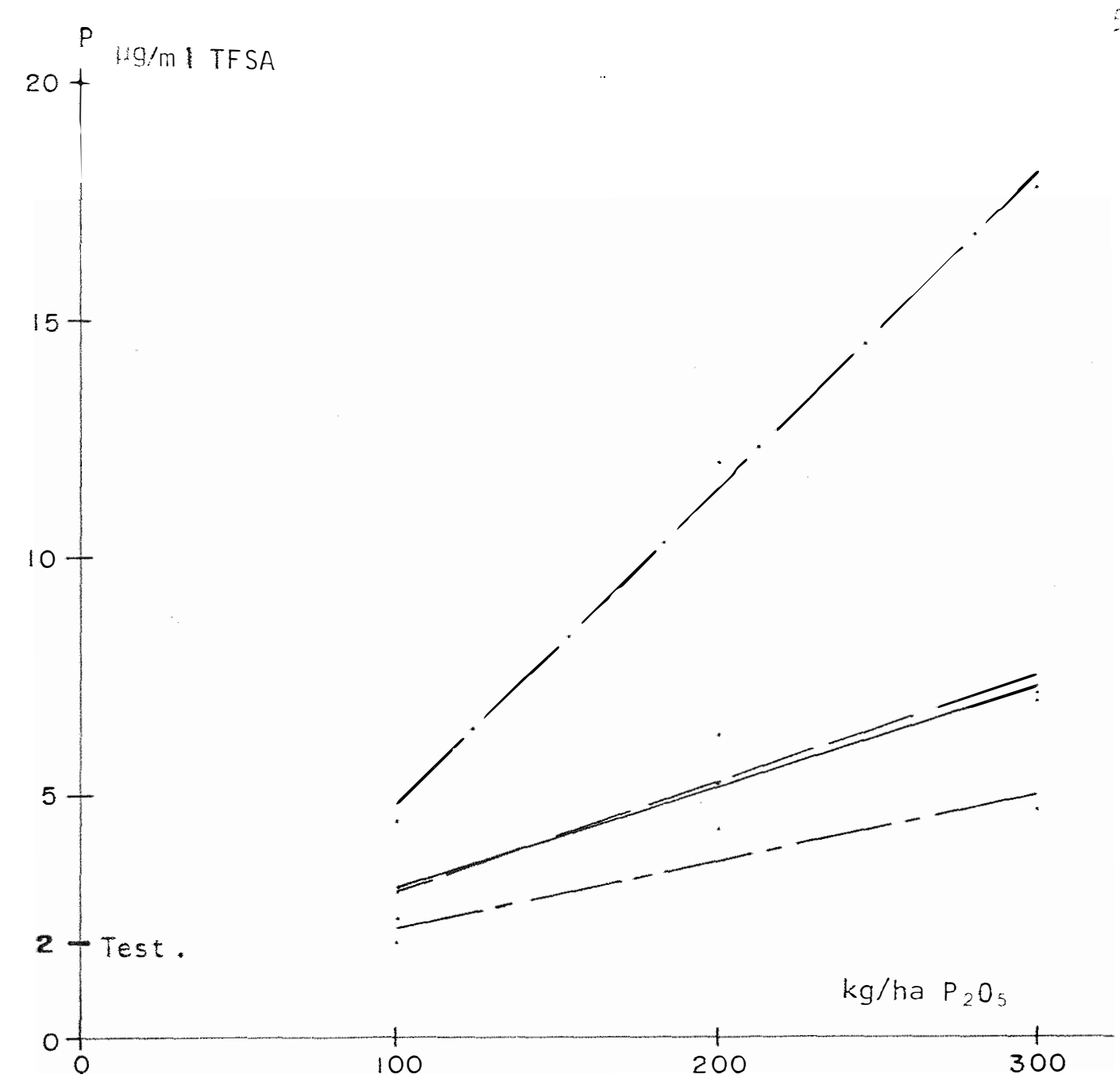

$\operatorname{FAPS}(1-2 \mathrm{~mm}) \quad Y=0,916 \div 0,00214 \mathrm{X}$

$r^{2}=0,99 * *$

FAPS $(2-4 \mathrm{~mm}) \quad Y=0,750 \div 0,0225 x$

$r^{2}=0,87 * *$

-_- Super simples $Y=-1,833+0,0662 X$

$r^{2}=0,99 * *$

Fosfato Araxá $Y=0,916 \div 0,0137 x$

$r^{2}=0,38 * *$

Figura 11. Efeito de doses de $P_{2} O_{5}$, no teor de Fósforo nos solos após a co The ita (Método BRAY-1). 


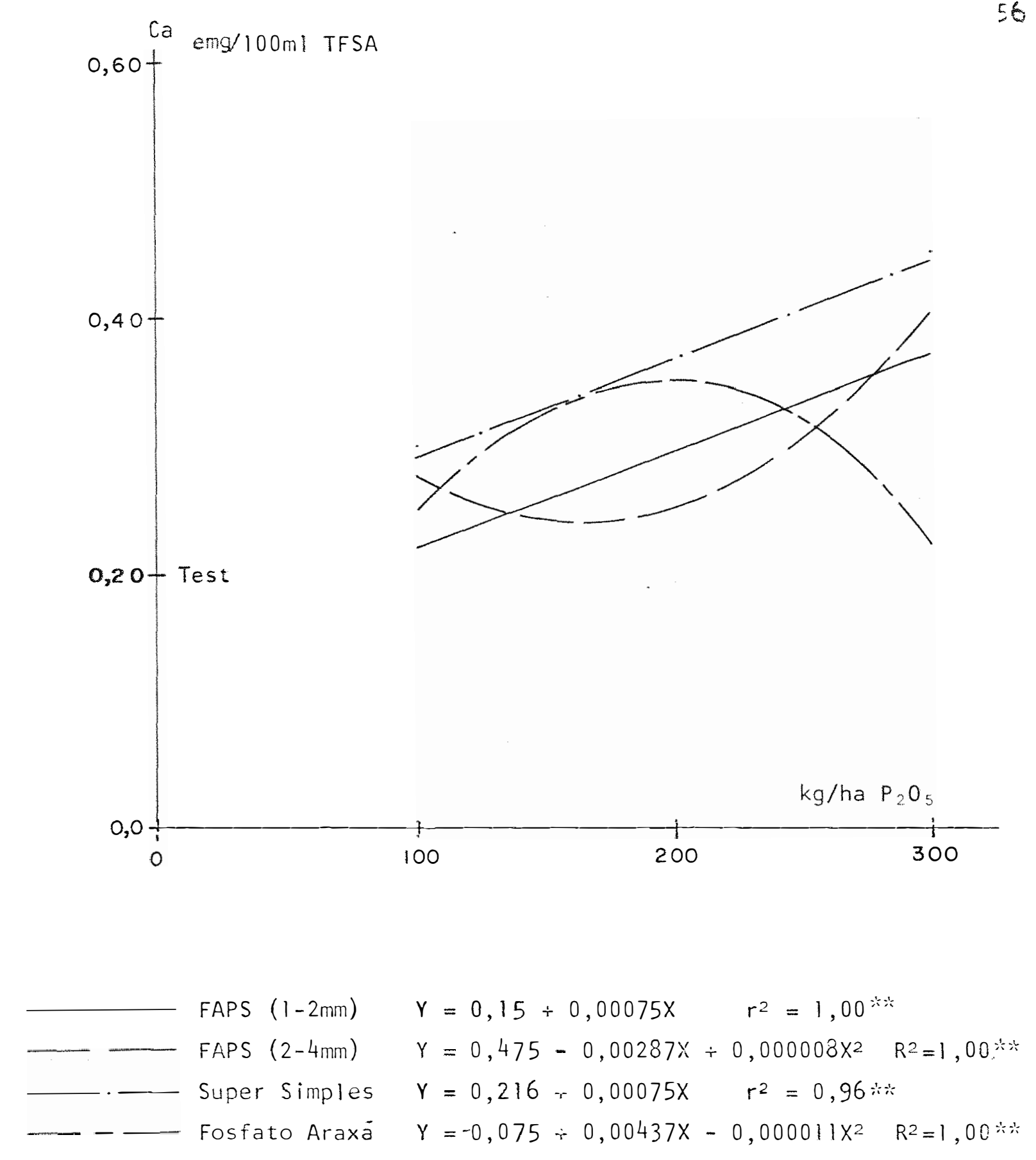

Figura 12. Efeito de doses de $\mathrm{P}_{2} \mathrm{O}_{5}$, no teor de Cálcio nos solos após a colheita. 


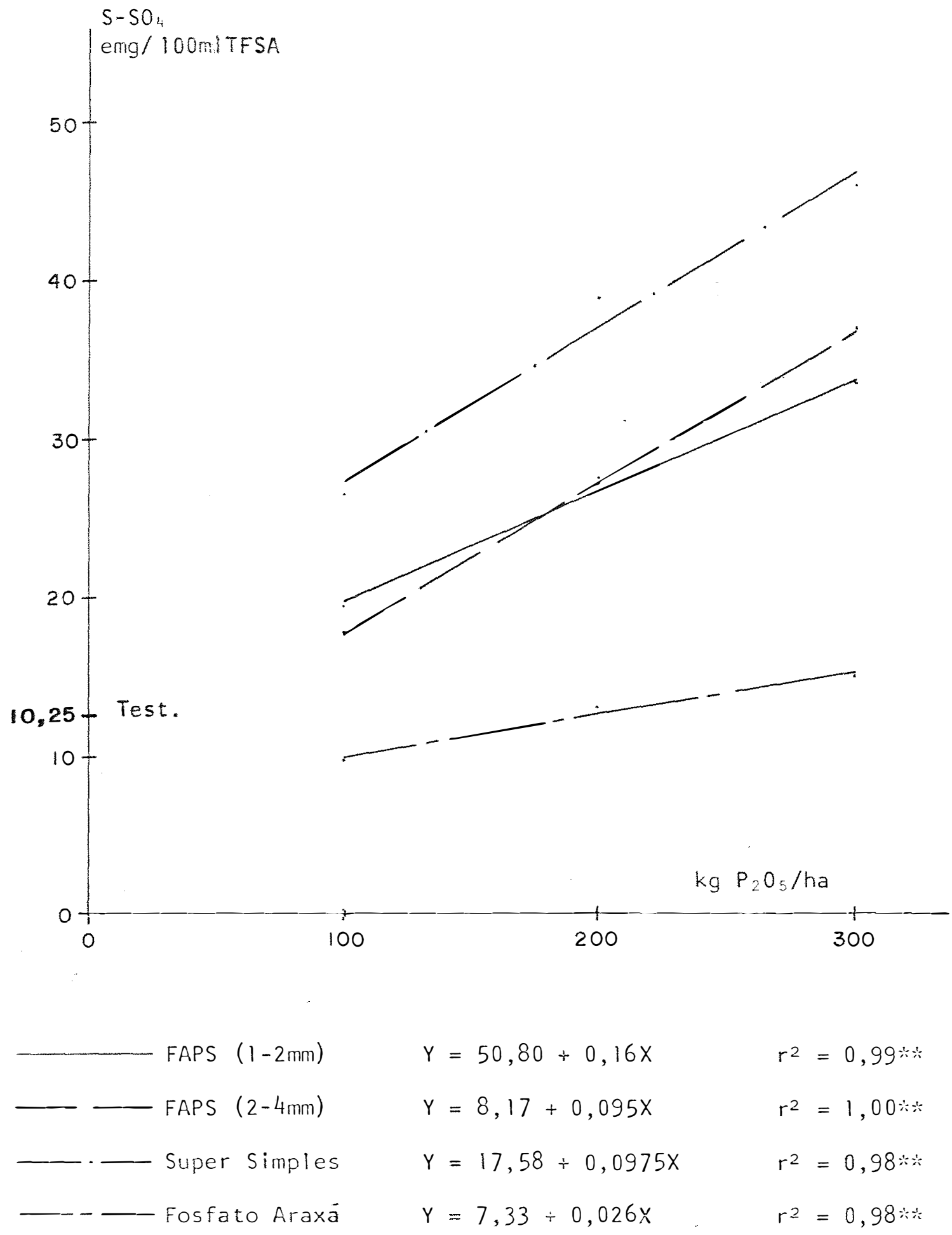

Figura 13. Efeito de doses de P:O5, no teor de Enxofre nos solos após a colheita. 


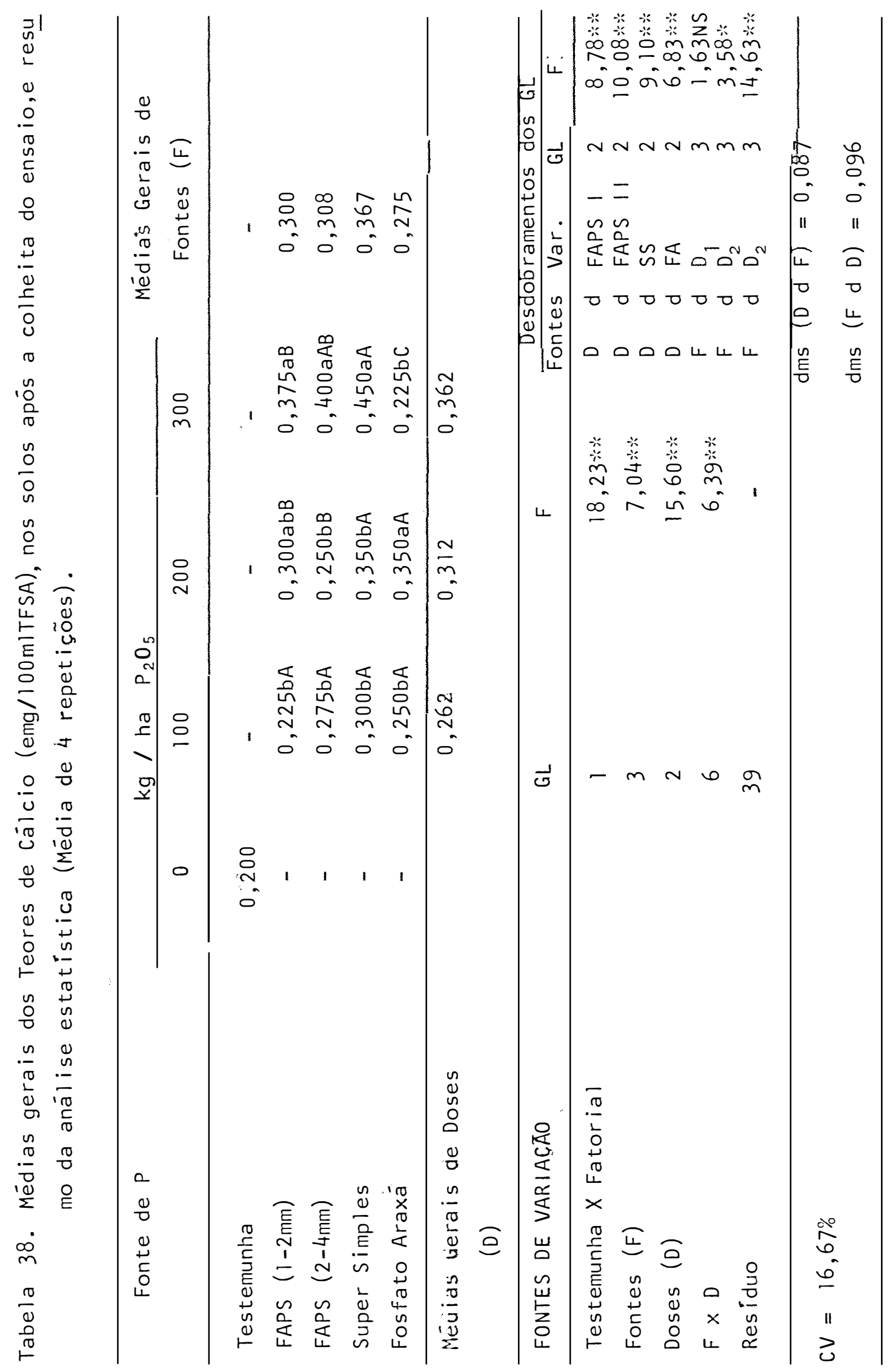




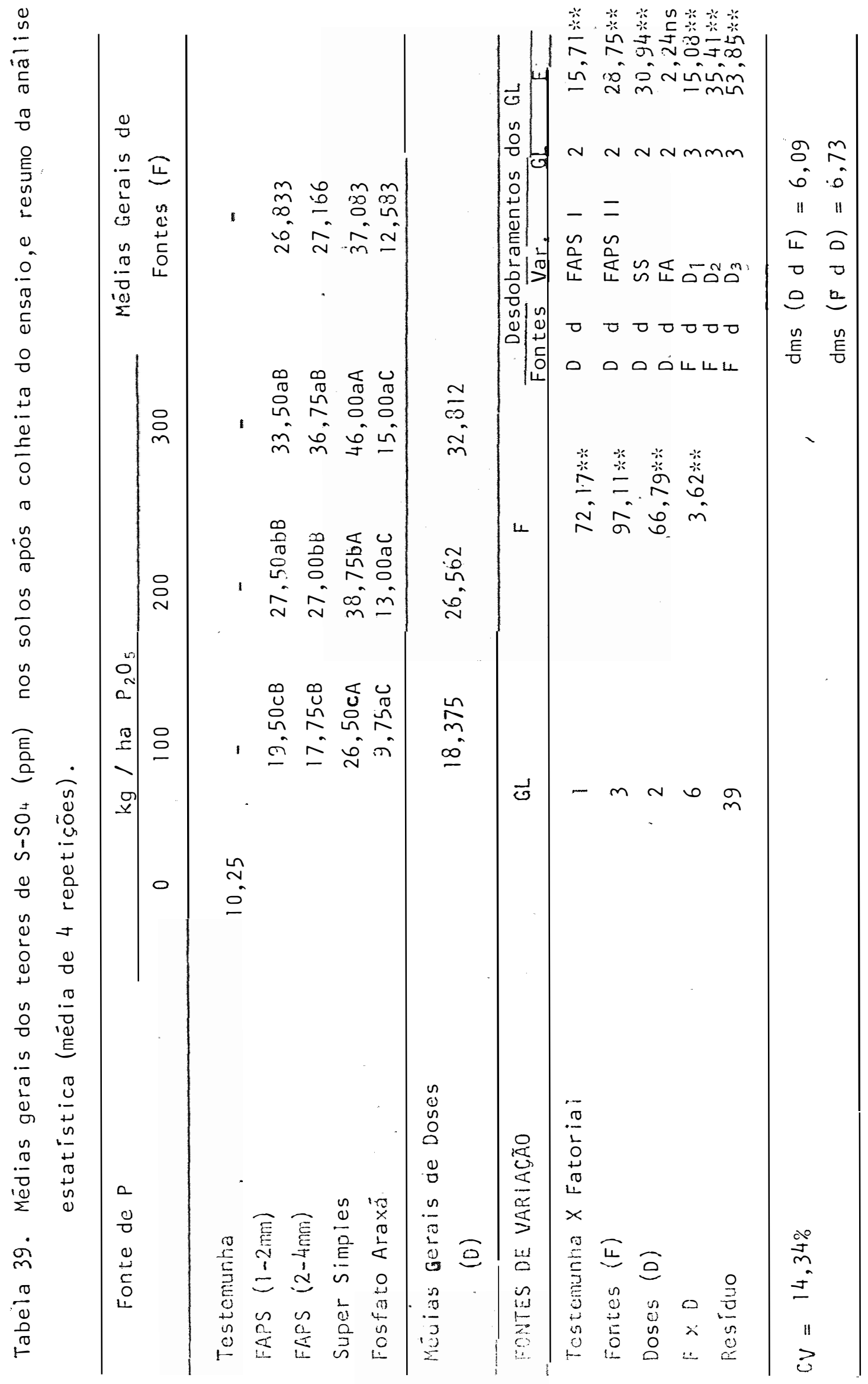


do também uma correlação significativa dos fosfatos com o conteūdo de Ca e S dos mesmos, bem como uma boa eficiência dos extratores utiliza dos.

4.4. Efeito dos Tratamentos sobre as Relações N/P, P/S e N/S da Matéria Seca.

O substrato de desenvolvimento de uma planta deve apresentar um adequado balanço iônico para os macronutrientes aniônicos $\mathrm{N}$, $P$ e $S$, refletindo assim, relações sobre os mesmos nas plantas, benéficos ou prejudiciais à produção e qualidade do produto obtido. As relações N/P, P/S e N/S da parte aérea das płantas acham-se respectivamente nas Tabelas 19, 20 e 21, enquanto que, nas de número 40, 41 e 42, são encontradas as médias com o resumo da anälise de variância corresponden te. De uma maneira geral observa-se uma diminuição da relação N/P com o aumento de doses de $\mathrm{P}_{2} \mathrm{O}_{5}$, enquanto que os valores médios dentro de cada fonte variam de 10,083 (Super Simples) a 16,167 (fosfato de Araxä). Para a relação $\mathrm{P} / \mathrm{S}$ há uma tendência de aumento com as doses de $\mathrm{P}_{2} \mathrm{O}_{5}$, enquanto que a faixa de variação dentro de fontes foi de 1,509 (super sim ples) a 0,572 (fosfato de Araxā). Já para a relação N/S a qual é a mais estudada, ocorrendo em plantas deficientes em S, teores mais altos de $\mathrm{N}$ solúvel, compostos de S solúveis, amida e um menor teor de: açücares (GILBERT; 1951), observa-se um efeito significativo de fontes e doses de $\mathrm{P}_{2} \mathrm{O}_{5}$ sobre a mesma. A faixa de variação dentro de fontes foi de 14,408 (FAPS-2-4mm) e 9,278 (fosfato de Araxā). Relação N/S em outras forrageiras citadas como adequadas tem-se de 11 a 12 para gramíneas (MC NAUGHT e CHRISTOFFELS, 1961) e menores de 11 em alfafa (PUHPHREY e 


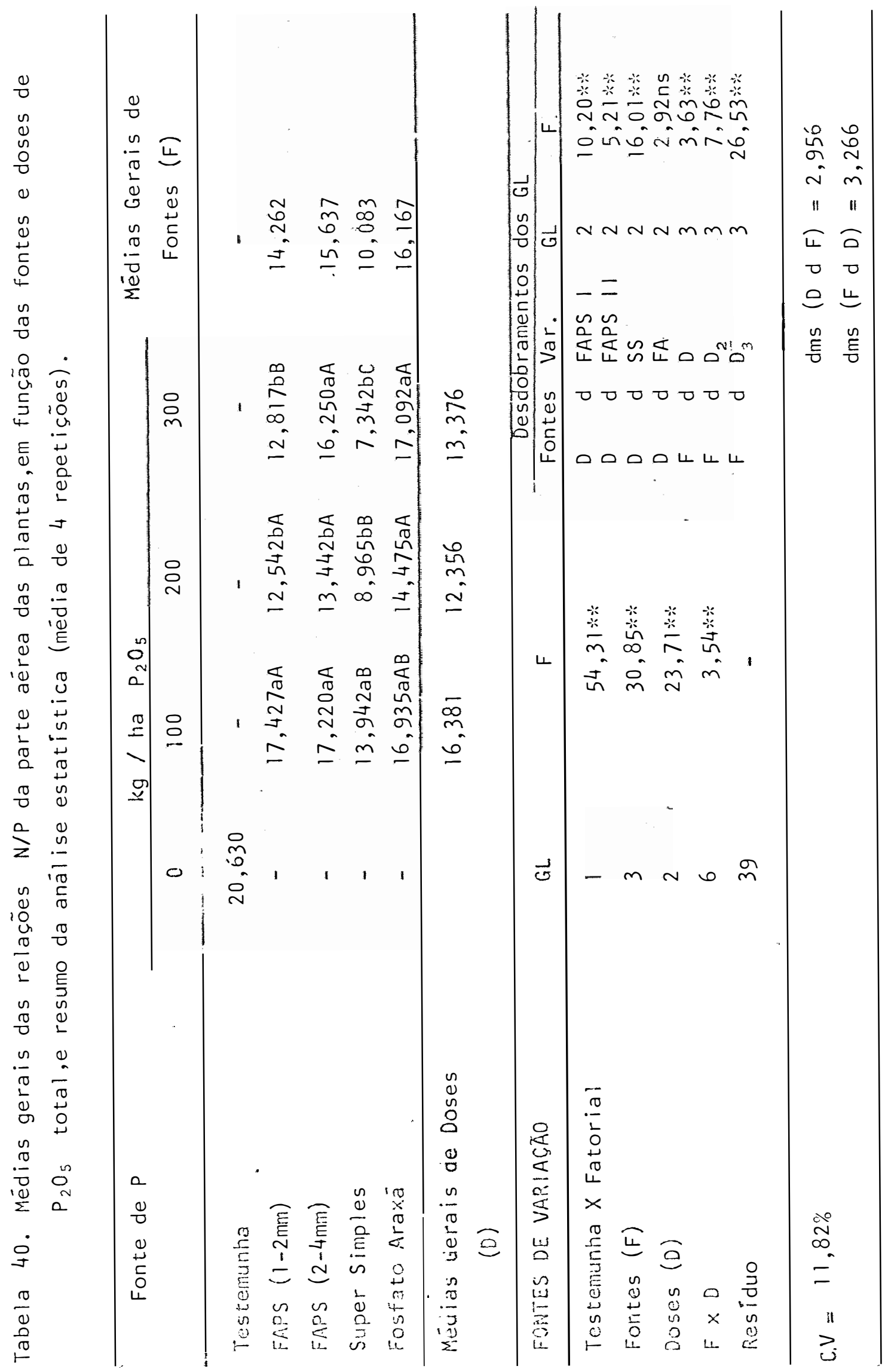




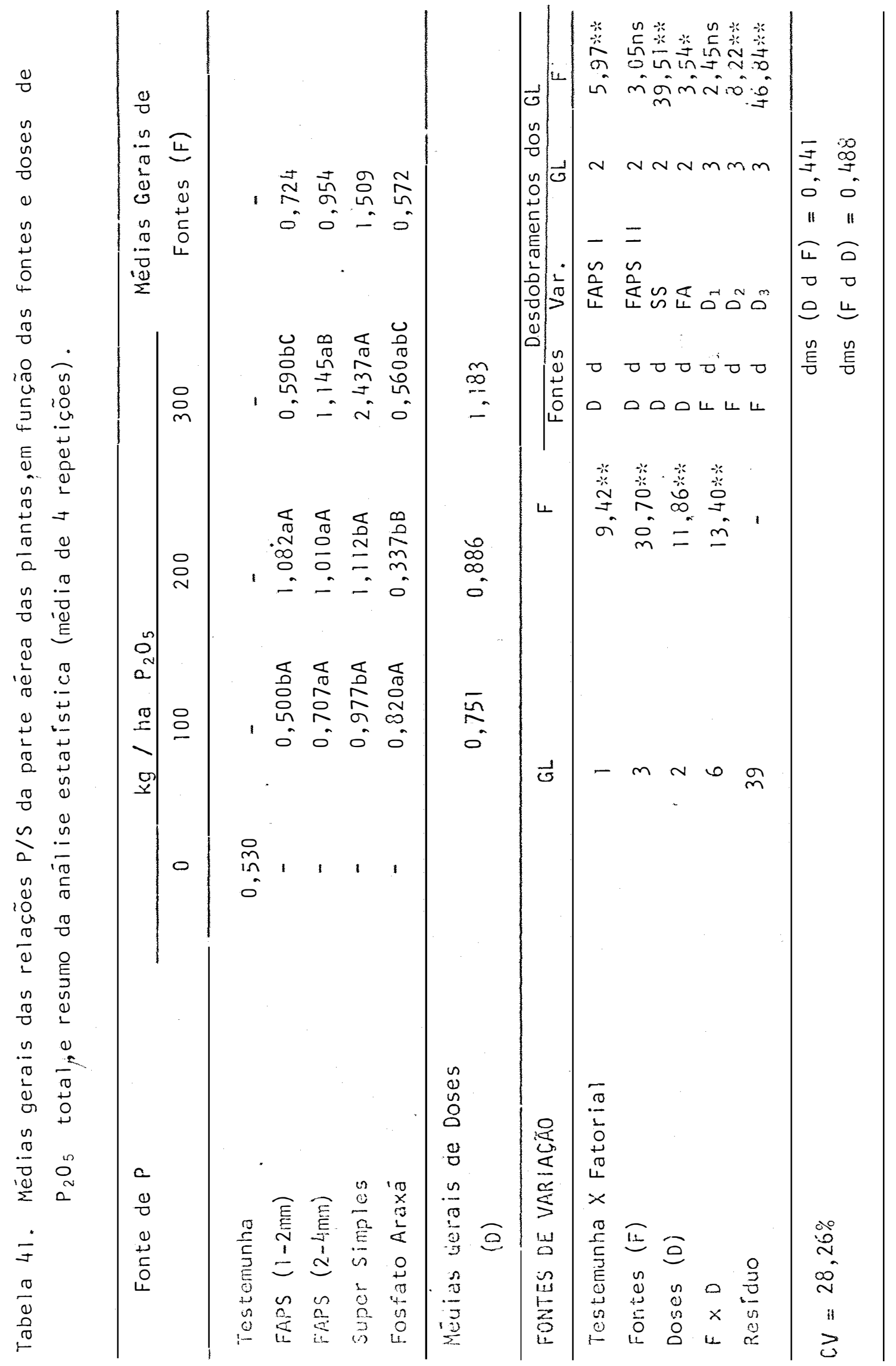




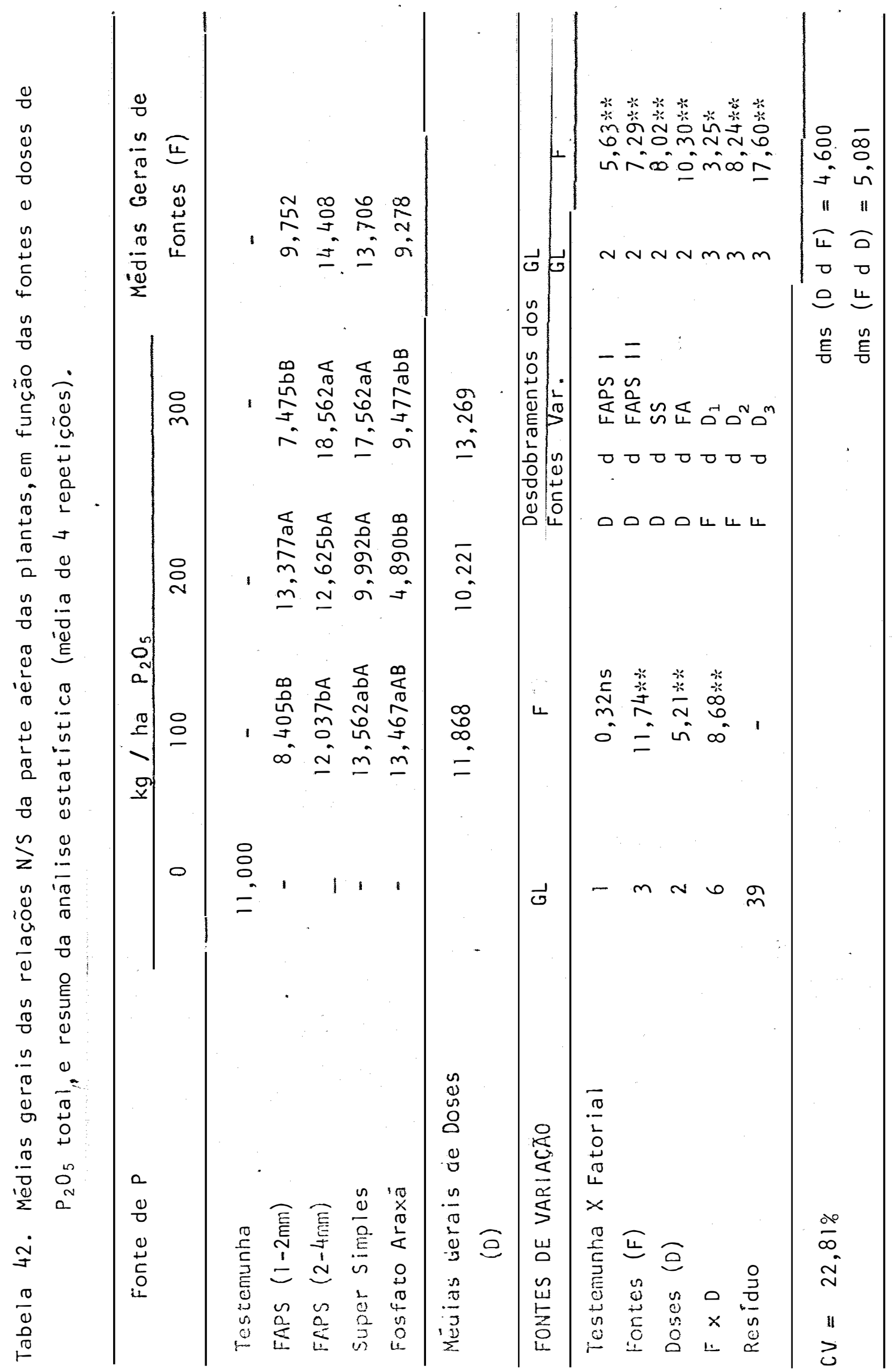


MOORE, 1965). Nas figuras de 14 a 16 são apresentados graficamente os efeitos de doses de $\mathrm{P}_{2} \mathrm{O}_{5}$ nas relações acima citadas.

4.5. Efeito dos Tratamentos sobre os Teores de Proteína e da Digestibidade da Matéria Seca.

Utilizando-se dos dados obtidos para as concentrações de Nitrogênio de parte aérea (Tabelas 22 e 23) estimaram-se os teores de proteína $(N \times 6,25)$ conforme os dados constantes nas Tabelas 43 e 44 . observa-se inicialmente uma diminuição significativa do teor de proté na na matéria seca das plantas que receberam adubação fosfatada, muito provavelmente devido a um efeito de diluição, jā que as produções de ma téria seca nessas plantas foram muito maiores. Por outro lado verifica-se também uma diminuição no teor da mesma com o aumento nas doses de $\mathrm{P}_{2} \mathrm{O}_{5}$, provavelmente devido ao efeito já acima mencionado, bem como com relação à fontes a seguinte ordem decrescente: Fosfato Araxā: > FAPS $(2-4 m m)>$ FAPS $(1-2 \mathrm{~mm})>$ Superfosfato Simples, sequência esta exatamente ao oposto observado para a produção de matéria seca, indicando mais uma vez o efeito de diluição (Figuras 17 e 18). Com relação à faixa de valores encontrada observa-se que a mesma está dentro da observada por ENGUNJOBI (1974) e ORELLANA (1981).

os valores originais da digestibilidade "in vitro" da matéria seca acham-se na Tabela 24 , enquanto que as médias gerais, bem co mo o resumo da análise de variância estão na Tabela 45.

Analisando-se estes dados, bem como os da Figura 19, observa-se um aumento significativo da digestibilidade com o aumento de 


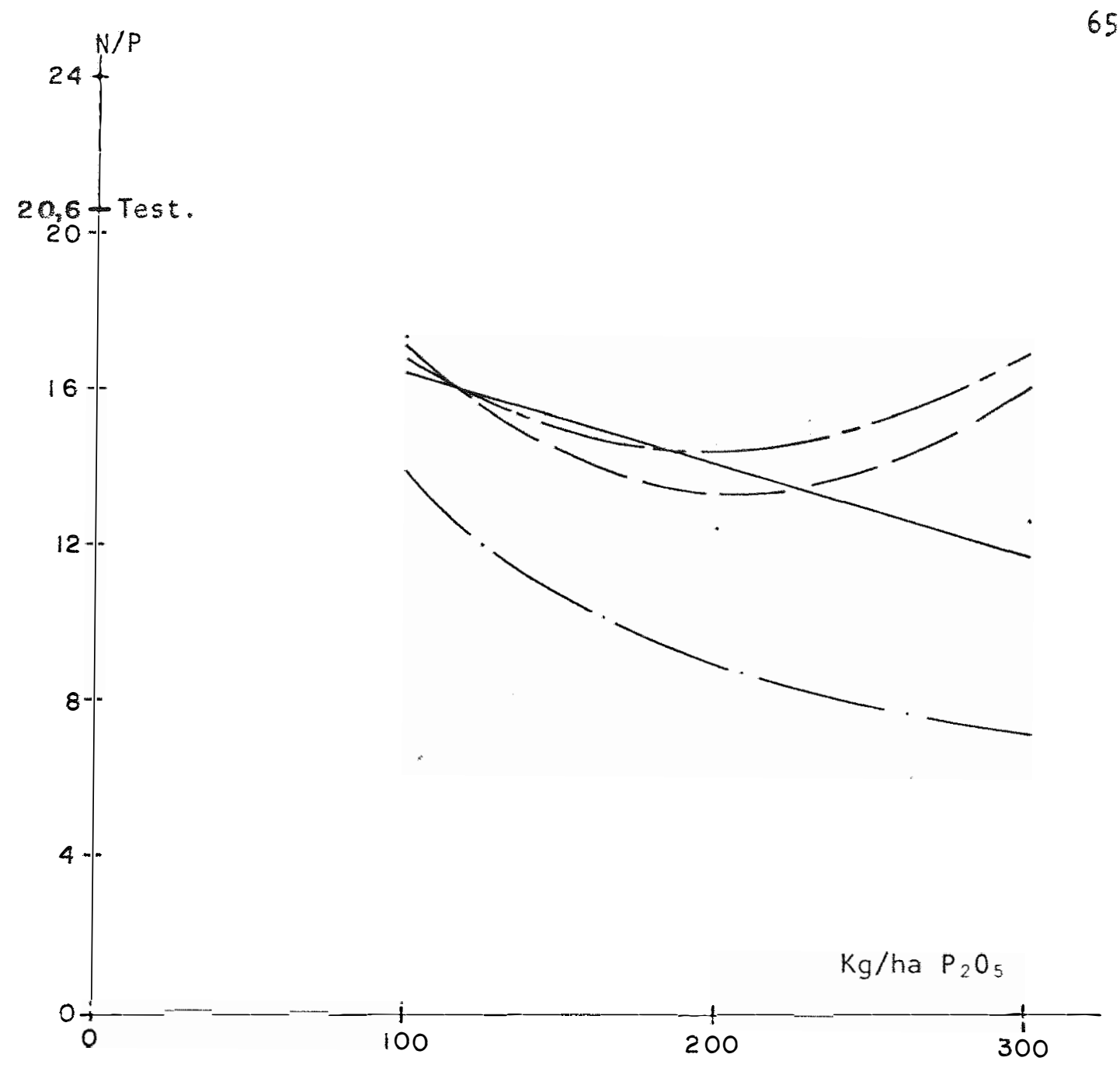

\begin{tabular}{lll}
- FAPS $(1-2 \mathrm{~mm})$ & $Y=18,872-0,0230 X$ & $r^{2}=0,70 * *$ \\
\hline FAPS $(2-4 \mathrm{~mm})$ & $Y=27,582-0,1365 X+0,000329 X^{2}$ & $R^{2}=1,00 * *$ \\
\hline Super Simples & $Y=22,275-0,1001 \times+0,000167 X^{2}$ & $R^{2}=1,00 * *$ \\
- Fosfato Araxá & $Y=24,472-0,1007 X+0,000253 X^{2}$ & $R^{2}=1,00 * *$
\end{tabular}

Figurá 14. Efeito de doses de $\mathrm{P}_{2} \mathrm{O}_{5}$, na relação $\mathrm{N} / \mathrm{P}$ da parte aérea. 


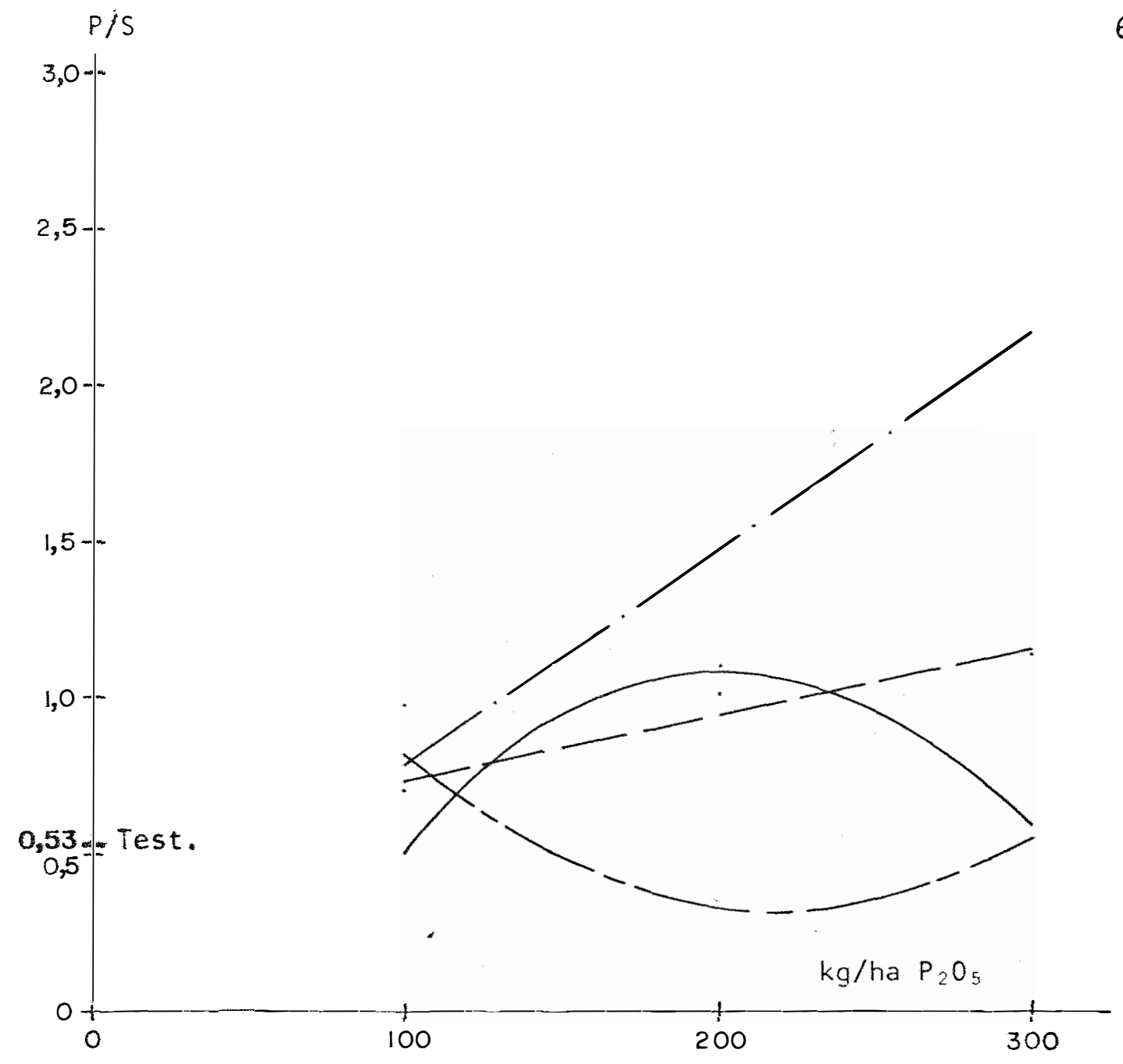

\begin{tabular}{lll} 
FAPS $(1-2 \mathrm{~mm})$ & $Y=1,1575+0,02195 X-0,0000537 X^{2}$ & $R^{2}=1,00 * *$ \\
\hline FAPS $(2-4 \mathrm{~mm})$ & $Y=0,5166+0,00218 X$ & $r^{2}=0,95 * *$ \\
- Super Simples & $Y=0,0908+0,00698 X$ & $r^{2}=0,82 * *$ \\
- - Fosfato Araxá & $Y=2,0075-0,0154 X+0,000035 X^{2}$ & $R^{2}=1,00 * *$
\end{tabular}

Figura 15. Efeito de doses de $P_{2} \mathrm{O}_{5}$, na relação $P / S$ da parte aérea. 


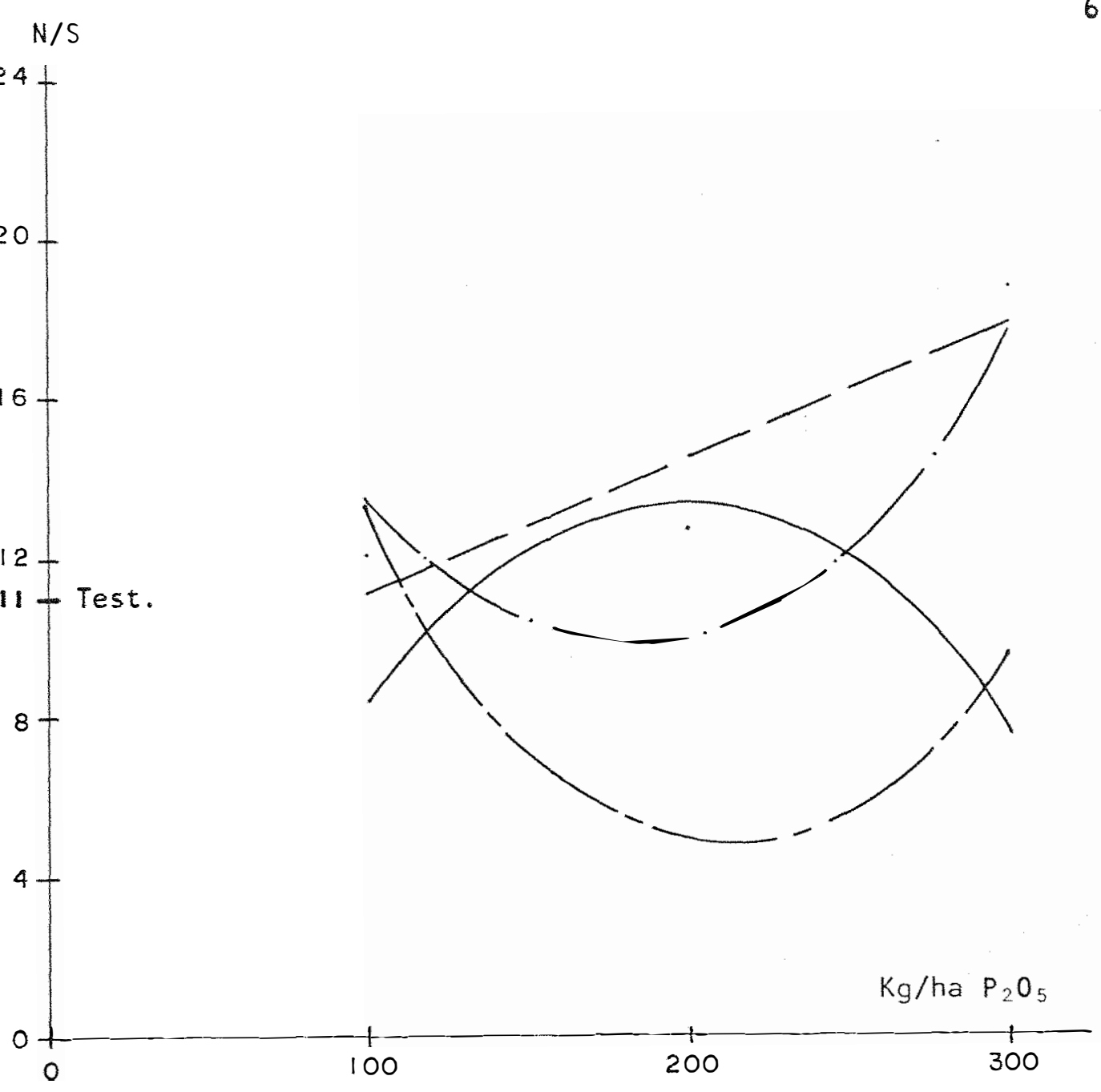

\begin{tabular}{lll}
- FAPS $(1-2 \mathrm{~mm})$ & $Y=0,744+0,2128 X-0,000543 X^{2}$ & $R^{2}=1,00 * *$ \\
\hline FAPS $(2-4 \mathrm{~mm})$ & $Y=7,883+0,0326 X$ & $r^{2}=0,82 * *$ \\
- Super Simples & $Y=28,272-0,2028 X+0,000557 X^{2} \quad R^{2}=1,00 * *$ \\
- Fosfato Araxá & $Y=35,210-0,2832 X+0,000658 X^{2} \quad R^{2}=1,00 * *$
\end{tabular}

Figura 16. Efeito de doses de $\mathrm{P}_{2} \mathrm{O}_{5}$, na relação $\mathrm{N} / \mathrm{S}$ da parte aérea. 


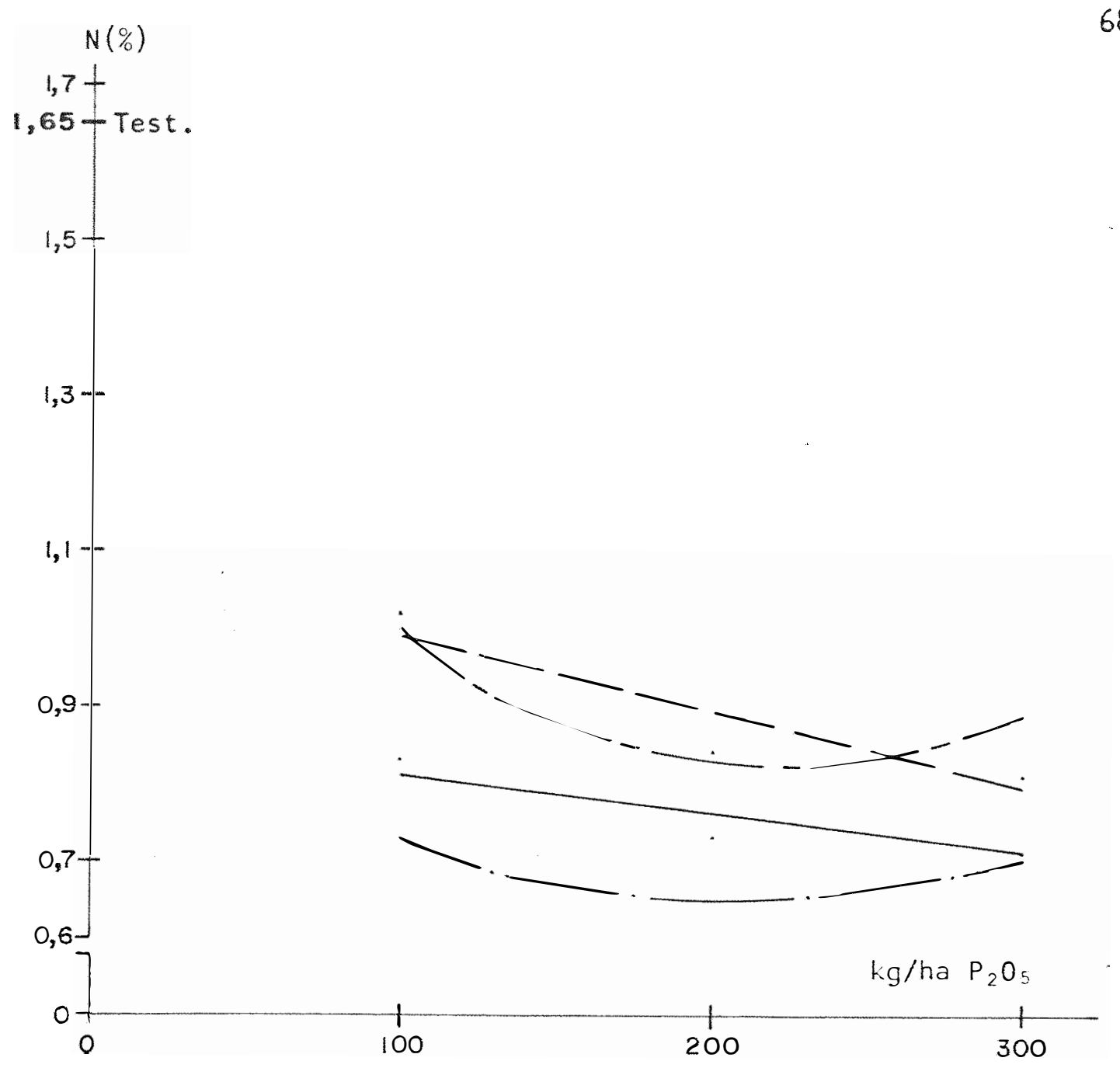

$$
\begin{array}{lll}
\text { FAPS }(1-2 \mathrm{~mm}) & Y=0,862-0,0005 X \quad r^{2}=0,62 * * \\
\text { FAPS }(2-4 \mathrm{~mm}) & Y=1,098-0,0010 X \quad r^{2}=0,84 * * \\
\text { Super Simples } & Y=0,942-0,0028 X+0,000007 X^{2} \quad R^{2}=1,00 * * \\
\text { Fosfato Araxá } & Y=1,432-0,0054 X+0,000012 X^{2} \quad R^{2}=1,00 * *
\end{array}
$$

Figura 17. Efeito de doses de $P_{2} 0_{5}$, na concentração de Nitrogênio na par te aérea. 


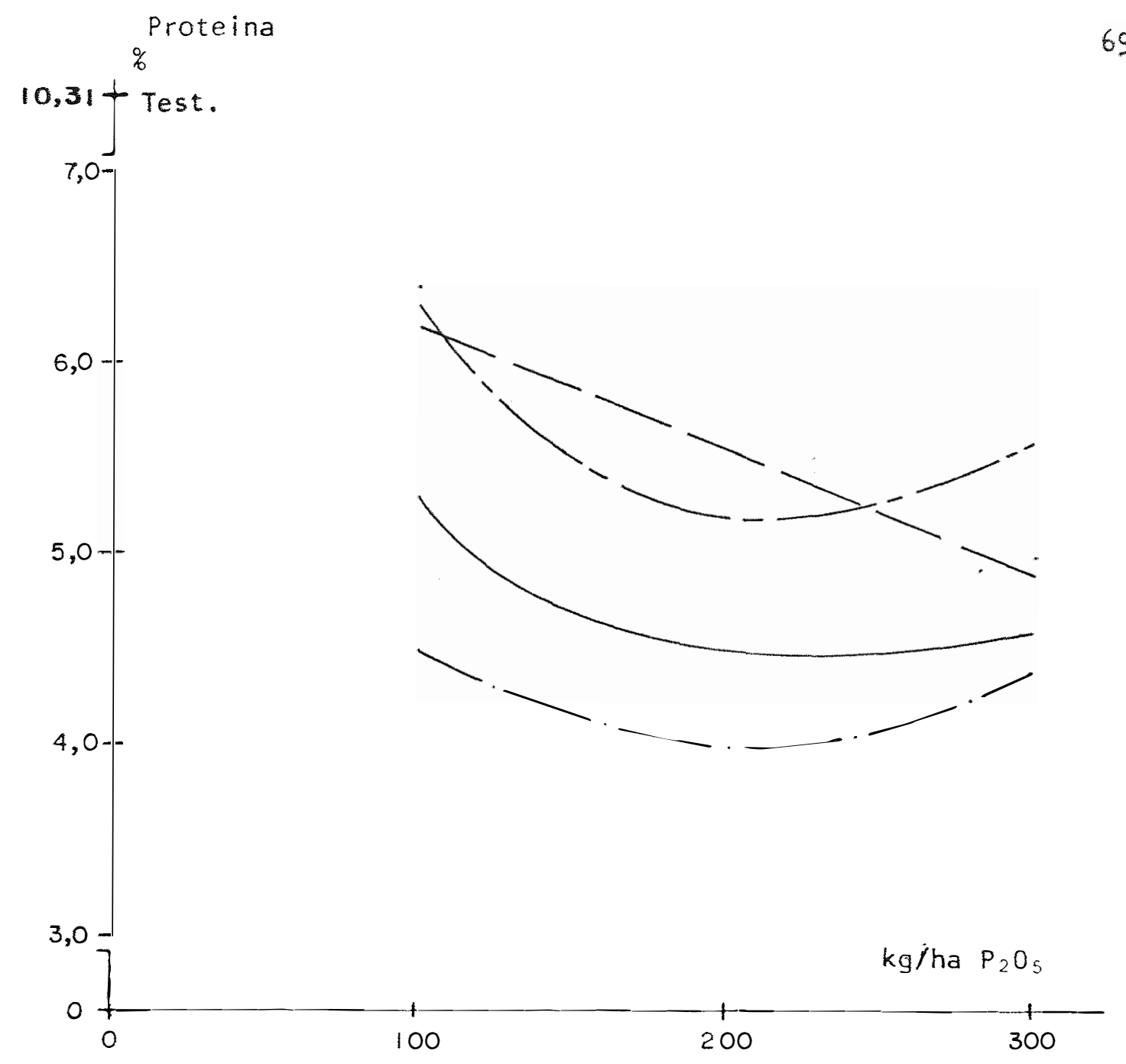

\begin{tabular}{lll} 
FAPS $(1-2 \mathrm{~mm})$ & $Y=7,127-0,023 X+0,00005 X^{2}$ & $R_{2}=1,00 * *$ \\
\hline FAPS $(2-4 \mathrm{~mm})$ & $Y=6,865-0,0065 X$ & $r^{2}=0,85 * *$ \\
\hline- super Simples & $Y=5,885-0,0175 X+0,00004 X^{2}$ & $R^{2}=1,00 * *$ \\
- Fosfato Araxá & $Y=8,952-0,0342 X+0,00008 X^{2}$ & $R^{2}=1,00 *$
\end{tabular}

Figura 18 . Efeito de doses de $\mathrm{P}_{2} \mathrm{O}_{5}$, no teor de proteina da parte aérea. 


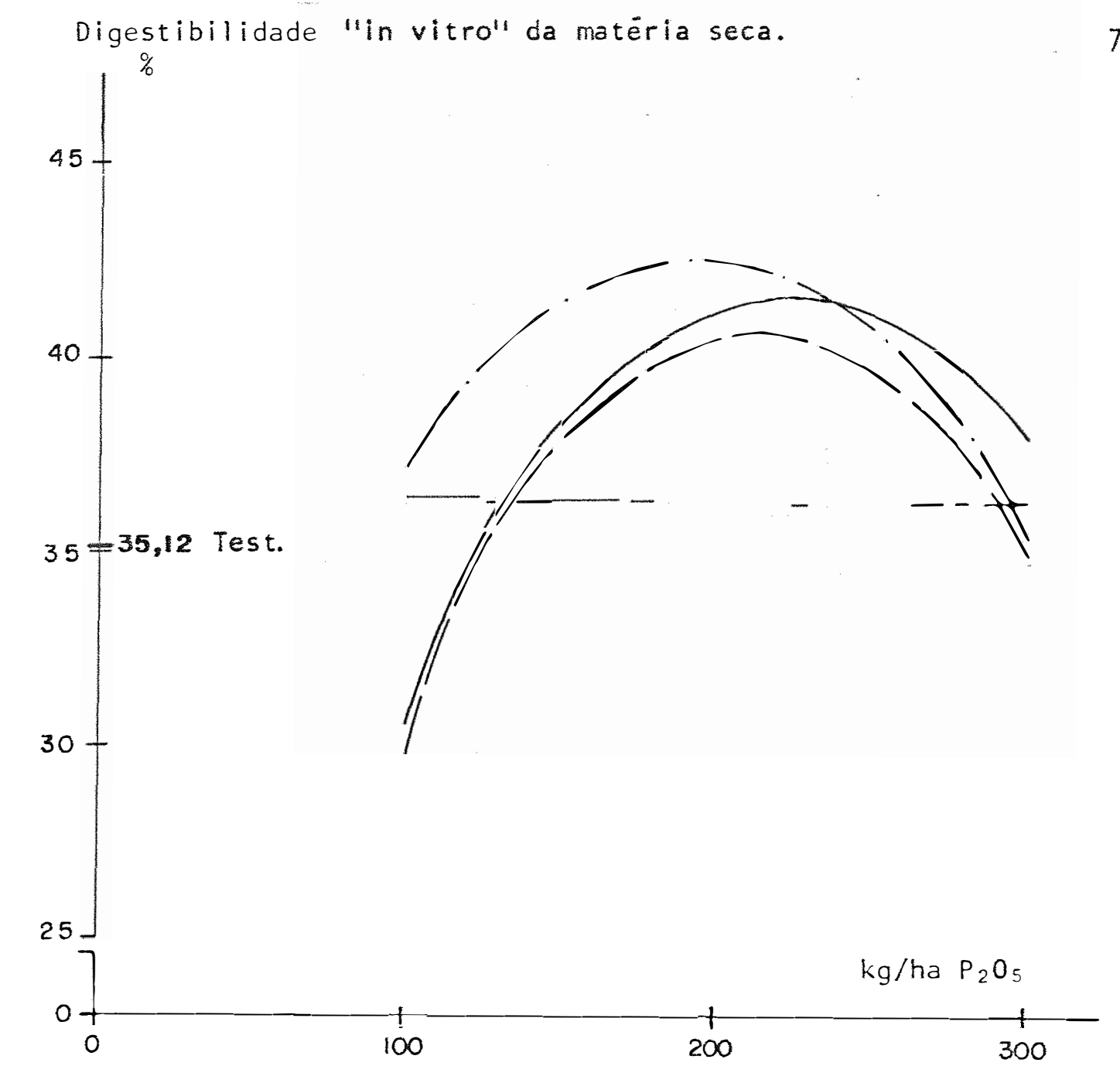

$\begin{array}{lll}- \text { FAPS }(1-2 \mathrm{~mm}) & Y=6,350+0,310 X-0,00068 x^{2} & R^{2}=1,00 * * \\ - \text { FAPS }(2-4 \mathrm{~mm}) & Y=2,333+0,357 X-0,000829 x^{2} & R_{2}=1,00 * * \\ - \text { Super Simples } & Y=19,177+0,243 X-0,00063 x^{2} & R_{2}=1,00 * * \\ - \text { - Fosfato Araxá } & Y=36,28 & \end{array}$

Figura 19. Efeito de doses de $P=0$, na digestibilidade "in vitro" da mate ria seca da parte aérea. 


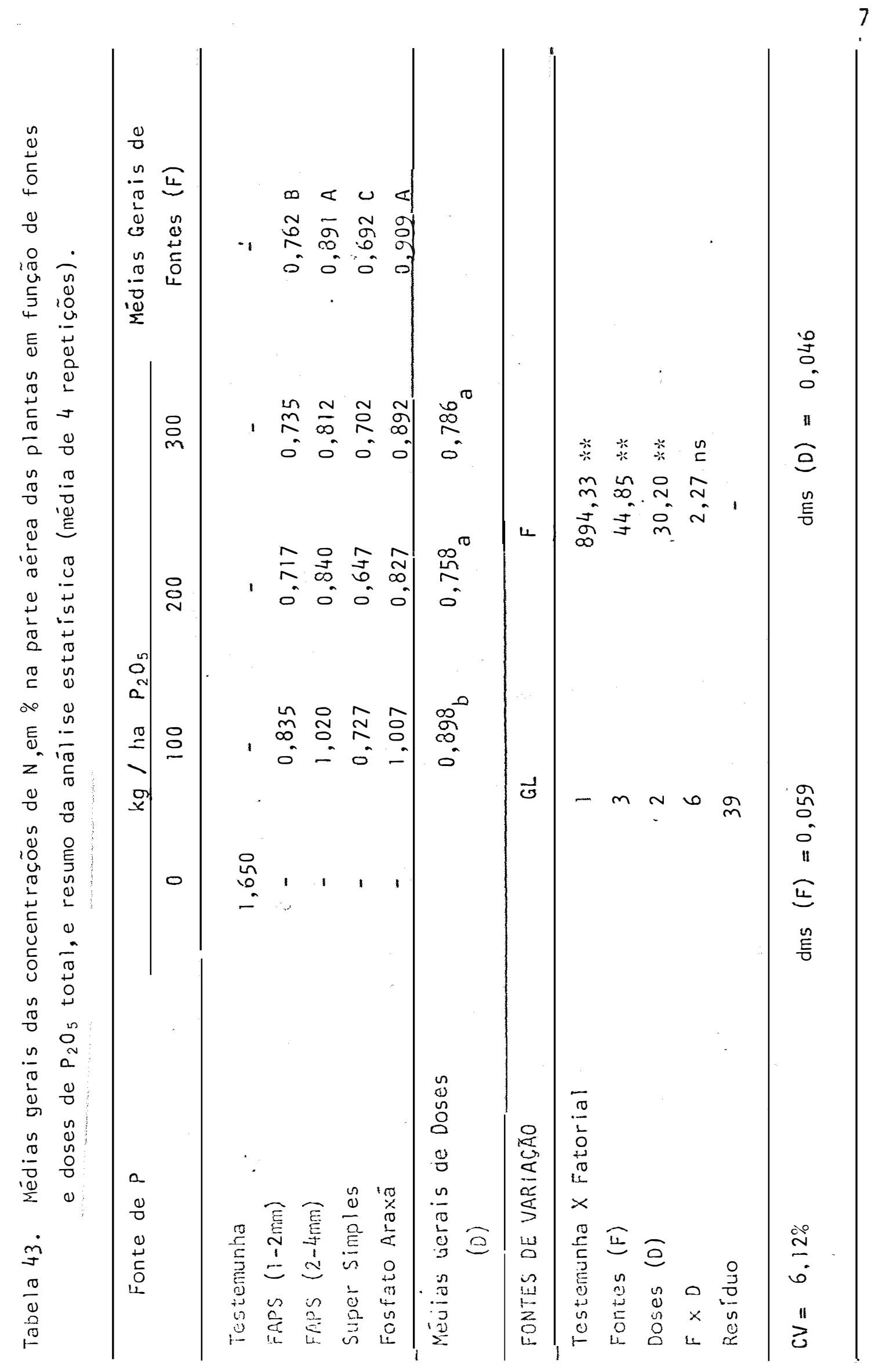




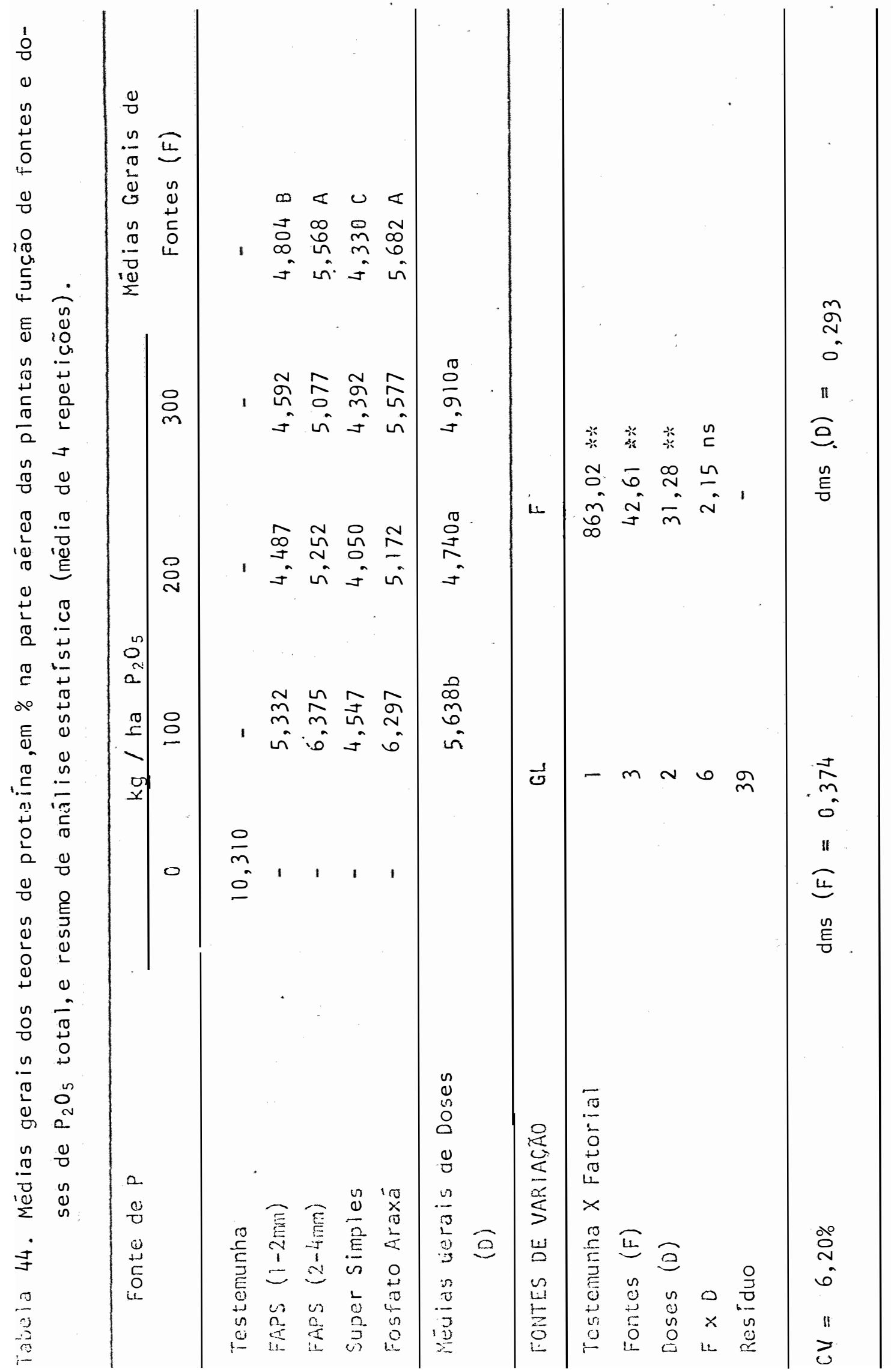




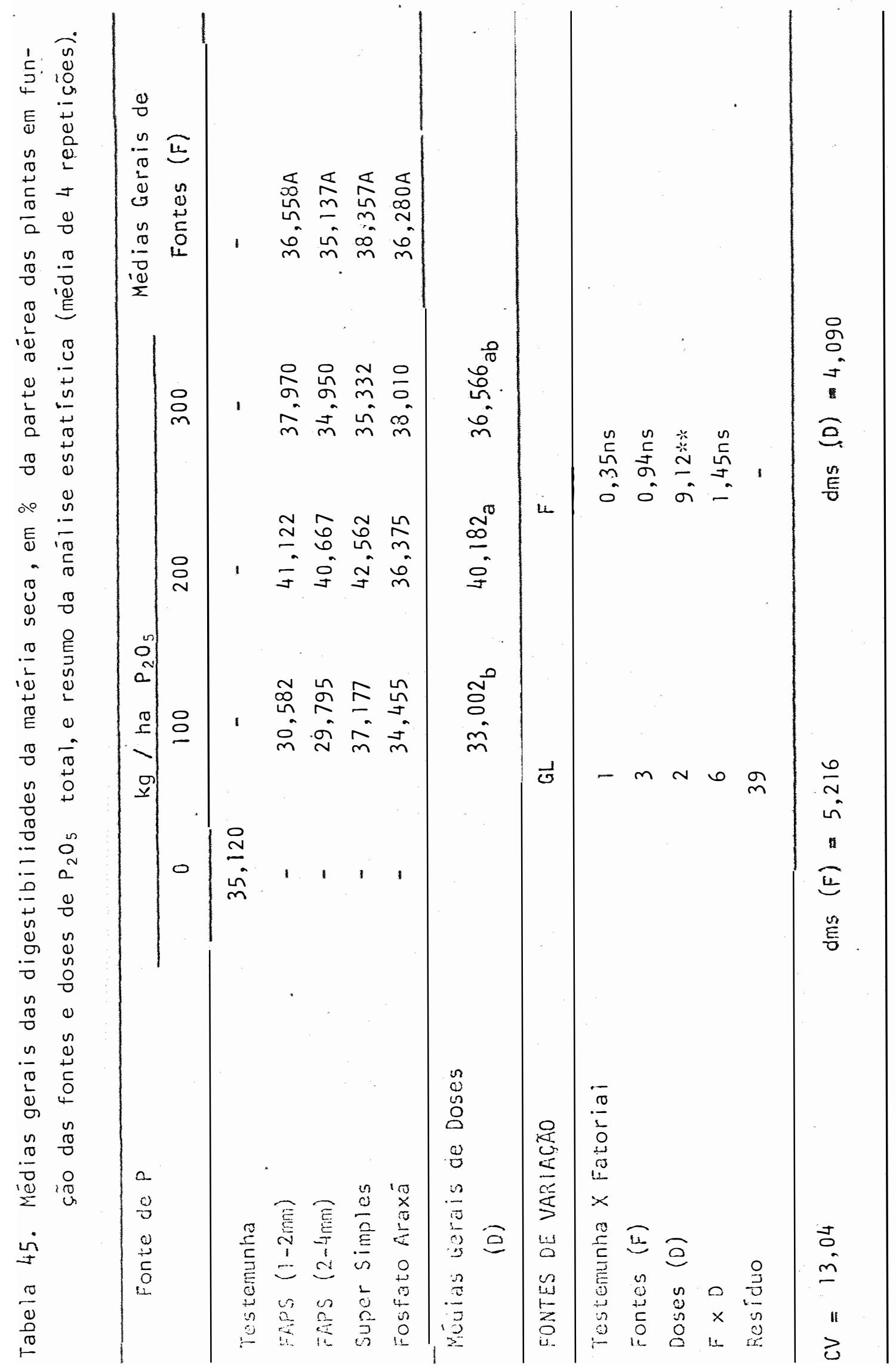


doses de $\mathrm{P}_{2} \mathrm{O}_{5}$ em todas as fontes utilizadas, com exceção do Fosfato de Araxā.

Os valores máximos de digestibilidade, 42,42 e $41 \%$ foram conseguidos respectivamente pela utilização de 193 (Superfosfato Simples), 228 (FAPS-1 e $2 \mathrm{~mm}$ ) e $215 \mathrm{~kg} / \mathrm{ha}$ de $\mathrm{P}_{2} \mathrm{O}_{5}$ (FAPS - 2 e $4 \mathrm{~mm}$ ).

Com relação aos valores mëdios encontrados, ou seja,por volta de $36 \%$, verificou-se que os mesmos estão mais baixos do que os ci tados por MILLER e RAINS (1963), ORELLANA (1981), estando, entretanto próximo do citado por ASARE (1974). 
5. CONCLUSÕES

Nas condições do experimento, os dados obtidos permitem concluir que:

- Houve efeito de adubação fosfatada na produção de matéria seca do capim Andropogon.

- A eficiência do FAPS na produção da matéria seca é ligeiramente inferior quando comparada ao superfosfato simples, mas superior aos fosfato de Araxá.

- O superfosfato, seguido pelo FAPS foram superiores ao fosfato de Araxá como fornecedores de $\mathrm{P}$ e Ca.

- A produção de matéria seca correlacionou-se positivamente com as quantidades absorvidas de $\mathrm{Ca}$ e $\mathrm{S}$, sendo que entretanto o efe to do $P$ não foi possível de ser separado do Ca, pois ambos tiveram al ta correlação entre si. 
- As quantidades absorvidas de fösforo (mg/vaso) foram:

0,$55 ; 7,34 ; 6,63 ; 10,62$ e 5,99, respectivamente para Testemunha, FAPS $(1-2 m m)$, fAPS $(2-4 m m)$, superfosfato simples e fosfato de Araxá.

- Os teores de P (Bray-1), $\mathrm{Ca}\left(\mathrm{KCl}\right.$ I,ON) e $\mathrm{S}^{-\mathrm{SO}_{4}}$ $\left(\mathrm{NH}_{4} \mathrm{OAc} 0,5 \mathrm{~N}\right)$ no solo, correlacionam-se com doses e fontes de $\mathrm{P}_{2} \mathrm{O}_{5}$ ut lizados.

- As relações N/P, P/S e N/S na parte aërea aos 75 dias após o plantio variaram respectivamente de 10 a $16 ; 0,57$ a 1,51 e 9 a 14.

- Os teores de protéína variaram de 4,6 a 5,7\%, decrescendo das fontes menos para as mais solúveis, bem como com o aumento de do ses de $\mathrm{P}_{2} \mathrm{O}_{5}$.

- Os valores máximos da digestibilidade "in vitro" da maté ria seca estimado em torno de $42 \%$ responderam à apl icação dos FAPS e do superfosfato. 
LITERATURA CITADA

ALCÂNTARA, P.B. e G. BUfARAH, 1979. Plantas forrageiras; gramíneas e le. guminosas. São Paulo, Nobel. $146 \mathrm{p}$.

ANDRADE, R.P., C. SANZONOWICZ; D.T. GOMES; C.M.C. ROCHA; W. COUTO; D. THOMAS E C.P.MOORE, 1980. Recomendações preliminares para a formação de pastagens de capim Andropogon. Planaltina EMBRAPA/CPAC. (EMBRAPA/ CPAC - Comunicado Técnico, 11). p. $1-3$.

ARAFERTIL, 1980. Fertilizantes produzidos pela Arafértil e sua aplicação em pastagens. (Depto. de Tecnologia, nọ AG. 001/80). 4 p. 
ASARE, E.0., 1974. Dry matter yield, chemical composition and nutritive value of buffel grass grown alone and in mixture with other tropical grasses and legumes. In: International Grassland Congress, 129, Grassland Utilization. 1. Moscow, URSS. Proceedings. p. 53-54.

ASHBY, D.L.; W.E. FENSTER e 0.J. ATTOE, 1966. Effect of partial acidulation and elemental sulfur on availability of phosphorus in rock phosphate. Agr. J. $\underline{58}$ : 621-625.

BARDSLEY, C.E. e J.D. LANCASTER, 1965. Ace tate soluble sulfate. In: Methods of soils analysis:chemical and microbiological properties.la ed. Madson American Society of Agronomy. p. 1111 - 1113.

BOWDEN, B.N., 1963. Studies on Andropogon gayanus Kunth 1. The use of Andropogon gayanus in agriculture. J. Exp. Agric., 31 (123): 266-273 .

BRAGA, J.M.; B.V. DEFELIPO e D. de ANDRADE, 1972. Adubação da soja em solos sob vegetação de cerrado na região do triângulo mineiro. Rev. Ceres. Viçosa, 19 (201): 52-62.

CENTRO INTERNACIONAL DE AGRICULTURA TROPICAL, 1978. Beef Production Program. Annual Report 1977. Centro Internacional de Agricultura Tropical, Cali, Colômbia. $114_{\text {p }}$. 
CENTRO INTERNATIONAL DE AGRICULTURA TROPICAL, 1979. Programa de ganado de carne. In: Informe Anual 1978. Cali, Colómbia, Pp. 81-87.

CENTRO INTERNACIONAL DE AGRICULTURA TROPICAL, 1980. Pastos Tropicales:

Boletim Informativo ne 3. Cali, Colômbia, $6 p$.

DASH, R.N.; S.K. MOHANTY e S.PATNAIK, 1981. Efficiency of $\mathrm{HCl}$-and $\mathrm{H}_{2} \mathrm{SO}_{4}$ -acidulated rock phosphates for a rice based cropping system. Fertilizer Res. 2: 109-118.

ENGUNJOBI, J.D., 1974. Dry matter, nitrogen and mineral element distribution in unburnt savanna during the year - Ecol.Plant: $9(1)$ : p. $1-10$.

EMPRESA GOIÁNIA DE PESQUISA AGROPECUÁRIA, 1979. Produção estacional dos. capins: Brachiaria decumbens c.v. IPEAN e cv. Australiana, Brachiaria humidicola (Quicuio da Amazônia), Panicum maximum c.v. Makueni (Makueni) Andropogon gayanus (Gamba), Hyparrhenia rufa (Jaraguä) Setaria anceps cv. Kazungula e Melinis minutiflora (Gordura). Goiânia. (EMGOPA - Relatörio Técnico). p. 45-49

EMRICH, E.S., 1967. Competição entre cinco gramíneas forrageiras para a formação de pastagens em solo de cerrado. In: REUNIÃO BRASILEIRA DE CERRADOS, 2a, Sete Lagoas, MG. ANAIS. p. 209-221. 
FALADE, J.A., 1975. The effect of phosphorus on growth and mineral composition of five tropical grasses. East. African Agric, and Forestry, J. Nairobi, $40(4): 342-350$

FERNANDES, F.M., 1981. Comparação de fontes e doses de adubos fosfatados na cultura da soja (Glycine max (L) Merril), em solo de cerrado. Pira cicaba, ESALQ-USP, 80 p. (Dissertação de Mestrado).

FRANCO, M., 1977. Fosfatos naturais parcialmente acidificados com $\mathrm{H}_{3} \mathrm{PO}_{4}$, $\mathrm{HCl} \mathrm{e}_{2} \mathrm{SO}_{4}$ na cultura de sorgo granífero em um solo de cerrado de Ituiutaba, MG. 75p (Dissertação de Mestrado).

GILBERT, G.S., 1951. The place of sulfur in plant nutrition. Annls. Rev. Bot., 17: $671-691$

GOEDERT, W.J. e F. LOBATO, 1980. Eficiência agronōmica de fosfatos em so lo de cerrado. Pesq. agropec. bras., Brasilia, 15(3): 311-318.

GOMES, F.P., 1973. Curso de estatística experimental. 5 ed. São Paulo, No bel. $530 p$.

GROF, B.B., 1981. The performance of Andropogon gayanus - legume associations in Colōmbia. J. Agric. Sci. 96: 233-238 
HAGGAR, R.J., 1969. Seasonal production of Andropogon gayanus. 111 .

Changes in crude protein content and in vitro dry-matter digestibility of leaf and stem portions. J.Agric. Sci. Camb., 77 (1): 47-52.

HAGGAR, R.M., 1970. Seasonal production of Andropogon gayanus. 1. Seasonal changes in yield components and chemical composition. J. Agric. Sci. Camb., 74 (3): 487-494.

HAGGAR, R.J. e M.B. AHMED, 1970. Seasonal production of Andropogon gayanus. 11 - Seasonal changes in digestibility and feed intake. J. Agric. Sci. Camb. 75 (3): 369-373.

HOAGLAND, D.R. e D.I. ARNON, 1950. The water culture method for growing plants without soil. Bekerley, Cal ifornia, Agricultural Experiment Station. (Circular 347).

JONES, C.A., 1979. The potential of Andropogon gayanus Kunt in the Oxisol and Ultisol Savannas of tropical Amërica. Herbage Abst., 49 (1): $1-8$

KHASAWNEH, F.E. e E.C. DOLL, 1978. The use of phosphate rock for direct application to soils. Adv. Agron. 30: 159-206.

KRUGG, F.J.; H. BERGAMIN FO; E.A.G.ZAGATTO e S.S.JORGENSEN; 1977. Rapid determination of sulphate in natural waters and plant digest by continous flow injection turbidimetry. Analyst, 102: 503-508 
LEON, L.A. e W.E. FENSTER, 1980. El uso de rocas fosforicas como fuente de fosforo em suelos äcidos e infertiles de sur America. In: IFDC.III Congresso Latinoamericano de lạ Ciēncia del Suelo, Heredia-Costa Rica$-24 p$.

LIMA, E., 1981. Resposta do sorgo sacarino (Sorghum bicolor (L) Moench) ao emprego de fontes e doses de fösforo em condições de casa-de-vegetação. Piracicaba, ESALQ-USP, 107 P. (Dissertação de Mestrado).

LOBATO, E., 1982. Adubação fosfatada em solos de região Centro-0este. In: EMBRAPA - Adubação Fosfatada no Brasil. Brasilia. p: 201-239.

LOT, L.A., 1981. Solubilização de fosfato natural em solos da região de Jaboticabal. F.C.A.V., UNESP-Jaboticabal-SP. 55p (Trabalho de Graduação).

MALAVOLTA, E.; G.C. VITTI; J.C.ALCARDE, C.A.ROSALEM; E D.FORNASIERI FO, 1981. Aproveitamento de um fosfato natural parcialmente solubilizado pelas culturas do arroz, milho e soja. 1-Resultados preliminares. Anais da E.S.A. "Luiz de Queiroz". Piracicaba, 38: 801-818. .

MC LEAN, E.0. e R.W.WHEELER, 1964. Partially acidulated rock phosphate as a source of phosphorus to plants. 1. Growth Chamber studies. Proc. Soil Sci. Soc. Amer., 29: 545-550.

MC NAUGHT, K.J. E P.J.E.CHRISTOFFELS, 1961. Effect of sulphur deficiency on sulphur and nitrogen levels in pastures and Lucerne. New Zealand. J. Agr. Res., $\underline{4}: 177-196$ 
MILLER, T.B. e A.B. RAINS, 1963. The nutritive value and agronomic aspects of some fodders in Northern Nigeria. 1. Fresh herbage. J. Brit. Grassld. Soc. Aberystwyth, 18: 158-167.

NAKAYAMA, L.H.1., 1982. Estudos agrícolas sobre o aproveitamento do fosfato de Araxă parcialmente solubilizado. Piracicaba, ESALQ-USP. 97p. (Dissertação de Mestrado).

NOORUDDIN E L.N.ROY, 1974. A note on the chemical composition digestibility and nutritive value of Andropogon gayanus at the flowering stage. Indian J. Anim. Sci. 44 (10): 797-798.

ORELLANA, A.P., 1981. Nutrição mineral e coeficiente de digestibilidade "in vitro" da matéria seca do Andropogon gayanus Var. bisquamulatus (HOCHST) HACK. Piracicaba, ESALQ-USP. 9lp. (Dissertação de Mestrado).

PEDREIRA, J.V.S., P.NUTI, B.E.S. CAMPOS, 1975. Competição de capins para produção de matéria seca. Bol. Ind. Anim., S.Paulo. 32(2): 319-323.

PUMPHREY, F.V. E D.P. MOORE, 1965. Diagnosing sulfur deficiency of alfafa (Medicago sativa L.) from plant anlysis. Agron. …, 57: 364-366.

RAIJ, B.van, 1978. Seleção de métodos de laboratório para avaliar a disponibilidade em solos. R. bras. ci. solo, Campinas, 2(1): 1-9. 
RAIJ, B.van e M.A.T.ZULLO, 1977. Mëtodos de anälise de solo. Campinas Instituto Agronômico, 16p. (Circular, 63).

REID, R.L. e A.J. POST, 1973. Studies on the nutritional quality of grasses and legumes in Uganda. 1 - Application of in vitro digestibility techniques to species and stage of growth effects Tropic. Agric. Trinidad 50 (1): 1 - 15 .

SARRUGE, J.R. e H.P. HAAG, 1974. Anālises guímicas em plantas. Piracicaba, ESALQ-USP, 56p. mimeo.

SFREDO, G.J.; C.M. BORKERT; D.S. CORDEIRO; J.B. PALHANO E R.C. DITTRICH, 1979. Comparação de cinco extratores de fósforo do solo, considerando-se o tempo de incorporação de três adubos fosfatados. R. bras. ci. solo, Campinas, 3 : $111-115$.

SINGH, R.D. e B.N.CHATTERJEE, 1965. Tillering of perrineal grasses in. the tropic in India. Kanke, Bigar, India, Ranchi Agricultura College e Researche Institute. 5p.

SINGH, R.D. e B.N. CHATTERJEE, 1968. Growth analysis of perinneal grasses in tropical India. I Herbage growth in pure grass swards. Exp. Agric. 4 (2): 117-125. 
SINGH, R.D., PREMCHAND e A. RAHAMAN, 1972. A herbage growth of pearl-millet Napier grass hibrid when compared with other grasses. Indian. J. of Agric. Sci, 42 (3): 218-222.

STEEL, R.G.D. E J.H. TORRIE, 1960 - Principles and procedures of statisties. New York, Mc Graw Hill, 481 p.

THOMAS, S.; R. ANDRADE; W. COUTO; C.ROCHA; P.MOORE, 1981. Andropogon gayanus Var. Bisquamulatus c.v. Planaltina: principais caracteristicas forrageiras. Pesq. agropec. bras. Brasilia, 16 (3): 347-355.

TILLEY, J.M.A. e R.A. TERRY, 1963. A two-stage technique for the "in vitro" digestion of forrage crops. J.British Grassl. Soc. 18:104-111.

VILELA, H., 1977. Manejo de Pastagens em Cerrados. In: IVọ Simpósio sobre manejo de pastagens. ESALQ, Piracicaba, SP. ANAIS P. 248-305. 
APENDICE 


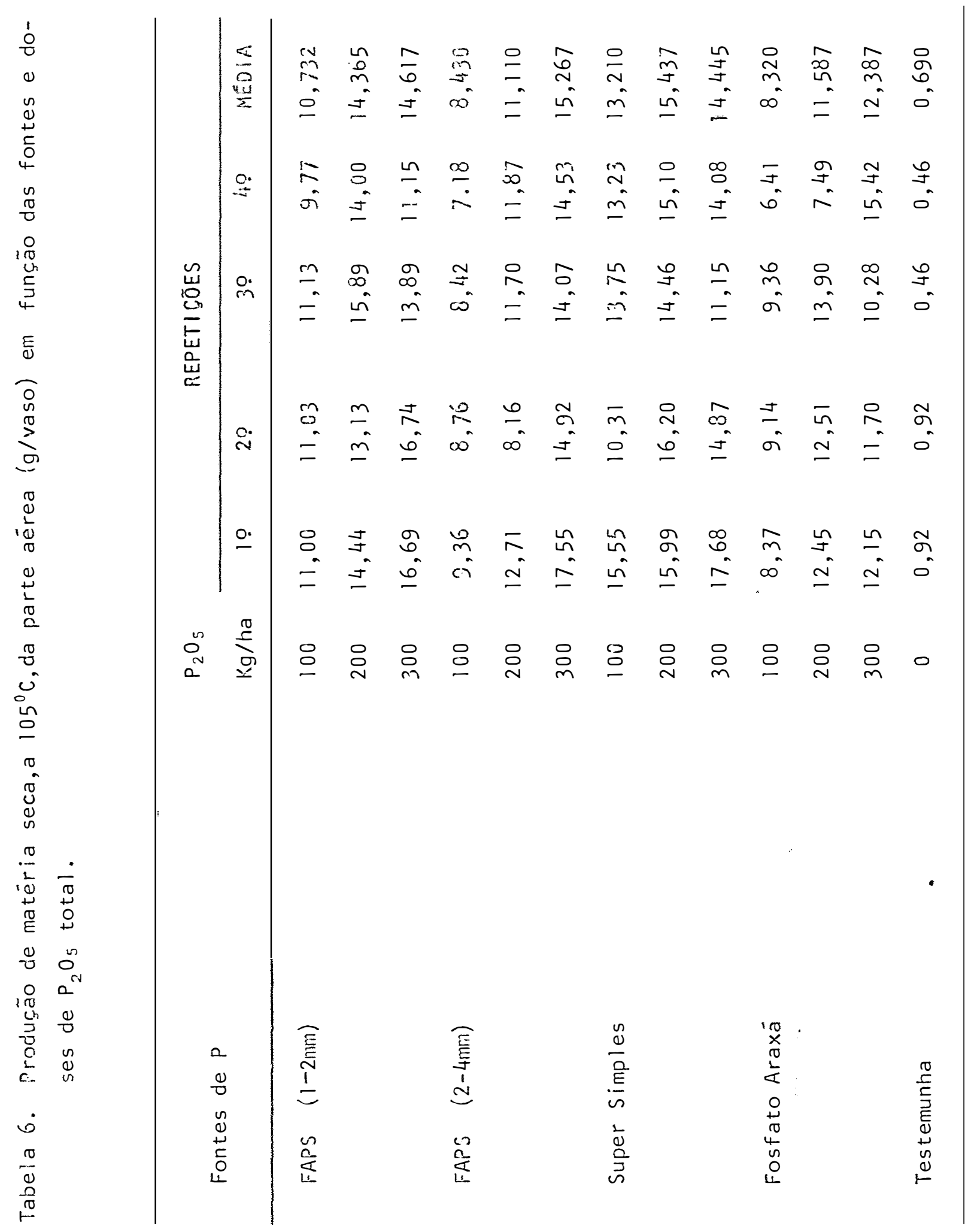


n
0
0
0

(1)

先

in

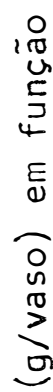

$\stackrel{n}{\frac{N}{N}}$

$\frac{n}{0}$

in

$\infty$

苍

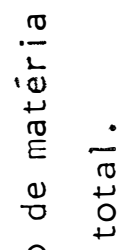

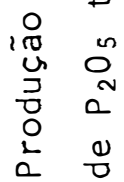

r

$\frac{\pi}{\frac{\pi}{0}}$

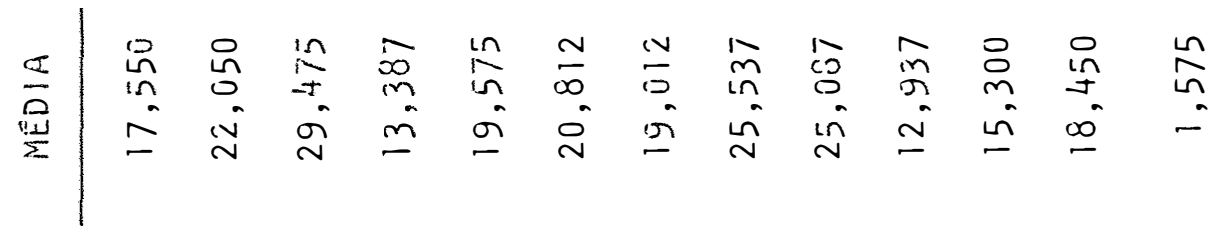

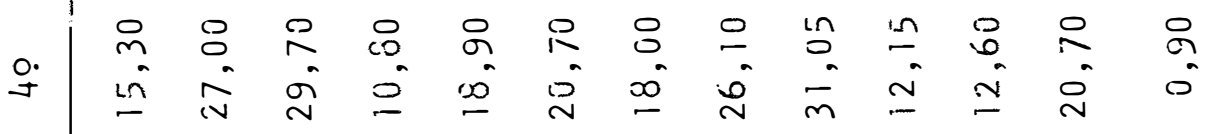

㟧

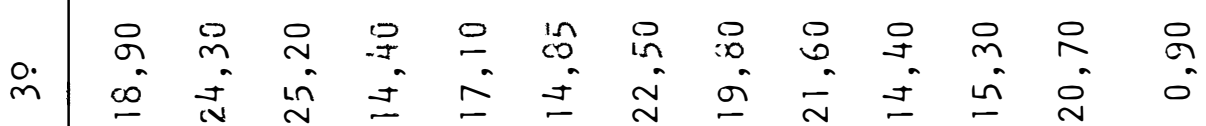

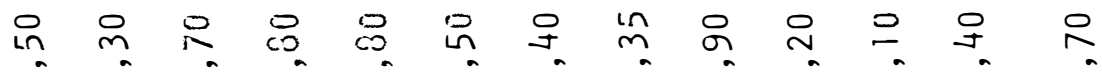
ก

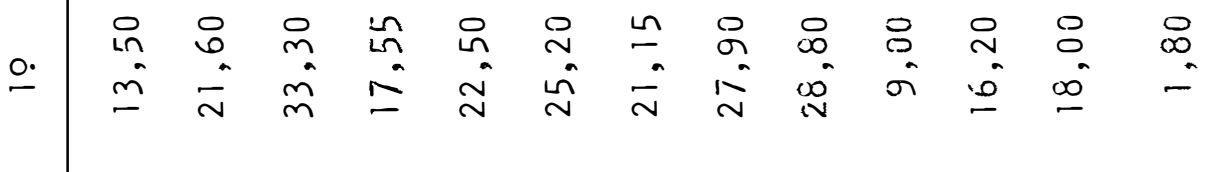

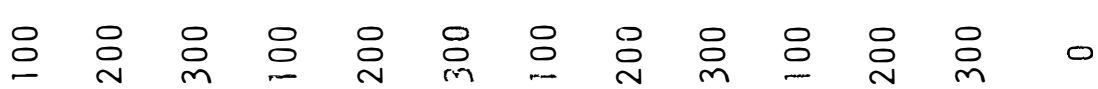

a

$\frac{0}{0}$

n $\quad 1$

茖

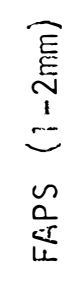

$\frac{n}{0}$
$\frac{E}{a}$
$\frac{n}{n}$
$\vdots$
0
$\frac{2}{3}$
$n$
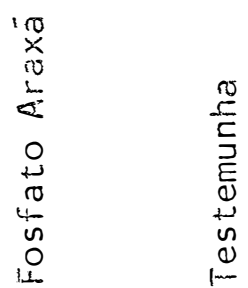


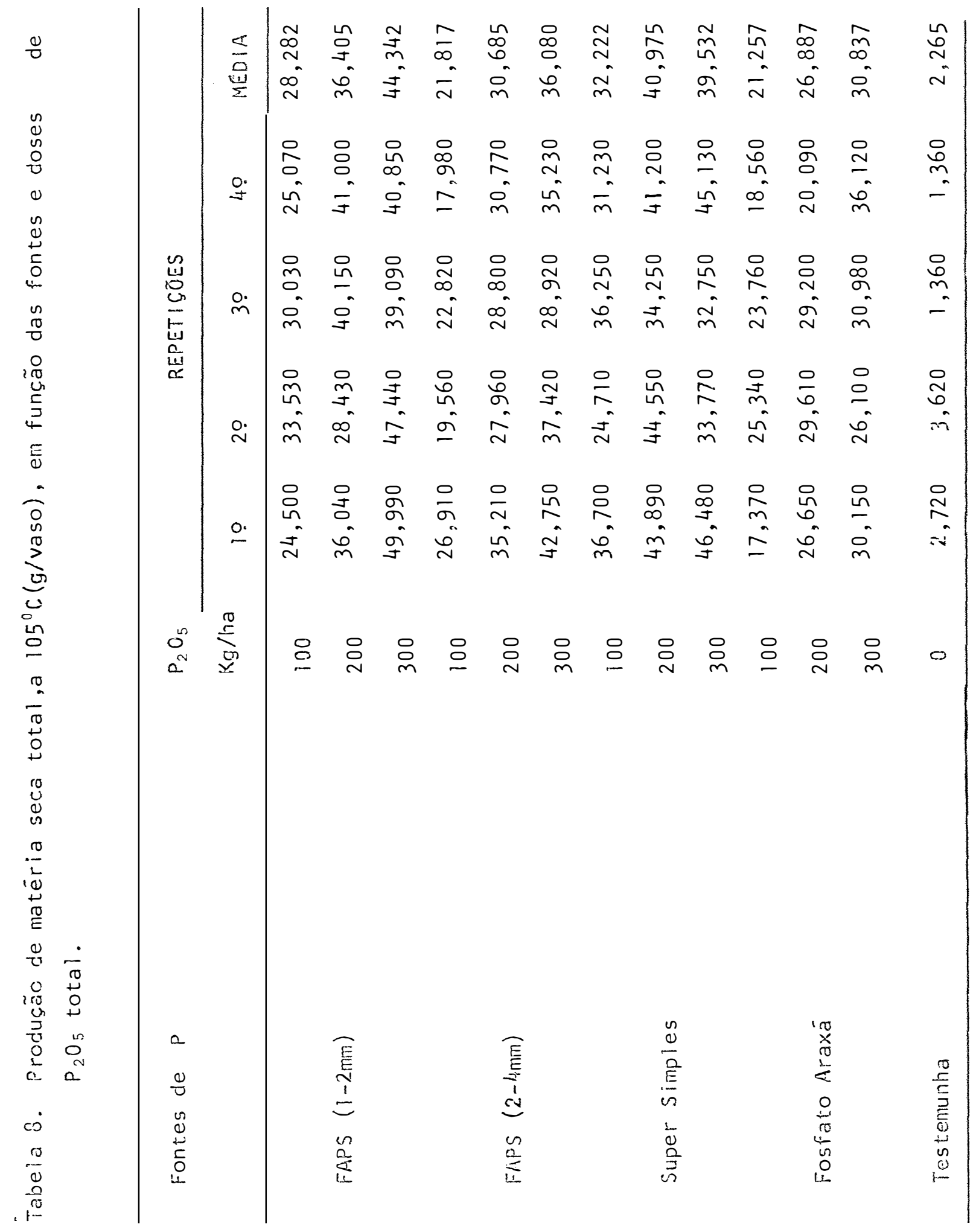




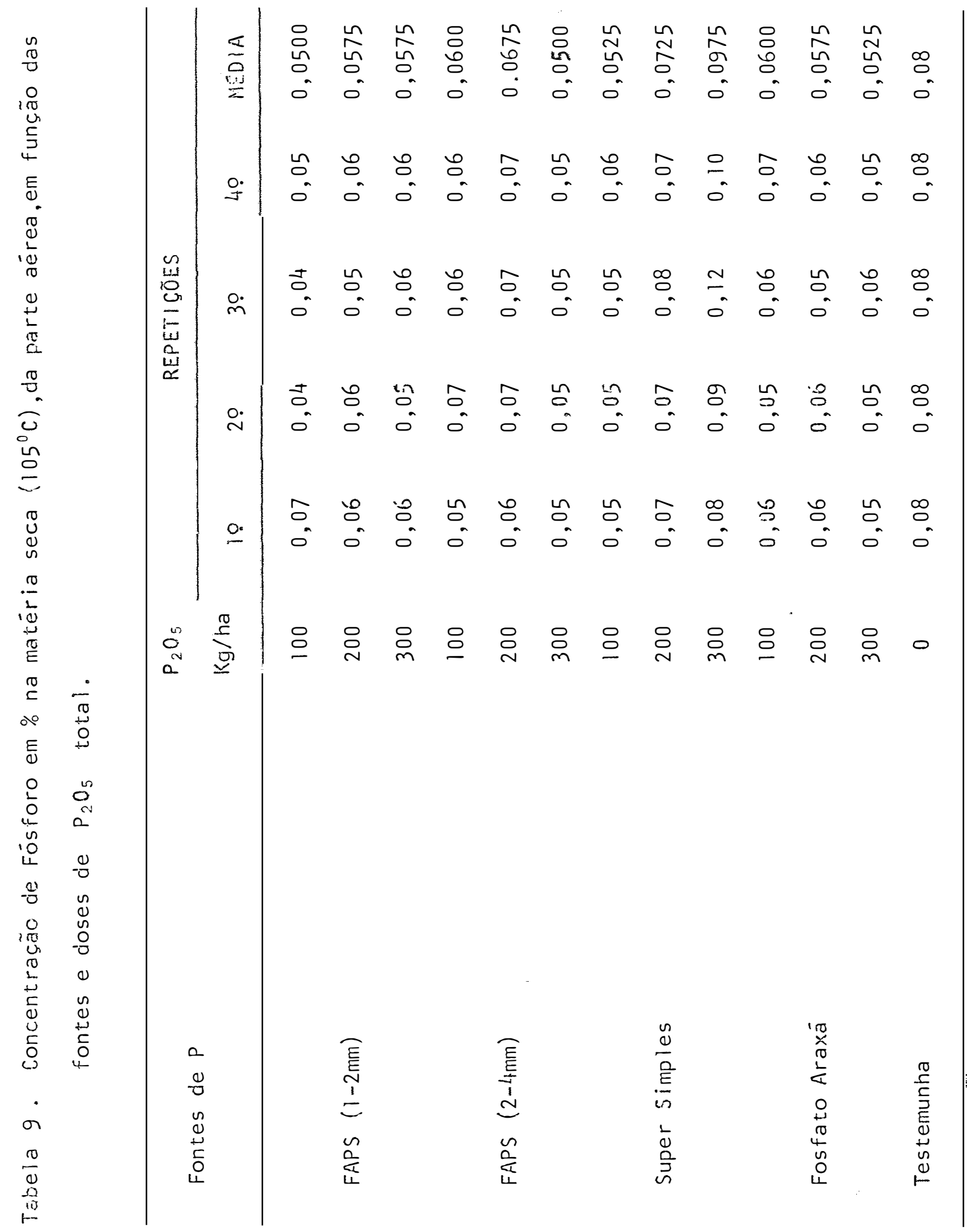




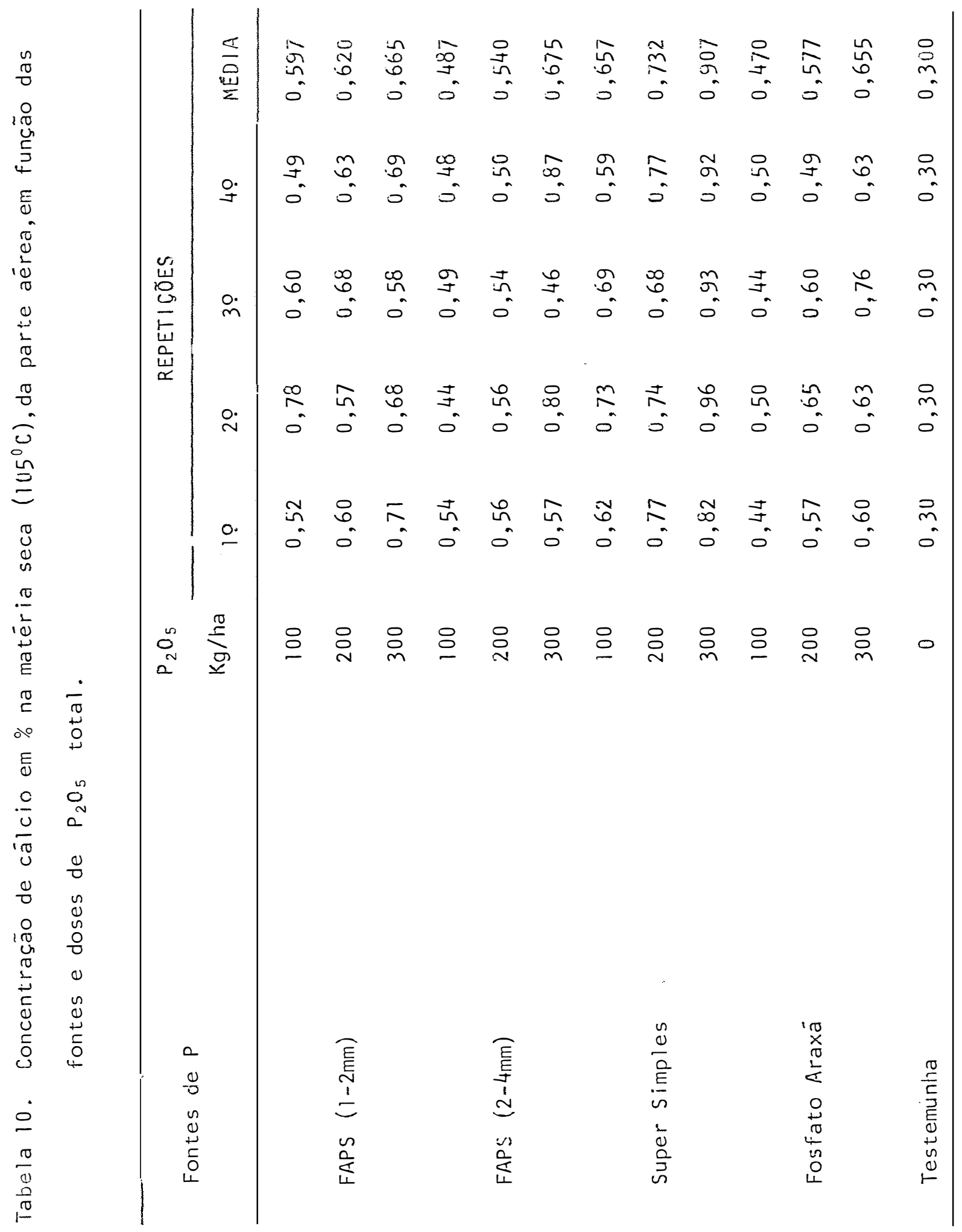




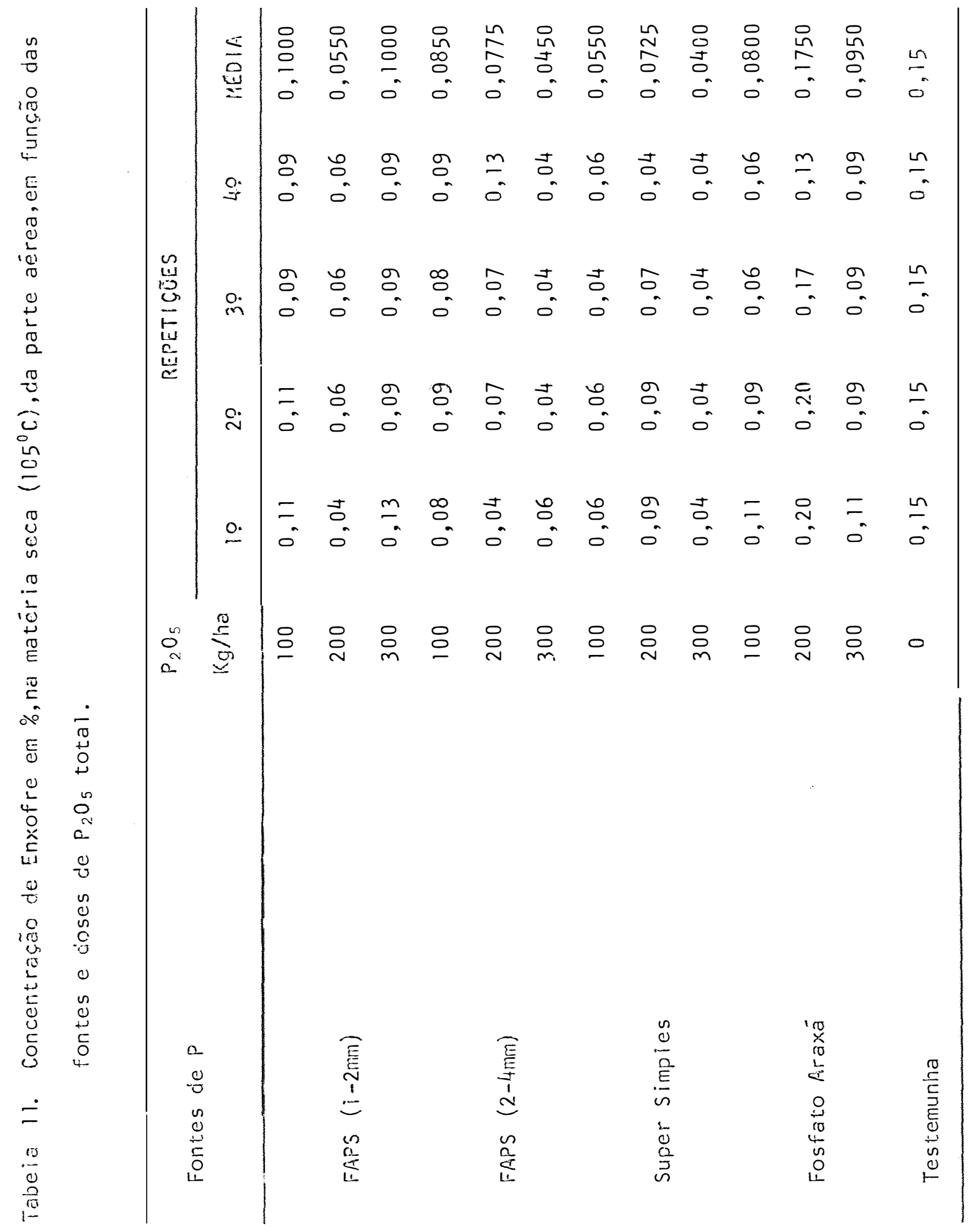




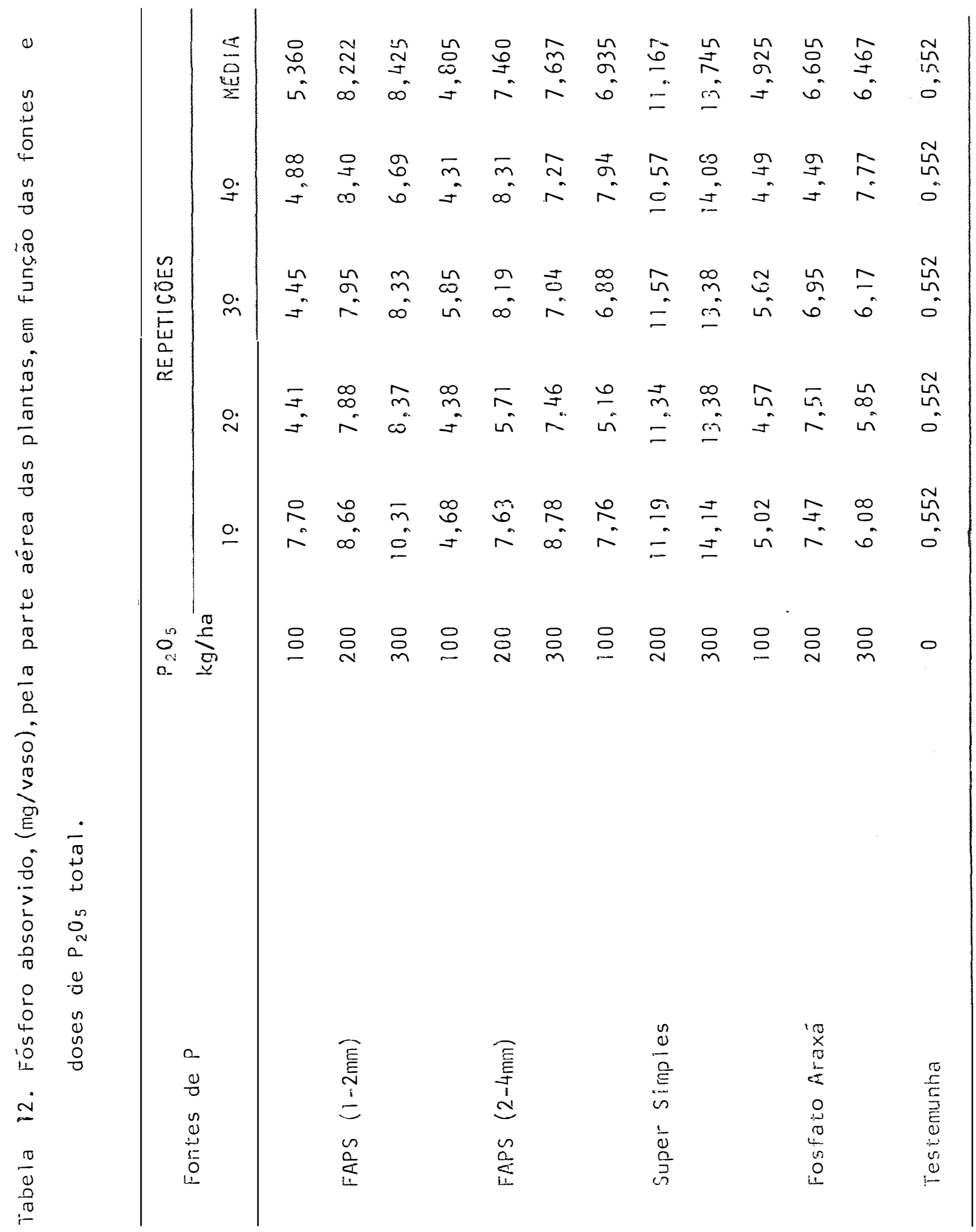




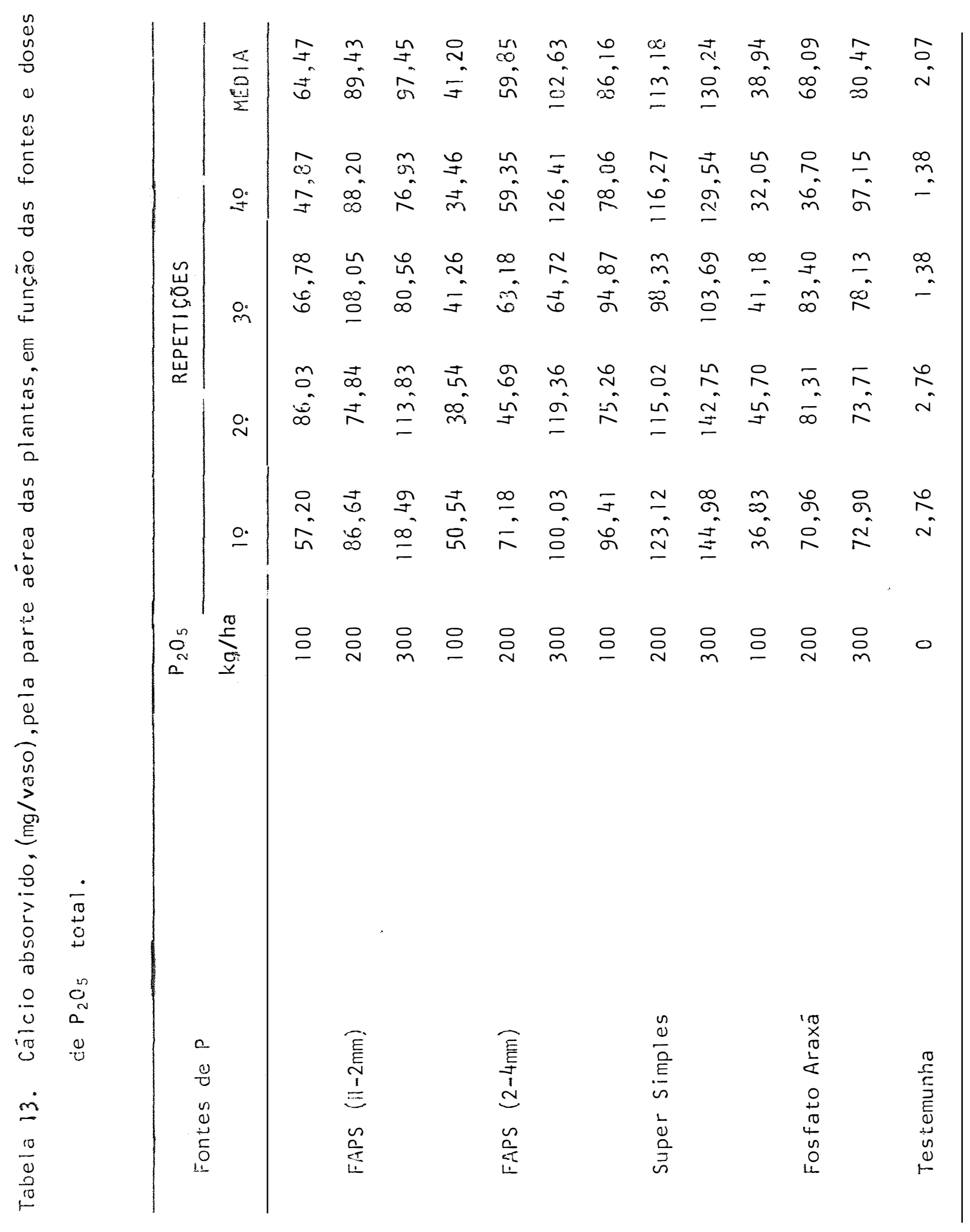




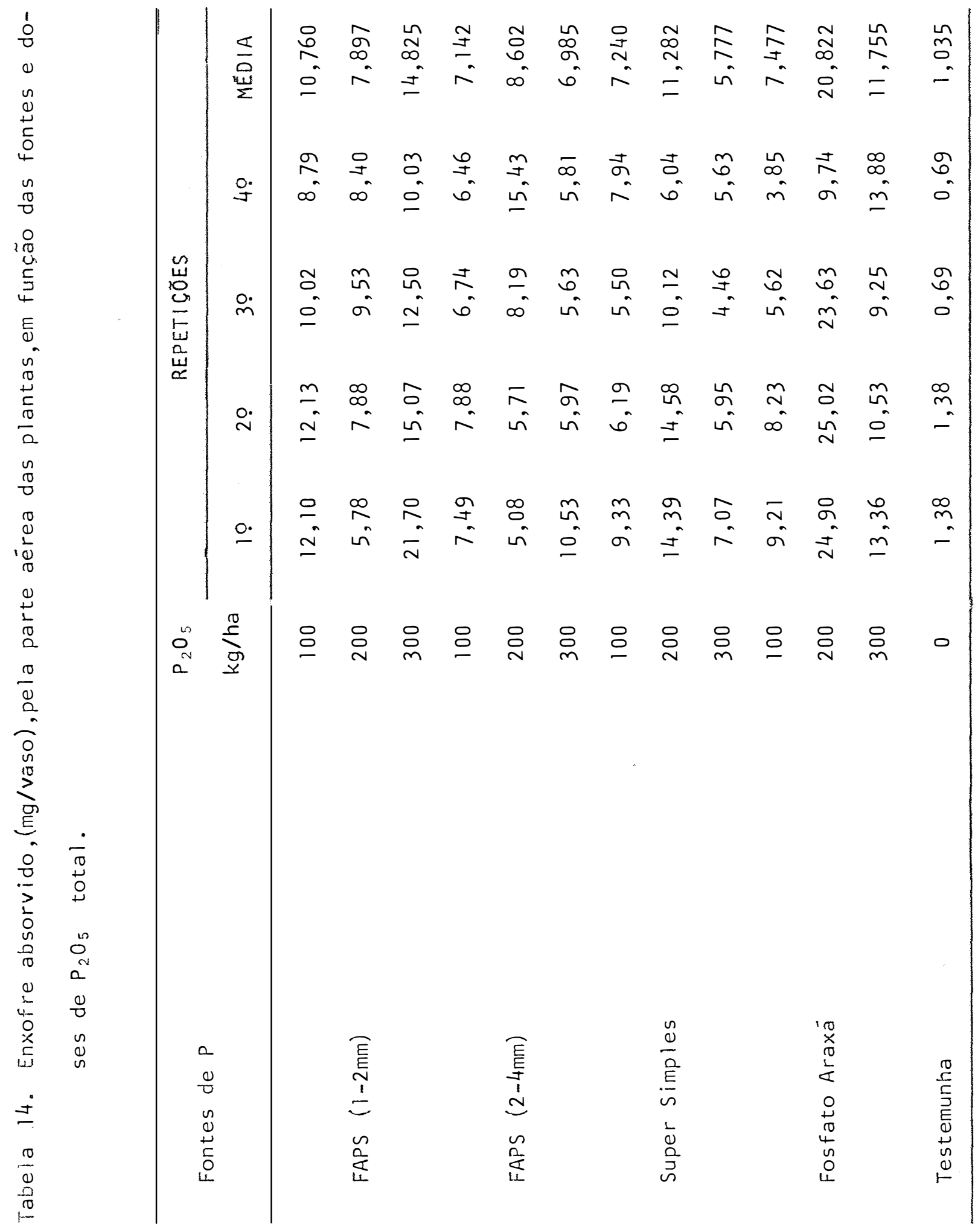




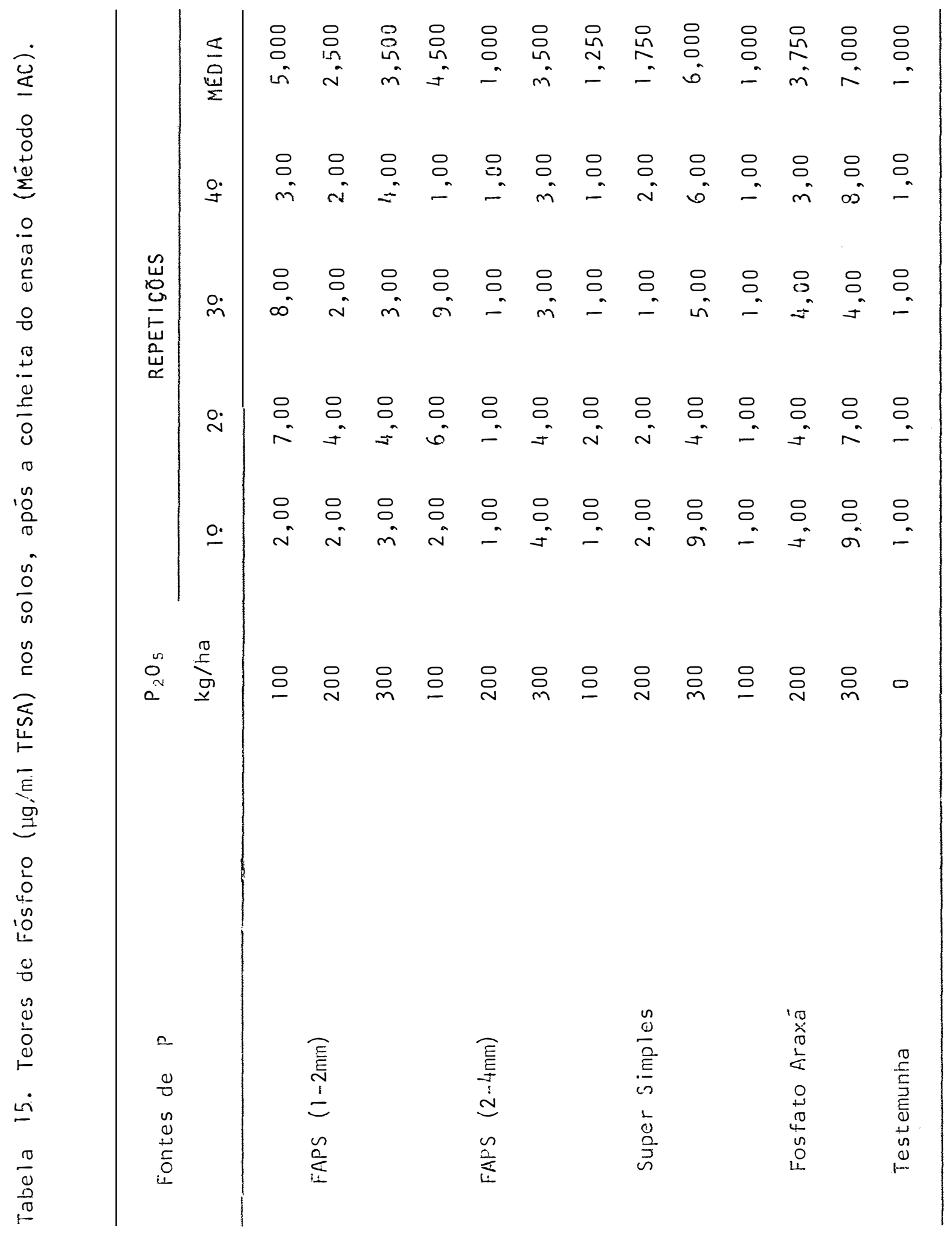




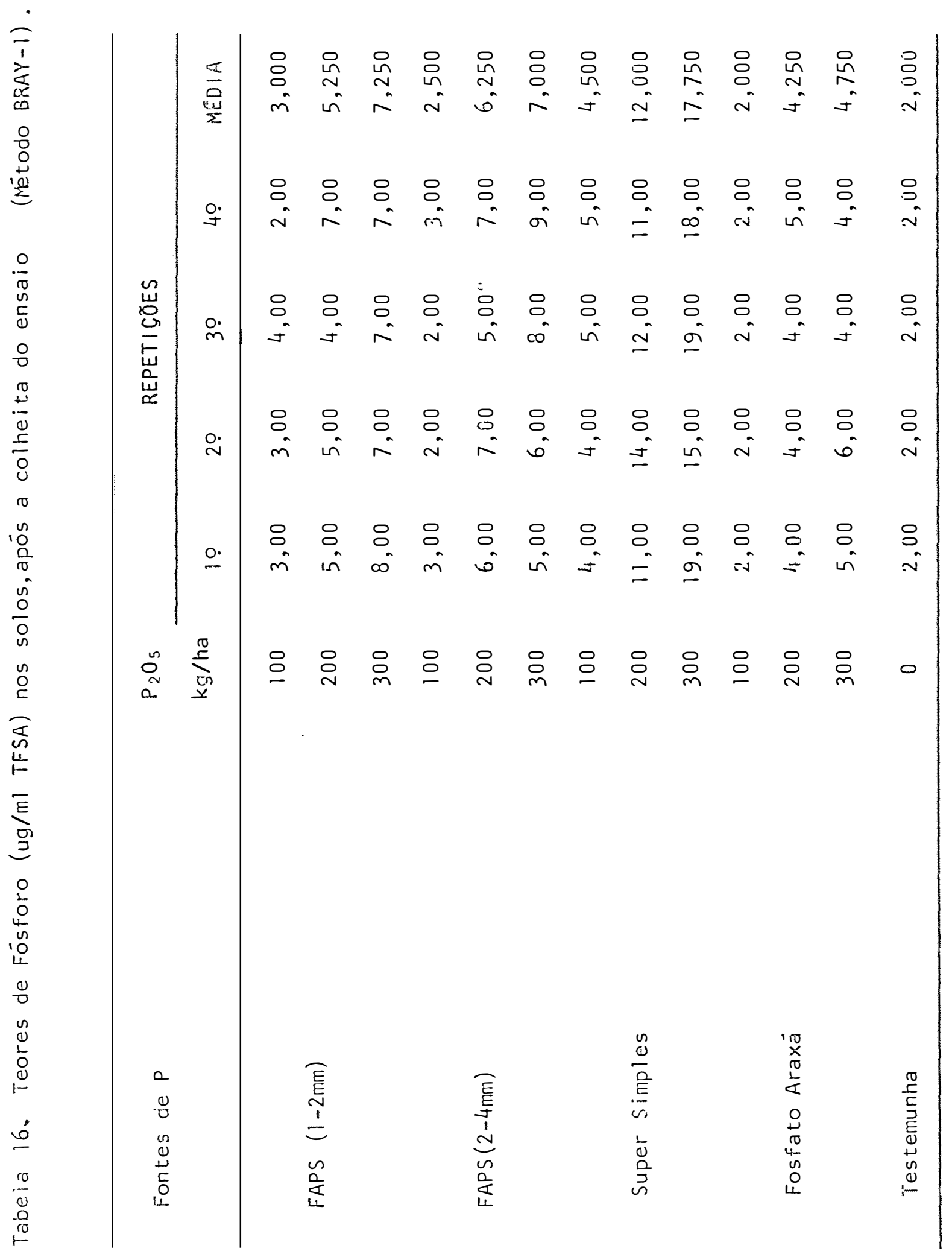




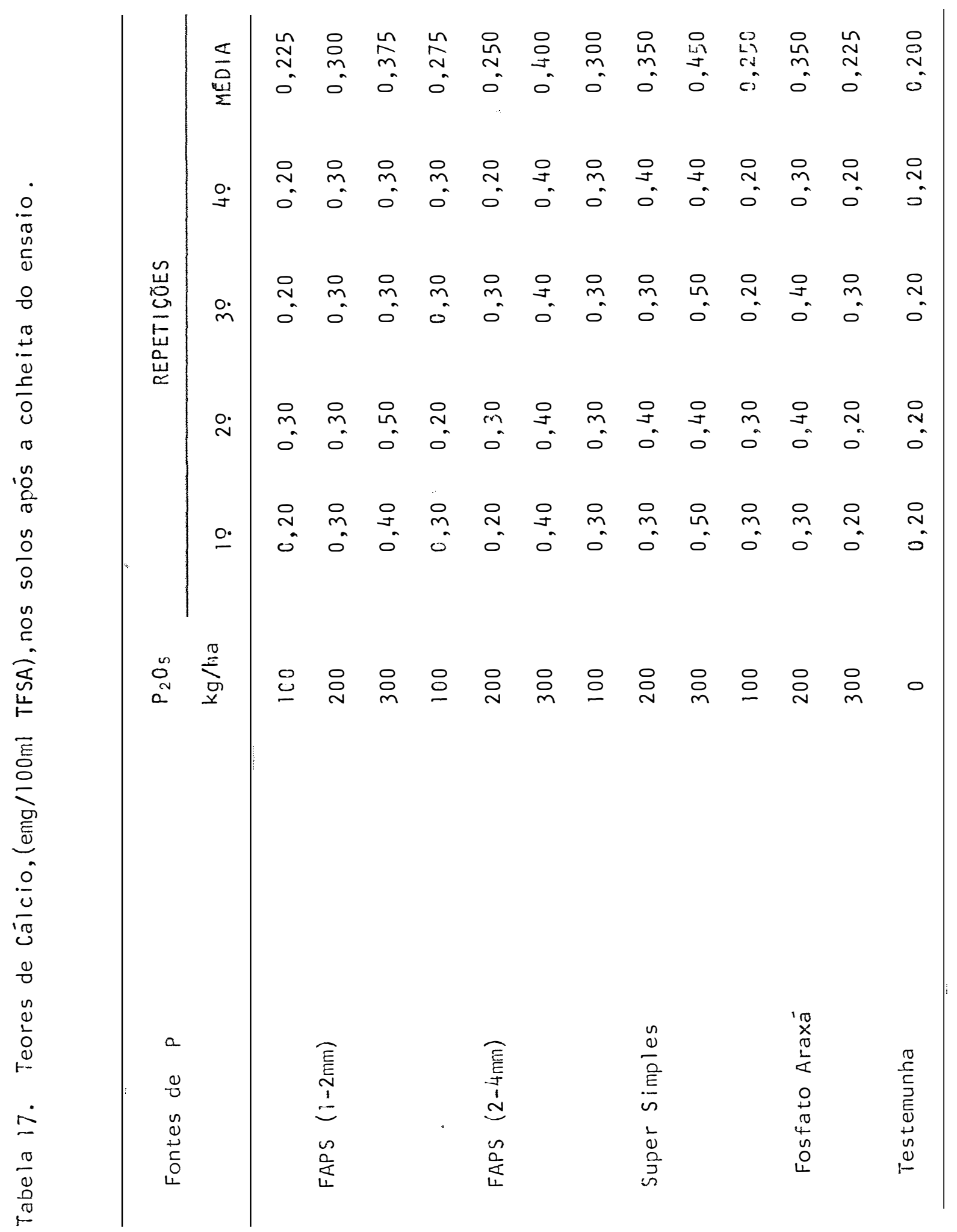




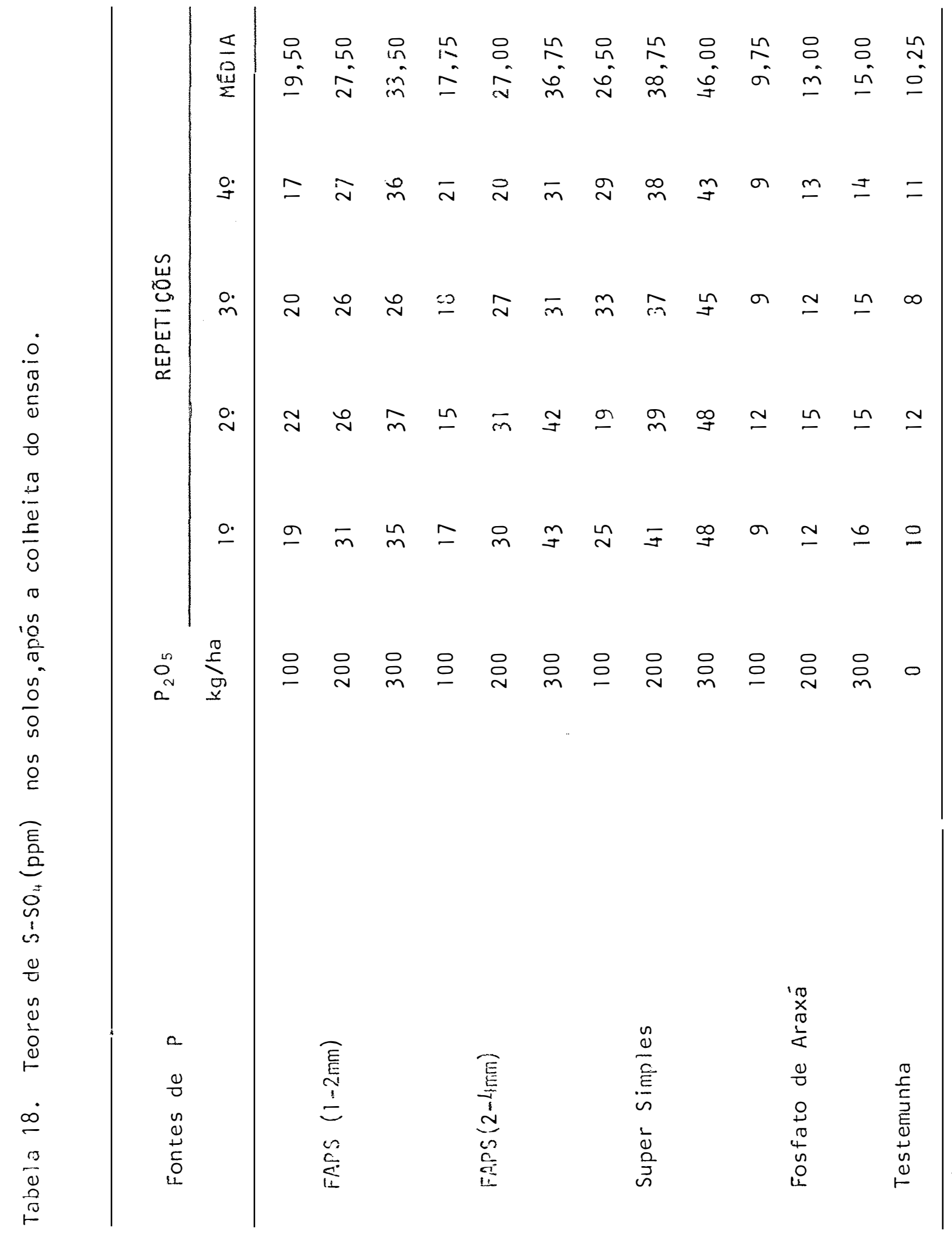




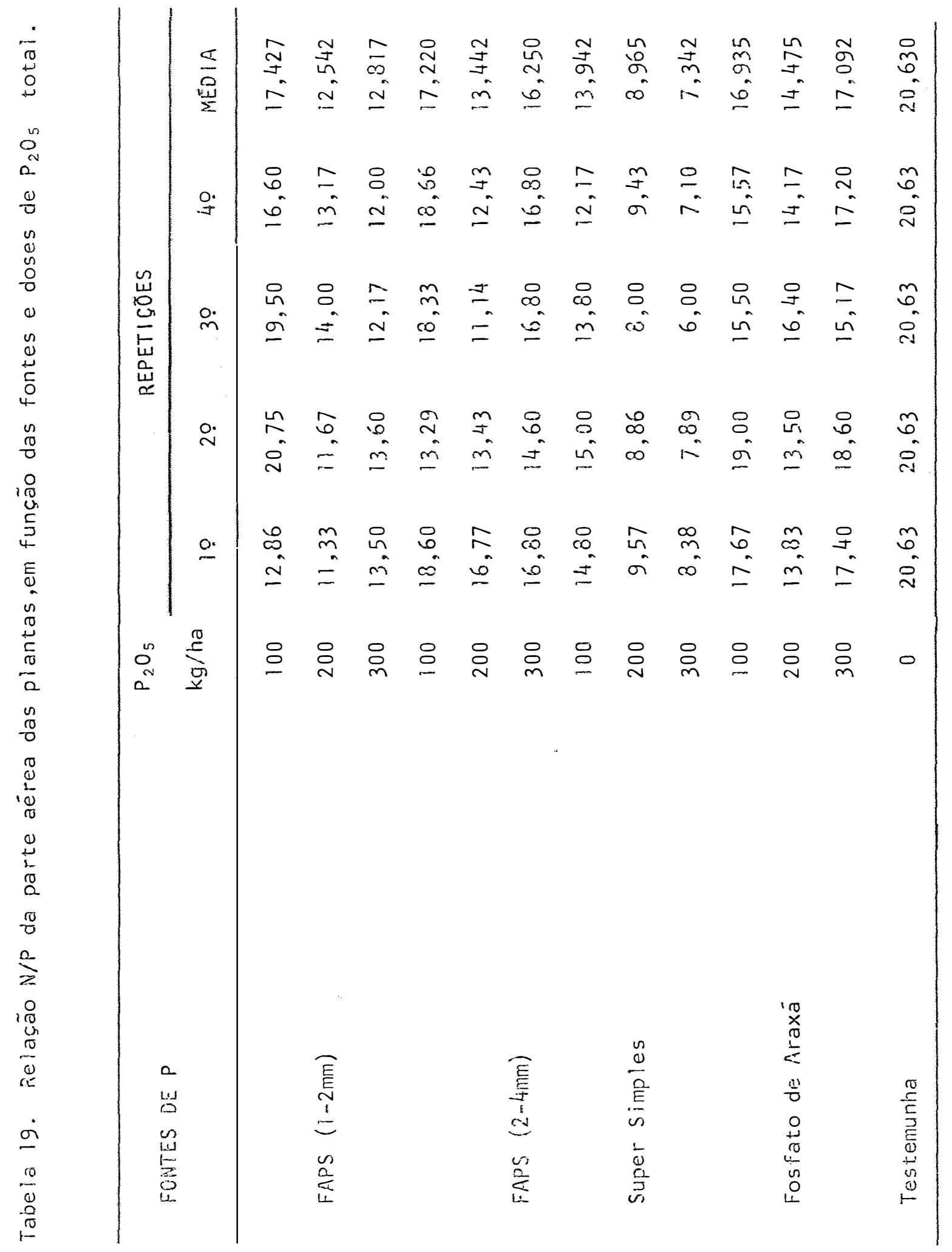




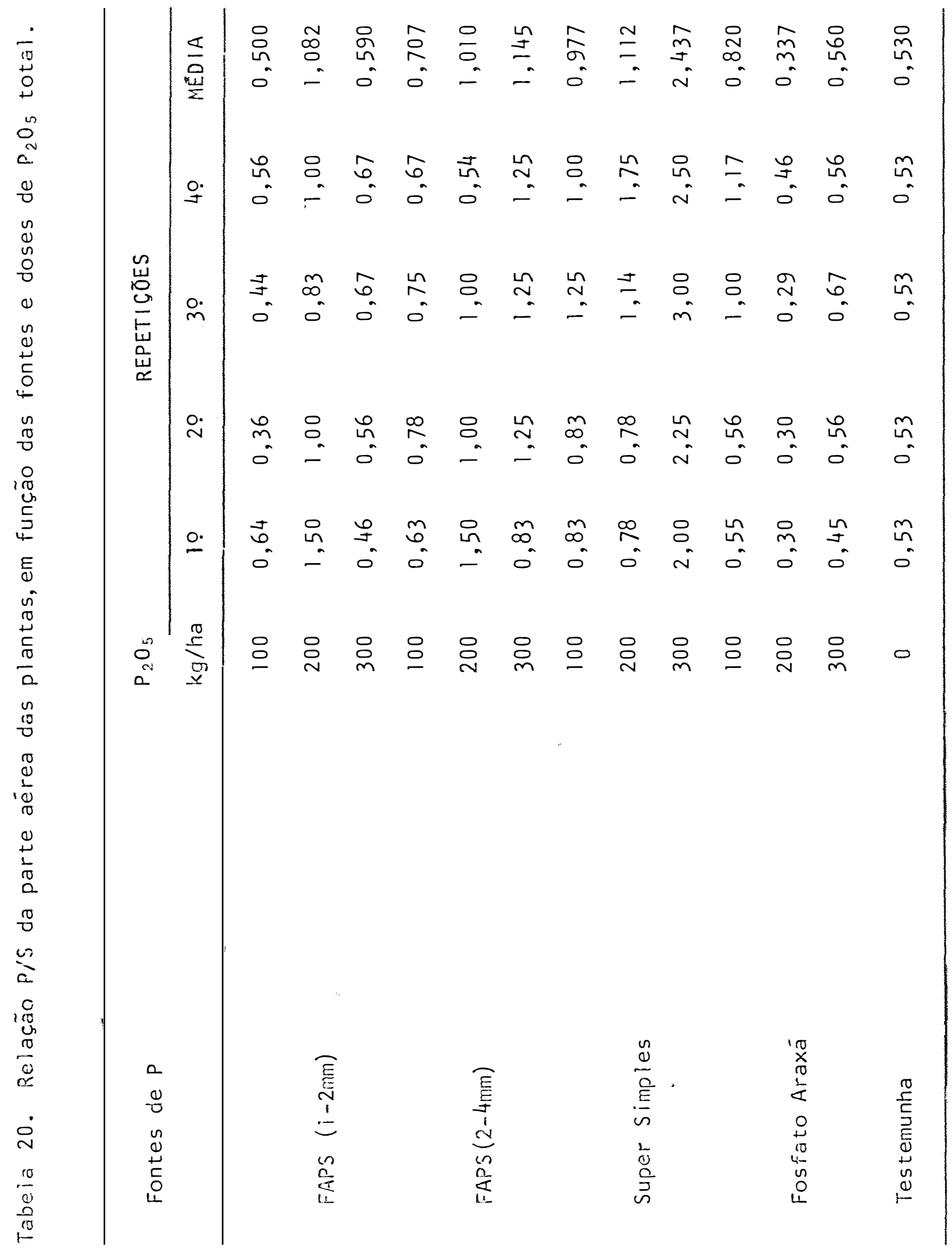




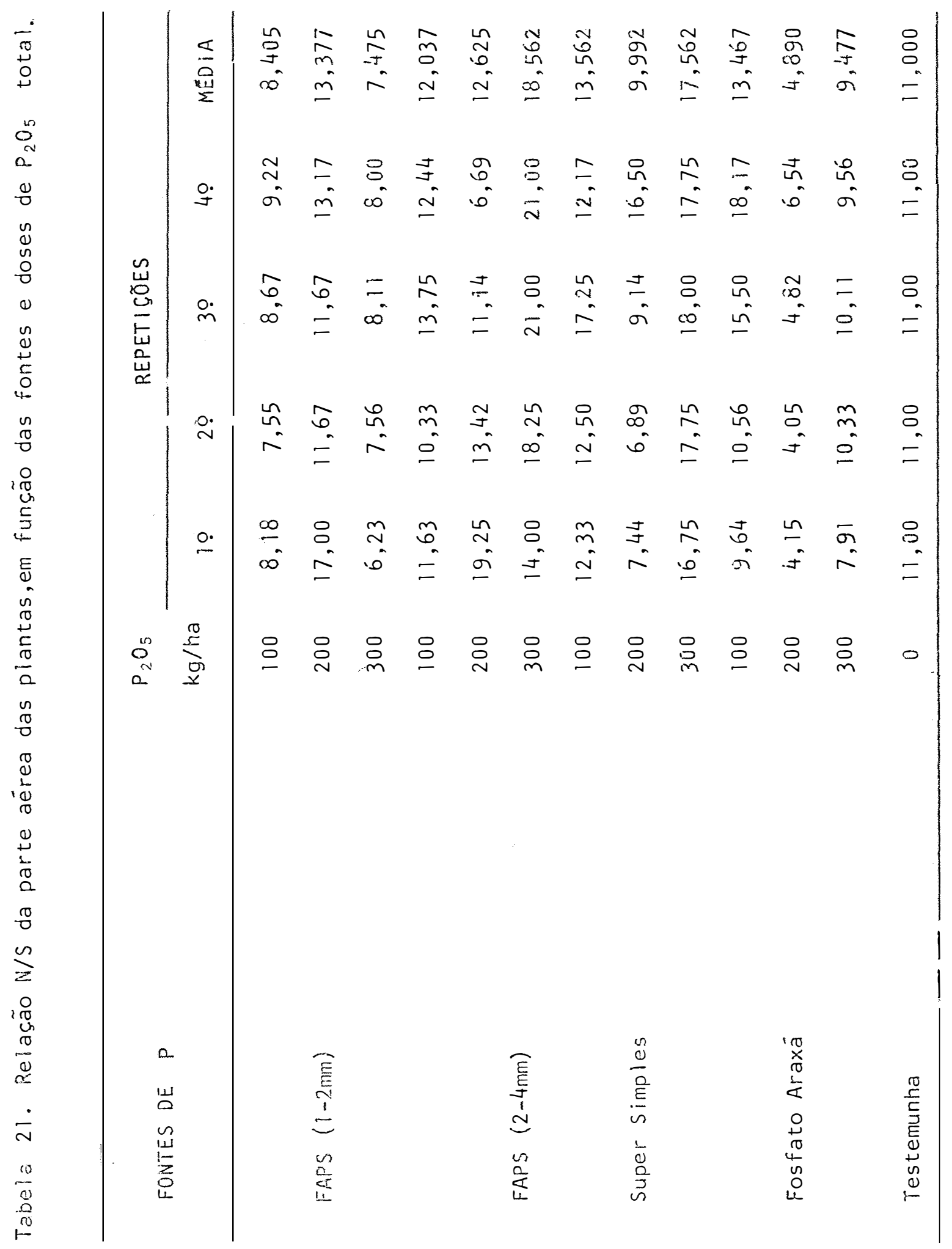




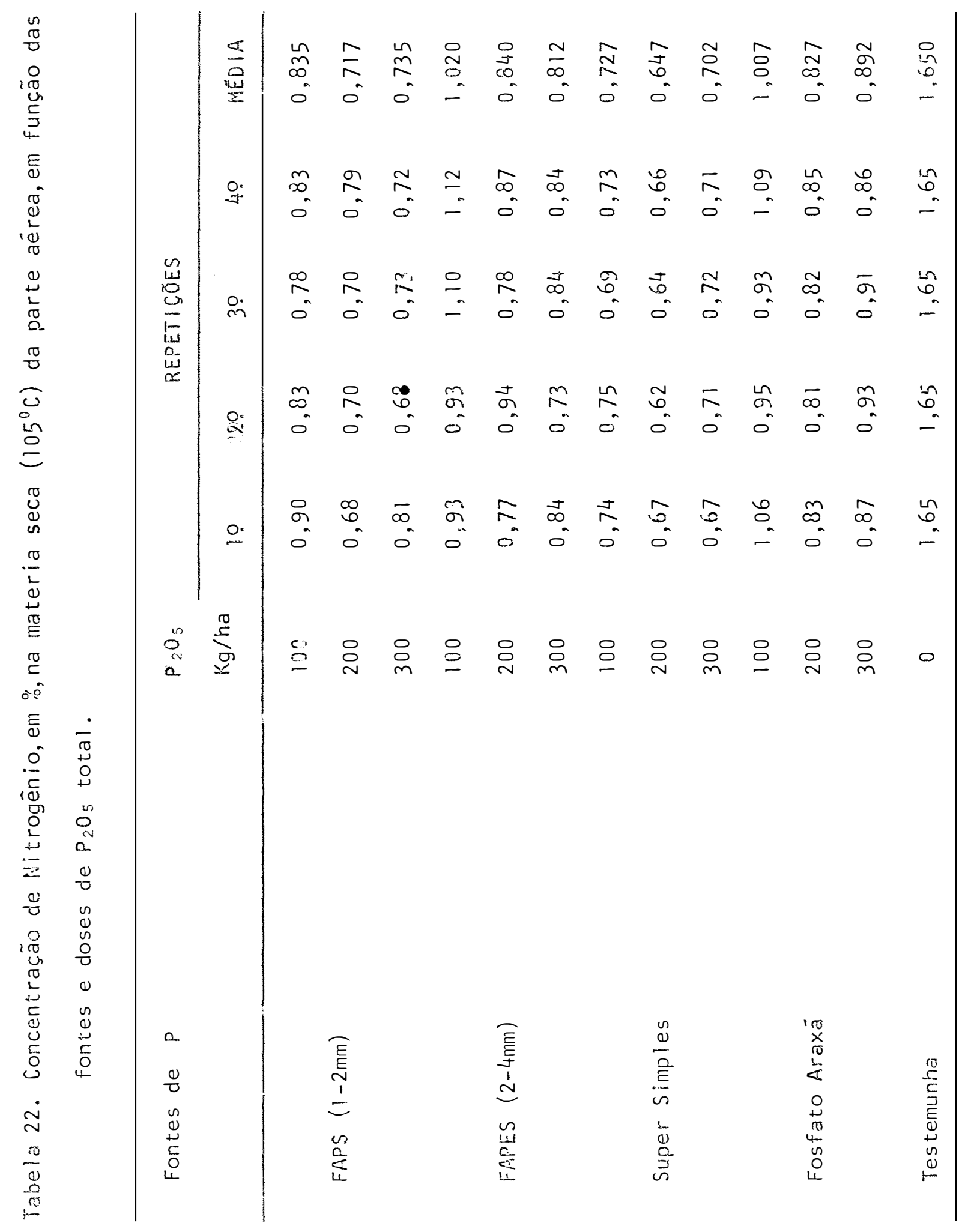




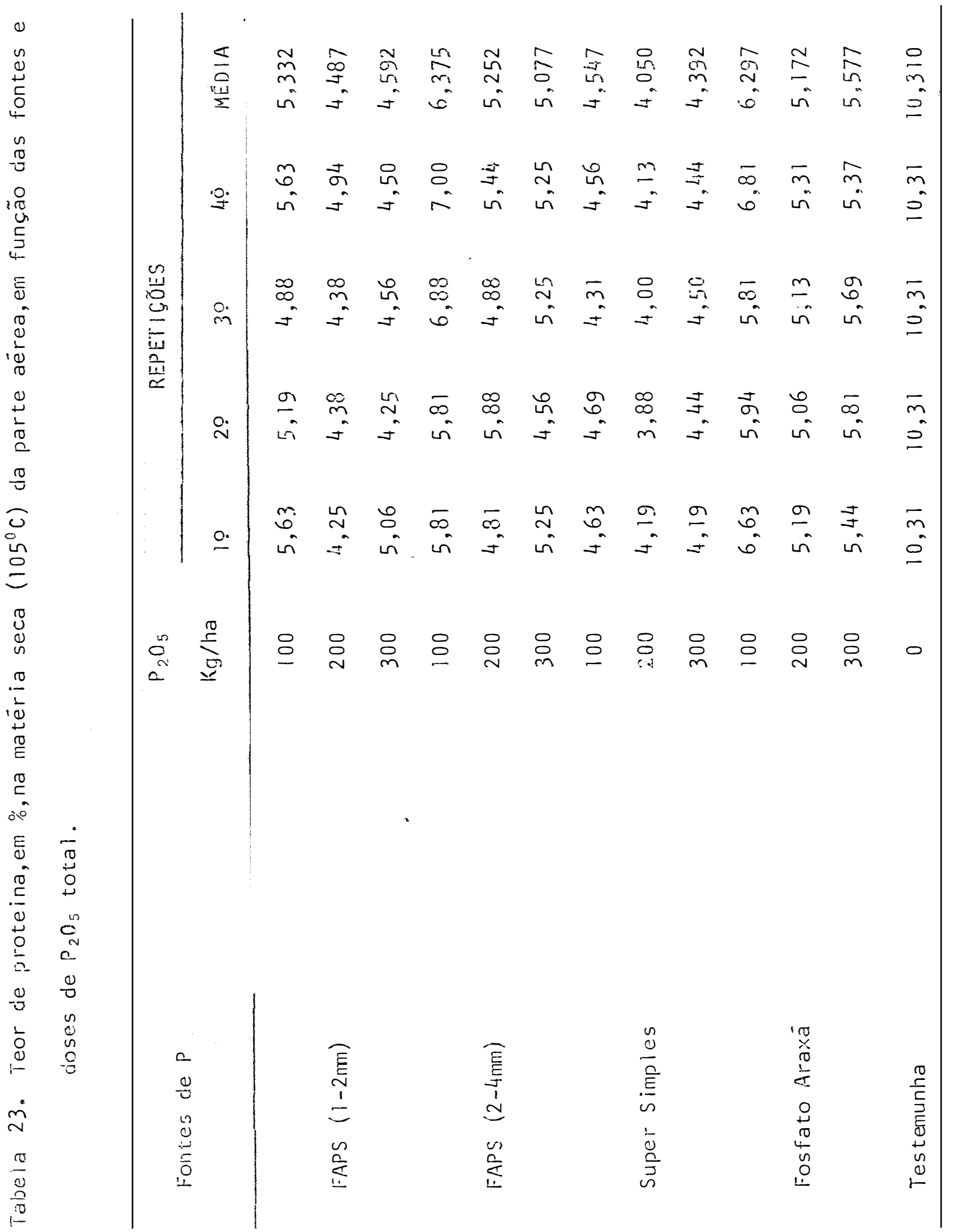




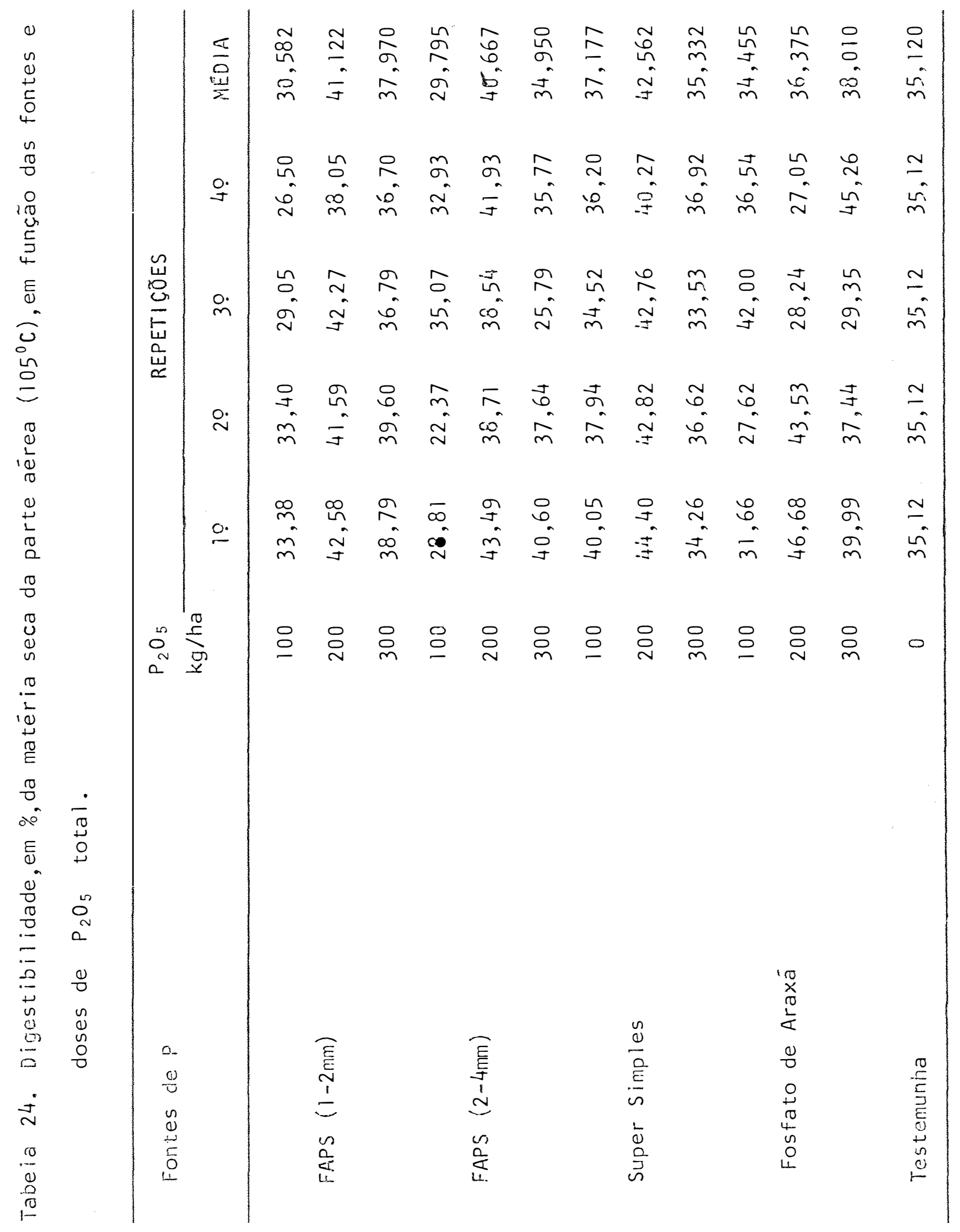

